\title{
Enhancing the Effectiveness of Work Groups and Teams
}

\author{
Steve W.J. Kozlowski and Daniel R. Ilgen \\ Michigan State University
}

SUMMARY-Teams of people working together for a common purpose have been a centerpiece of human social organization ever since our ancient ancestors first banded together to hunt game, raise families, and defend their communities. Human history is largely a story of people working together in groups to explore, achieve, and conquer. Yet, the modern concept of work in large organizations that developed in the late 19th and early 20th centuries is largely a tale of work as a collection of individual jobs. A variety of global forces unfolding over the last two decades, however, has pushed organizations worldwide to restructure work around teams, to enable more rapid, flexible, and adaptive responses to the unexpected. This shift in the structure of work has made team effectiveness a salient organizational concern.

Teams touch our lives everyday and their effectiveness is important to well-being across a wide range of societal functions. There is over 50 years of psychological research-literally thousands of studies-focused on understanding and influencing the processes that underlie team effectiveness. Our goal in this monograph is to sift through this voluminous literature to identify what we know, what we think we know, and what we need to know to improve the effectiveness of work groups and teams.

We begin by defining team effectiveness and establishing the conceptual underpinnings of our approach to understanding it. We then turn to our review, which concentrates primarily on topics that have well-developed theoretical and empirical foundations, to ensure that our conclusions and recommendations are on firm footing. Our review begins by focusing on cognitive, motivational/affective, and behavioral team processes-processes that enable team members to combine their resources to resolve task demands and, in so doing, be effective. We then turn our attention to identifying interventions, or "levers," that can shape or align team processes and thereby provide tools

Address correspondence to Steve W.J. Kozlowski, Department of Psychology, 309 Psychology Building, Michigan State University, East Lansing, MI 48824-1116; e-mail: stevekoz@msu.edu. and applications that can improve team effectiveness. Topic-specific conclusions and recommendations are given throughout the review. There is a solid foundation for concluding that there is an emerging science of team effectiveness and that findings from this research foundation provide several means to improve team effectiveness. In the concluding section, we summarize our primary findings to highlight specific research, application, and policy recommendations for enhancing the effectiveness of work groups and teams.

\section{INTRODUCTION}

"Houston, we've had a problem." Apollo 13 was more than halfway on her journey to Earth's moon on what was to have been a routine mission to collect samples when, suddenly, the mission and the lives of the crew were in grave jeopardy. One of the spacecraft's two oxygen tanks exploded, blowing out the entire side of the service module and damaging the remaining oxygen tank. Within 3 hours, all oxygen stores were depleted, and the craft lost water, electrical power, and propulsion. The situation was critical, time was short, and there was no margin for error. A team of NASA engineers was hastily assembled. Their mission: problem-solve, adapt, and invent a way for the crew to survive and to pilot their damaged spacecraft back to Earth. The team was successful, transforming a potentially disastrous mission into a legend of effective teamwork (NASA Goddard Space Flight Center, n.d.).

Jump to Nepal, deep in the heart of the Himalaya Mountains. Several international teams were mounting that annual campaign of human striving and accomplishment, attempting to reach the summit of Mt. Everest-“an intrinsically irrational act" (Krakauer, 1997, p. xvii). The teams were led by renowned mountaineers, but this season on Everest turned out to be the most disastrous one of all time. On one team, of five teammates who reached the peak, four, including the veteran leader, died. Nine climbers from four other expeditions also perished. Before the month was out, 16 climbers lost their lives attempting to 
reach the treacherous summit. Although the harsh, unforgiving, and constantly changing environment played a major role in this tragedy, the perilous conditions were exacerbated by failures of team leadership, coordination, and communication (Krakauer, 1997).

Teams of people working together for a common cause touch all our lives. From everyday activities like air travel, fire fighting, and running the United Way drive to amazing feats of human accomplishment like climbing Mt. Everest and reaching for the stars, teams are at the center of how work gets done in modern life. Although how teams function is often beneath the level of everyday awareness, unexpected successes, such as Team USA's winning of the Olympic Gold Medal for Hockey, and failures, such as FEMA's sluggish response to hurricane Katrina, make team functioning and team effectiveness highly salient. Failures of team leadership, coordination, and communication are welldocumented causes of the majority of air crashes, medical errors, and industrial disasters. They have also been implicated in many political and military catastrophes, including the miscalculated Bay of Pigs invasion, the mistaken downing of a civilian airliner by the USS Vincennes, the failure of the USS Stark to take defensive action against a hostile missile attack, and the failure to prevent the tragedy of 9/11. Our point is simple: teams are central and vital to everything we do in modern life. Our purpose in this monograph is to elucidate what more than 50 years of research on small groups and teams can tell us about the processes that contribute to team effectiveness and, based on that knowledge, to identify leverage points that can be used to make teams more effective.

\section{Review Focus and Structure}

Organizations around the world are well along a decade-and-ahalf evolution in the design of work-shifting from individual jobs in functionalized structures to teams embedded in more complex workflow systems (Devine, Clayton, Phillips, Dunford, \& Melner, 1999; Lawler, Mohrman, \& Ledford, 1992, 1995; Mathieu, Marks, \& Zaccaro, 2001). A variety of forces are driving this shift. Increasing competition, consolidation, and innovation create pressures for skill diversity, high levels of expertise, rapid response, and adaptability. Teams enable these characteristics (Kozlowski, Gully, Nason, \& Smith, 1999). The increasing penetration of computers into all facets of the workplace coupled with broadband communication allows teams to be located together or distributed across time and space (Bell \& Kozlowski, 2002b). Multicultural teams linked across the globe by technology are on the rise.

Concomitant with this shift in the organization of work is the shift in research focus from the study of small interpersonal groups in social psychology to the study of work teams in organizational psychology. This shift in the core of team research was explicitly recognized by Moreland, Hogg, and Hains (1994), who noted the relative decline of group research in social psy- chology, and by Levine and Moreland (1990), who concluded that small-group research "is alive and well and living elsewhere [outside the confines of social-psychology laboratories]" (p. 620). At least seven major reviews of the work-team literature in organizational psychology appeared between 1990 and 2000 (see Bettenhausen, 1991; Cohen \& Bailey, 1997; Gully, 2000; Guzzo \& Dickson, 1996; Guzzo \& Shea, 1992; Hackman, 1992; Sundstrom, McIntyre, Halfhill, \& Richards, 2000). ${ }^{1}$ More recent reviews of work-team research (Ilgen, Hollenbeck, Johnson, \& Jundt, 2005; Kozlowski \& Bell, 2003) reflect the emerging perspective of work teams as dynamic, emergent, and adaptive entities embedded in a multilevel (individual, team, organization) system (cf. Arrow, McGrath, \& Berdahl, 2000; Kozlowski et al., 1999; Marks, Mathieu, \& Zaccaro, 2001). That is, teams are complex dynamic systems that exist in a context, develop as members interact over time, and evolve and adapt as situational demands unfold.

Dynamic complexity; emergent team processes and phenomena; and development, evolution, and adaptation are key themes that will be reflected in our review. We will describe what we mean in more detail in the next section, but a brief overview here is useful because it sets the structure for our focus and approach. As illustrated in Figure 1, a team is embedded in a broader system context and task environment that drives team task demands; that is, the task requirements necessary to resolve the problem or situation presented by the environment and the load placed on team members' resources. A dynamic, shifting, and complex environment creates commensurate team task demands that members have to resolve though a coordinated process that combines their cognitive, motivational/affective, and behavioral resources. As Figure 1 shows, this process is cyclical and reciprocal. When team processes are aligned with environmentally driven task demands, the team is effective; when they are not, the team is not. Our approach is guided by this basic heuristic and the focal points of our review are captured in the highlighted portion of the figure. We first consider team effectiveness as a dynamic process. We next review the research base to identify critical team processes and emergent states that contribute to team effectiveness. Having established that research foundation, we then consider factors that can influence, shape, and create appropriate team processes. Thus, our basic questions in this review are: What are the key team processes and emergent states that influence team effectiveness? How can these processes and states be leveraged to better create, develop, and manage effective work teams?

\footnotetext{
${ }^{1}$ Kerr and Tindale (2004) reviewed research on small-group performance and decision making that, while taking a social-psychological focus, shows an interesting overlap in some research topics that are more central to an organizational-psychology focus - especially theory and research on shared or collective cognition as it relates to team performance and effectiveness. See also the review in this journal by Mannix \& Neale (2005) on team diversity, decision making, and performance.
} 


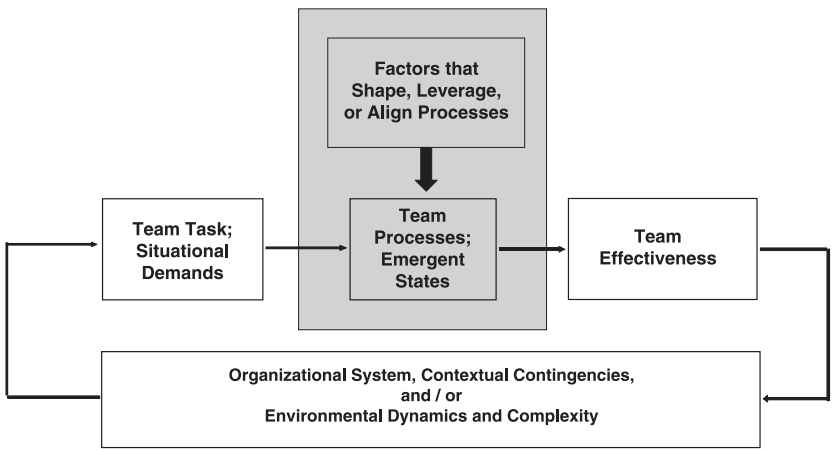

Fig. 1. Conceptual framework and review focus. The figure illustrates that environmental dynamics and complexity drive team task demands; team processes and emergent states align team-member resources to resolve task demands and yield team effectiveness; and team outputs (effectiveness) reciprocally influence the environment, in an ongoing cycle. The focus of this report is shaded: team processes and emergent states; and the factors that shape, leverage, or align them.

There has been well over a half century of research in both social psychology and organizational psychology on small groups and teams and related topics. Virtually all of the research papers close with the obligatory acknowledgement that "more research is needed." And, while it is true that there is much we psychologists do not yet know about team effectiveness, there is much that we do. There is a substantial knowledge base. The real challenge is sifting through this vast literature to isolate those promising team processes that reliably influence team effectiveness and that can also be shaped by deliberate intervention.

Our intent in this review is to focus on those key areas in which theory and research findings are well developed and therefore provide a solid substantive basis for actionable recommendations. Although this review is ultimately guided by our own theoretical perspectives, empirical research, and professional judgment, we relied on three primary strategies to identify key areas. First, we sought research topics that were sufficiently mature that they had been the target of one or more meta-analytic reviews. ${ }^{2}$ Meta-analytic findings provide a quantitative foundation for our most forceful conclusions and recommendations. Second, we sought topics that, though not meta-analyzed, had been the subject of substantial systematic empirical research. For these areas, our conclusions and recommendations are strong but not unequivocal. Finally, we also considered areas that reflect emerging theory and promising, though not yet extensive, research support. The potential of these areas is more a matter of our judgment and the conclusions and recommendations are therefore intended to be more circumspect. As in any such endeavor, our decisions about what to include and exclude will not please everyone. We offer apologies in advance to all whose work may have been overlooked.

\footnotetext{
${ }^{2}$ Meta-analysis statistically combines the findings from many primary studies that examine the same relationship to provide an estimate of the magnitude of the relationship, correlation, or "effect size" in the population.
}

We now begin by articulating our theoretical perspective, as it highlights important themes of our review and its structure. We next review research on team processes and emergent states, giving recommendations about those that are actionable and those that require further development and research attention. We then shift to an identification of several potent intervention "levers" that can shape team processes. If you want to know how to enhance team effectiveness, this is how it can be accomplished. The policy implications in these two core sections are self-evident. Finally, we close with a summary of our many recommendations and more general policy implications for the enhancement of team effectiveness.

\section{The Nature of Teams and Team Effectiveness}

\section{What Is a Team?}

A team can be defined as (a) two or more individuals ${ }^{3}$ who (b) socially interact (face-to-face or, increasingly, virtually); (c) possess one or more common goals; (d) are brought together to perform organizationally relevant tasks; (e) exhibit interdependencies with respect to workflow, goals, and outcomes; (f) have different roles and responsibilities; and $(\mathrm{g})$ are together embedded in an encompassing organizational system, with boundaries and linkages to the broader system context and task environment (Alderfer, 1977; Argote \& McGrath, 1993; Hackman, 1992; Hollenbeck et al., 1995; Kozlowski \& Bell, 2003; Kozlowski, Gully, McHugh, Salas, \& Cannon-Bowers, 1996; Kozlowski et al., 1999; Salas, Dickinson, Converse, \& Tannenbaum, 1992).

\section{What Is Team Effectiveness?}

The conceptualization of team effectiveness that has shaped the last 40 years of theory and research is based on the logic of an input-process-output (I-P-O) heuristic formulated by McGrath (1964; cf. Gladstein, 1984; Salas et al., 1992). In this framework, inputs refer to the composition of the team in terms of the constellation of individual characteristics and resources at multiple levels (individual, team, organization). Processes refer to activities that team members engage in, combining their resources to resolve (or fail to resolve) task demands. Processes thus mediate the translation of inputs to outcomes. Although team processes are by definition dynamic, they are most typically addressed in static terms-as constructs that emerge over time (i.e., emergent states) as team members interact and the team develops (Kozlowski et al., 1999; Marks et al., 2001). Output has three facets: (a) performance judged by relevant others external to the team; (b) meeting of team-member needs; and (c) viability, or the willingness of members to remain in the team (Hackman, 1987).

\footnotetext{
${ }^{3}$ Some scholars distinguish dyads from teams made up of three or more people. In our view, many two-person teams (e.g., aircrews) exhibit the same basic work processes underlying team effectiveness as larger teams. However, we do acknowledge that teams of three or more enable coalitions and related interpersonal interaction complexities that are absent in dyads.
} 
These tripartite facets capture the prevalent conceptualization of team effectiveness. Although McGrath's heuristic is a useful organizing framework-it was developed to organize the research literature on small groups circa 1964-it was not intended to be a theory or a formal causal model of team effectiveness. It has, nonetheless, been frequently interpreted as a model to be tested. We think that while the I-P-O model is a useful organizing heuristic, treating it as a causal model encourages taking a limited and static perspective on team effectiveness and the dynamic processes that underlie it.

\section{A Dynamic View of Team Processes and Effectiveness}

We adopt a more contemporary perspective that has evolved over the last decade, which conceptualizes the team as embedded in a multilevel system that has individual, team, and organizationallevel aspects; which focuses centrally on task-relevant processes; which incorporates temporal dynamics encompassing episodic tasks and developmental progression; and which views team processes and effectiveness as emergent phenomena unfolding in a proximal task- or social context that teams in part enact while also being embedded in a larger organization system or environmental context (Arrow et al., 2000; Ilgen et al., 2005; Kozlowski \& Bell, 2003; Kozlowski et al., 1999; Kozlowski, Gully, McHugh et al., 1996; Marks et al., 2001). We now briefly highlight the key themes of this extension, elaboration, and refinement of the I-P-O heuristic; these themes play an important role in our conceptualization and organization of the literature and in our effort to make actionable recommendations based on that literature.

\section{Multilevel System Context}

Individual team members comprise the team as a collective entity, an entity that also serves as the social context that influences individual members (Hackman, 1992). Moreover, as illustrated in Figure 1, team members and work teams are embedded in a broader organizational system and task environment that drives the difficulty, complexity, and tempo of the team task. The interactions are reciprocal in that team performance outputs resolve task demands emerging from the surrounding system or environment and change the state of the system or environment in some fashion. These changes can shift unexpectedly and the team must adapt to the changing demands. Thus, it is necessary to understand the system context and linkages across multiple levels-individual, team, organization - as key sources of contingencies or demands on the team that necessitate aligned team processes (Kozlowski et al., 1999; Kozlowski, Gully, McHugh et al., 1996).

The degree to which teams are embedded in or tightly linked to the organizational system or a dynamic task environment can vary. Some teams or small units, while part of an organizational system, are more tightly linked to a dynamic task environment that is their dominant embedding context for task activity. As an example, consider a surgical team in the operating room (OR) where what is happening with the patient right now (e.g., dropping blood pressure, respiratory difficulty, erratic heartbeat) defines the task environment, which then drives team task demands and team-member activity. Relative to the broader organizational-system context (e.g., new policies adopted by hospital administration), the task environment is the primary context in which the OR team is embedded. The situation is similar for aircrews or firefighting teams, in which the task environment (i.e., take-offs, storms, and landings, or fire, fuel, wind, and humidity, respectively) is the primary embedding context. For other teams, the broader organizational system is the primary context. A cross-functional project team making a recommendation to management on product development or a top-management team (TMT) revising organizational strategy to meet stiff competition are more tightly included in the organizational system as the primary embedding context.

\section{The Team Task}

The central focus on what teams have to do-their task-is the key factor that distinguishes a social-psychological perspective on the study of teams, in which the task is merely a means to prompt interpersonal interaction, from an organizational perspective, in which the task is the source of goals, roles, and taskbased exchanges. For the latter, interpersonal interaction is relevant, but it is in the background rather than the foreground. The team task determines two critical issues. First, it sets minimum requirements for the resource pool—the constellation of team-member individual differences and capabilities-that is available across team members. If members collectively lack necessary knowledge, skills, abilities, or resources to resolve the team task, the team cannot be effective. Second, the team task determines the primary focus of team-member activities. Our focus is on teams that primarily do things (e.g., action or production teams) and that, in the process of striving toward and accomplishing goals, also have to make decisions (e.g., project teams or TMTs) and create, invent, and adapt solutions to resolve task-driven problems. ${ }^{4}$

Thus, the team task determines the workflow structure and coordination demands (i.e., exchanges of behavior, information, etc.) necessary for accomplishing individual and team goals and resolving task requirements. Team processes as emergent constructs or "states" are a way to capture coordination of teammember effort and factors relevant to it, as well as the alignment of team processes with task demands. In that sense, appropriately aligned team action processes are critical enablers of team effectiveness (Kozlowski et al., 1999; Kozlowski, Gully, McHugh et al., 1996; Marks et al., 2001; Salas et al., 1992).

\footnotetext{
${ }^{4}$ Our primary focus is on action teams because it covers the broadest type of teams relevant in organizations. Decision making and creativity are important aspects of action but are not the unitary focus of activity. Readers interested in the specific and extensive research in these areas are directed to Kerr and Tindale (2004) for a recent review on group decision making. Similarly, we do not specifically review the voluminous research on team composition and diversity. Interested readers are directed to Mannix and Neale (2005) for a comprehensive review.
} 
Time

Team processes develop and unfold over time (McGrath, 1991). The extent to which team processes align with task demands is a function of team learning, skill acquisition, and development. Key temporal dimensions include (a) task cycles or episodes that "entrain" the team to task dynamics by making specific, iterative, and repeated demands on team processes (Ancona \& Chong, 1996; Kozlowski, Gully, McHugh et al., 1996; Marks et al. 2001) and (b) linear development of indeterminate duration across the team's life cycle of formation, development, maintenance, and decline/dissolution (Tuckman, 1965; Kozlowski et al., 1999). The important points here are that team tasks are not fixed - they vary in their demands on team processes - and that team process capabilities are not fixed-they compile and improve as team members accrue experiences and learn how to work together better. And, although processes are clearly dynamic, over time stable process constructs, or what Marks et al. (2001) call emergent states, develop, providing a means to capture or summarize team processes.

\section{Our Approach}

We begin our review by establishing what we know about critical team processes and emergent states and how they contribute to team effectiveness. Our purpose is to identify processes that have well-established, research-based linkages to team effectiveness that therefore should be targets for interventions to improve team functioning. We then highlight research-based interventions that can leverage team processes. With that foundation, we provide recommendations for enhancing team processes and effectiveness and offer suggestions for future research and applications.

\section{TEAM PROCESSES, EMERGENT STATES, AND EFFECTIVENESS}

Conceptually, process captures how team members combine their individual resources, coordinating knowledge, skill, and effort to resolve task demands. Team effectiveness (i.e., performance evaluated by others, member satisfaction, viability) is an emergent result that unfolds across levels (individual to dyadic to team) and over time. This perspective on team processes is clearly dynamic, but it is also the case that the repeated interactions among individuals that constitute processes tend to regularize, such that shared structures and emergent states crystallize and then serve to guide subsequent process interactions. Process begets structure, which in turn guides process. Allport (1954) described this reciprocal nature of process and structure in terms of "ongoings," Katz and Kahn (1966) in terms of "role exchanges," Kozlowski and Klein (2000) in terms of "emergent phenomena," and Marks et al. (2001) in terms of "emergent states." Thus it is important to appreciate that while processes are dynamic and therefore difficult to capture in real time, they yield collective cognitive structures, emergent states, and regular behavior patterns that have been enacted by, but also guide, team processes.

In that sense, team cognitive structures, emergent states, and routinized behavior patterns are the echoes of repeated process interactions (Kozlowski \& Klein, 2000) and, hence, are indicative of the nature and quality of dynamic team processes. Following the structure set by Kozlowski and Bell (2003) and Ilgen et al. (2005) in their previous reviews, we classify team processes and their echoes according to whether they are cognitive, affective/motivational, or behavioral in nature. ${ }^{5}$

\section{Team Cognitive Processes and Structures}

Small-group research has a long tradition of studying cognitive constructs such as group norms and role expectations that guide interpersonal interactions among team members. While not denying the importance of interpersonal interactions, research in organizational psychology has tended to address cognitive constructs that are more focused on guiding task-relevant interactions among team members. Indeed, work groups and teams have been characterized as processors of information (Hinsz, Tindale, \& Vollrath, 1997). We focus on a set of team cognitive constructs that represent the structure of collective perception, cognitive structure or knowledge organization, and knowledge or information acquisition-constructs that have amassed a sufficient research foundation to support their value for enhancing team effectiveness. These collective constructs include unit and team climate, team mental models and transactive memory, and team learning.

\section{Unit and Team Climate}

The notion of climate as an interpretation of the group situation or environment can be traced back to early work by Lewin, Lippitt, and White (1939), with much research and development over the intervening decades (see Forehand \& Gilmer, 1964; James \& Jones, 1974; Ostroff, Kinicki, \& Tamkins, 2003 for comprehensive reviews). Contemporary theory and research regard climate as cognitively based, descriptive, interpretive perceptions of salient features, events, and processes (James \& Jones, 1974) that characterize the "strategic imperatives" (Schneider, Wheeler, \& Cox, 1992) of the organizational and team context. Although such perceptions originate within the person, exposure to strong strategic imperatives or situations (González-Romá, Peiró, \& Tordera, 2002); perceptual filtering and interpretation by leaders (Kozlowski \& Doherty, 1989); and social interaction, sharing of perspectives, and collective sense making (Rentsch, 1990) can shape a convergent emergent

\footnotetext{
${ }^{5}$ Any effort to classify team processes into the cognitive, motivational/affective, and behavioral categories we adopted will have some topics that could potentially fit in an alternate category. The classification simply reflects our judgment of best fit. Moreover, as we indicated in the introduction, our selection of topics was driven by the sufficiency of theory and the research base to provide a basis for recommendations. We make no claim of exhaustive coverage of every possible topic or investigation.
} 
process that yields consensual, collective climate perceptions within teams, larger units, or organizations (Kozlowski \& Klein, 2000). ${ }^{6}$ Research has established the emergence of collective climates at the organizational level (Kozlowski \& Hults, 1987), in smaller units such as bank branches (Schneider \& Bowen, 1985), and within teams embedded in organizations (Anderson \& West, 1998; Hofmann \& Stetzer, 1996).

There is a large and growing research base demonstrating that collective climate relates to the performance, member satisfaction, and viability facets of individual, team, and unit effectiveness. For example, Schneider and Bowen (1985) showed that a shared, collective climate in which service was the salient strategic imperative predicted customers' satisfaction with their bank branch. Kozlowski and Hults (1987) demonstrated that a shared organizational climate of the strategic imperative to stay technically up-to-date and innovative predicted individual performance, continuing education activities, and positive job attitudes for engineers in organizations pressured by technological competition and change. Anderson and West (1998) showed that a team climate for innovation predicted overall team innovativeness, novelty of innovations, and number of innovations. Hofmann and Stetzer (1996) showed that a team climate for safety predicted safety-related behaviors and actual accident rates in a chemical plant where high-reliability performance is necessarily a high priority. At the individual level, a recent path analysis of correlations estimated via meta-analysis demonstrated that climate perceptions influence job performance, well-being, and job withdrawal (e.g., intentions to quit; Carr, Schmidt, Ford, \& DeShon, 2003).

Moreover, research on both service climate and safety climate has been systematic, developing a set of findings that convincingly demonstrate significant effects on customer perceptions of service quality (Schneider \& Bowen, 1985; Schneider, White, \& Paul, 1998) and increases in safety-related behaviors with corresponding reductions in objective accident indicators, respectively (Hofmann \& Stetzner, 1996; Zohar, 2000, 2002; Zohar \& Luria, 2004). Schneider et al. (1998), for example, showed that organizational policies and practices relating to a strategic imperative for service influenced shared employee perceptions of the service climate, which in turn influenced customer perceptions of service quality.

As research supporting the utility of collective climates for predicting meaningful organizational, unit, and individual outcomes began to accrue, researchers also began to explore factors that influenced perceptual consensus and the emergence of unit climate. Harkening back to the roots of climate theory (Lewin et al., 1939), Kozlowski and Doherty (1989) proposed that leaders shape the interpretation of climate for those team

${ }^{6}$ When individuals within a team or higher-level unit show high consensus or agreement on their perceptions of the climate, their perceptions can be aggregated (by averaging) to represent the construct at the team or higher level. High within-unit agreement provides statistical support for treating the unit mean as a collective construct. members with whom they have a good leader-member exchange (LMX; Graen, Orris, \& Johnson, 1973) relationship. Their results showed that team members with good LMX relations had climate perceptions that were both similar to their leader and consensual with each other, relative to those with poor LMX relations, whose perceptions were discordant with the leader and each other. More recent research has provided results consistent with this, showing that team leaders and the quality of their LMX relationships they enact with team members play a key role in shaping the nature and strength of climate perceptions (Hofmann \& Morgeson, 1999; Hofmann, Morgeson, \& Gerras, 2003; Zohar, 2002; Zohar \& Luria, 2004).

Rentsch (1990), building on Schneider and Reichers' (1983) suggestion that social interaction shapes consensual climate, showed that networks of individuals with frequent informal social interactions showed greater consensus on climate relative to consensus within those individuals' formal organizational units. This research demonstrates nicely the theoretical assertion that social interaction contributes to shared climates.

In an effort to better capture climate emergence, Brown, Kozlowski, and Hattrup (1996) suggested that sharing, consensus, or agreement on climate perceptions ought to be a substantive phenomenon of interest rather than a mere statistical justification for aggregating individual climate perceptions to represent unit climates. Rather than treating the emergence of climate as all or none (i.e., if agreement is above threshold, climate perceptions are aggregated; if it is below threshold, there is no support for aggregation), they argued that degree of perceptual agreement could be conceptualized as measuring the extent to which climate perceptions were dispersed, had started to converge, or were highly consensual within the unit and therefore the extent to which climate had emerged. On this basis, Chan (1998) and Brown and Kozlowski (1999) proposed dispersion models in which perceptual agreement indexed the strength or degree to which a perceptual construct, in this case climate, emerged at a higher level of analysis (Kozlowski, 1999).

Subsequent work has generated support for this dispersiontheory conceptualization. For example, Schneider, Salvaggio, and Subirats (2002) reported data showing that aggregated (unit means) individual-level employee perceptions of unit (bank branches, $N=118$ ) service climate significantly interacted with unit climate strength (unit standard deviation indexing the degree of within-unit consensus), thereby demonstrating that greater within-unit consensus or strength yielded stronger relationships between service climate and aggregated customer perceptions of service quality concurrently and over a 3-year time interval. Examining data from 197 work units, GonzálezRomá et al. (2002) showed that social interaction and leaderinforming behavior was positively related to climate strength within units. Moreover, climate strength interacted with aggregated innovation climate to influence average unit satisfaction and commitment, and climate strength interacted with aggregated goal orientation to influence average unit commitment. 
Based on this systematic body of theory development and empirical support, we conclude that a collective climate that captures the strategic imperatives reflective of the core mission and objectives of an organization, unit, or team is a key emergent cognitive structure that shapes processes relevant to goals and their accomplishment. We further conclude that factors influencing climate consensus or strength-such as strategic imperatives, leadership, and social interaction-represent leverage points for shaping collective climates to influence team effectiveness.

\section{Team Mental Models and Transactive Memory}

Team mental models and transactive memory both refer to cognitive structures or knowledge representations that enable team members to organize and acquire information necessary to anticipate and execute actions. As we detail below, team mental models refer to knowledge structures or information held in common, whereas transactive memory refers to knowledge of information distribution within a team (i.e., knowledge of who knows what). Although these concepts may seem to bear some superficial resemblance to team climate, they are quite distinctive. Where climate tends to be more general in nature, team mental models and transactive memory are more specific to the team task and work system. Where climate is about what should be aimed for and, perhaps, why, team mental models and transactive memory are about how the knowledge to do it is organized, represented, and distributed.

Team mental models capture the shared, organized understanding and mental representation of knowledge or beliefs relevant to key elements of the team's task environment (Klimoski \& Mohammed, 1994). The concept of a mental model developed in the human-factors literature as an expert's cognitive representation of a system that could be used for predicting system states and for generating inferences about system behavior (Rouse \& Morris, 1986). Cannon-Bowers, Salas, and Converse (1993) posited that such cognitive representations, held in common by team members, might help enable team members to anticipate needs and actions and thereby "implicitly" coordinate their behavior and improve team effectiveness. We should highlight that the enhancement of coordination has been posed in the context of action teams that perform critical tasks under dynamic uncertainty (e.g., cockpit crews, surgical teams, command and control, combat teams), where coordination is a critical team process. This speculation energized considerable interest and activity in the team-research community.

Four primary content domains of team mental models were originally proposed (Cannon-Bowers et al., 1993). They include (a) knowledge about the equipment and tools used by the team (equipment model); (b) understanding of the team task, including its goals, performance requirements, and problems (task mental model); (c) awareness of team-member composition and resources, including representations of what individual members know and believe and their skills, preferences, and habits (team-member model); and (d) what team members know or believe about appropriate or effective processes (team-interaction model or teamwork schema).

One of the biggest challenges in research and application centers on how to measure and represent team mental models as group-level cognitive structures (Mohammed, Klimoski, \& Rentsch, 2000). Mohammed et al. (2000) identified four techniques, including pathfinder networks (PF; which generates a node and link structural representation based on ratings of the psychological proximity among concepts), multidimensional scaling (MDS; which generates a representation in geometric space based on ratings of the psychological proximity of concepts), interactively elicited cause mapping (IECM; which characterizes the causal linkage among concepts based on observation, interviews, and questionnaire data), and text-based cause mapping (TBCM; which characterizes the causal linkage among concepts based on text-based input), that can be useful for measuring team-level cognitive structure. The evaluation of the strengths and weaknesses of these different techniques by Mohammed et al. (2000) was based on seven criteria including the treatment of content, evaluation of structure, a clear standard, reliability evidence, effectiveness, utility for team analyses, and other considerations. They concluded that the decision of which technique to use depends on the research question under examination and on the team context. For example, if researchers know the key concepts of a domain and want to capture the structural relations among concepts (e.g., to compare expert and novice mental model structures), then PF and MDS are appropriate because they provide tools to represent, describe, and compare structures. On the other hand, if researchers are interested in measuring team members' belief relations, then IECM and TBCM may be more appropriate because they necessitate the direct elicitation from participants of concepts and relational information that capture the richness of cognitive content. Researchers also have to be mindful of levelsof-analysis concerns when data are gathered from individuals but when the goal is to represent the team level (Kozlowski \& Klein, 2000).

The presumption of the shared-mental-model literature is that team effectiveness will improve if team members have a shared understanding of the task, team, equipment, and situation (Cannon-Bowers et al., 1993). Although the notion of a common or shared team mental model has tended to dominate the research, there is recognition that team mental models may be more complex, in the sense that members do not necessarily have isomorphic (i.e., identical) knowledge structures but possess some sharing and also some unique structural information (e.g., based on role distinctions) that is compatible with that of other member roles (e.g., Banks \& Millward, 2000; Kozlowski, Gully, Salas, \& Cannon-Bowers, 1996). This conceptualization of networked knowledge incorporates aspects of a distributional model somewhat similar to the notion of transactive memory. However, most empirical work has focused on shared knowledge organization. 
Although there have been some concerns regarding the adequacy of empirical work relative to conceptual development (Mohammed \& Dumville, 2001), research has accumulated to provide solid support for the general presumption that shared mental models are associated with team effectiveness. Minionis, Zaccaro, and Perez (1995), for instance, used concept maps to examine shared mental models among team members in a computer-based, low-fidelity tank simulation. Their results indicated that shared mental models enhanced performance on collective tasks requiring interdependence among team members but did not impact those tasks that could be completed without coordinated actions - which is consistent with the general thesis. Mathieu, Heffner, Goodwin, Salas, and CannonBowers (2000) examined the effect of shared mental models on team processes and performance using two-person teams performing a PC-based combat flight simulation. Their results indicated that both teamwork and taskwork mental models related positively to team process and performance and that team processes fully mediated the relationship between shared mental models and performance.

There has also been theory and research to identify interventions that enhance the development of team mental models. Focusing on leadership, Kozlowski and colleagues (Kozlowski, Gully, McHugh et al., 1996; Kozlowski, Gully, Salas et al., 1996) posited that team leaders could play a key role in shaping team mental models by linking task cycles or episodes to a regulated learning process. Prior to action, the leader helps set team learning goals commensurate with current team capabilities; during action, the leader monitors team performance (and intervenes as necessary); and as the team disengages from action, the leader diagnoses performance deficiencies and guides process feedback. This cycle iterates and the leader increments the complexity of learning goals as team skills develop and compile. Marks, Zaccaro, and Mathieu (2000) showed that leader prebriefs that focused on appropriate team task strategies yielded better team mental models, processes, and performance. Other research focusing on the effects of leader pre-briefs (planning, strategies) and debriefs (feedback) has also shown positive effects on team mental models and team performance (SmithJentsch, Zeisig, Acton, \& McPherson, 1998; Stout, CannonBowers, Salas, \& Milanovich, 1999). Planning, strategies, and contingencies enable teams to overcome obstacles to goal accomplishment (Tesluk \& Mathieu, 1999), and training (described below) that focuses on skills relevant to diagnosis, feedback, and planning is also important (Blickensderfer, Cannon-Bowers, \& Salas, 1997). As a set, this research suggests that team leaders can play a central role in shaping the formation of shared mental models (as well as in team learning; Edmondson, 1999).

In addition, there are several training techniques that are effective for shaping the development of team mental models and enhancing team performance. For example, using a low-fidelity tank simulation, Marks et al. (2000) employed a concept- mapping technique to assess team mental models and showed that mental-model formation was influenced by leader pre-briefs and team-interaction training. Mental models, in turn, influenced team-communication processes and performance. Moreover, the effects of team mental models and communication processes on team performance were stronger when the task conditions were novel, suggesting that team mental models may help team members adapt to the unexpected. Marks, Sabella, Burke, and Zaccaro (2002) examined the effects of crosstraining (i.e., training on other team-member responsibilities in an interdependent task) on team-interaction mental models and their subsequent effects on coordination, back-up behavior (i.e., helping a teammate), and performance. Their results indicated that cross-training improved team-interaction mental models, assessed via PF, and that the effects of team mental models on team performance were mediated by improved coordination and back-up behavior. Blickensderfer et al. (1997) developed the technique of team self-correction training as a means to enhance the natural mechanism by which team members correct their team attitudes, behaviors, and cognitions. Team self-correction training focuses on skills relevant to (a) event review (following a task episode), (b) error identification, (c) feedback exchange, and (d) planning for subsequent task episodes.

Much of this growing empirical support for the efficacy of shared team mental models for fostering team processes and performance has been conducted in the context of action or command-and-control teams-real or simulated-but there is evidence in more recent work that it extends to other types of teams, such as TMTs (e.g., Ensley \& Pearce, 2001; Knight et al., 1999).

On the basis of this systematic body of theory development and growing empirical support, we conclude that a shared team mental model that captures the structure of relations among key aspects of the team, its task and role system, and its environment is a key emergent cognitive structure that shapes coordination processes relevant to team goals and their accomplishment. We conclude that factors influencing the development of shared team mental models_-such as leadership, training, and common experience-represent leverage points for shaping the formation of team mental models that influence team effectiveness.

The concept of transactive memory, as a memory system distributed across group members, was first proposed by Wegner to explain why close personal relationships often foster the development of common memory (Wegner, Giuliano, \& Hertel, 1985), and much of the formative work on transactive memory has studied it in the context of intimate relationships (e.g., dyads in dating relationships). From a team perspective, transactive memory is a group-level collective system for encoding, storing, and retrieving information that is distributed across group members (Wegner, 1986, 1995; Wegner et al., 1985). In contrast to the more uniform knowledge sharing characteristic of shared mental models, transactive memory is conceptualized as a set of distributed, individual memory systems that combines the 
knowledge possessed by particular members with shared awareness of who knows what (Wegner, 1995).

In that sense, one can conceptualize transactive memory as a network, with team members and their unique knowledge representing nodes with links representing other members' awareness of that unique knowledge. When each team member learns in a general sense what other team members know in detail, the team can draw on the detailed knowledge distributed across members of the collective. The development of transactive memory involves the communication and updating of information members have about the areas of the other members' unique knowledge. Each member keeps track of other members' expertise, directs new information to the matching member, and uses that tracking to access needed information (Mohammed \& Dumville, 2001; Wegner 1986, 1995). In this way, team members use each other as external memory aids, thereby creating a compatible and distributed memory system.

Given the presumed distribution of specialized memories across team members, transactive memory systems should be more cognitively efficient, allowing high specialization and greater capacity. Conceptually, such systems should reduce the cognitive load on individuals, enlarge the collective pool of expertise, and minimize redundancy (Hollingshead, 1998b). On the other hand, there are likely to be limits to the size of such a distributed memory system, at which point tracking costs may outweigh memory gains. There are important concerns that relate to conflicts of expertise, failure to capture important information, and diffusion of responsibility (Wegner, 1986). And, there are time lags and efficiency costs for accessing a distributed memory that may be detrimental to team effectiveness in time-critical situations (Kozlowski \& Bell, 2003).

Transactive memory is an intriguing concept that augments the focus on shared knowledge that dominates the team-mentalmodel literature. Unfortunately, however, empirical research on transactive memory is not commensurate with its theoretical development. Moreover, compared to the research base on team mental models, research on team transactive memory is still in its infancy. In an early application by Liang, Moreland, and Argote (1995), undergraduates were trained to assemble a radio either individually or in groups that were later tested with their original group or in a newly formed group that was composed by mixing members from different groups. Members of groups that had trained together evidenced stronger transactive-memory systems specialized for remembering different aspects of the task, they coordinated more effectively, and they showed greater trust in other members' expertise. In addition, transactive memory mediated the effects of group training on task performance. A follow-up study conducted by Moreland (1999) used a similar task and design. He used a more direct measure of transactive memory by assessing the complexity of group members' beliefs about other members' expertise, belief accuracy, and agreement about the distribution of expertise within the group. Rulke \& Rau (2000) used qualitative methods to examine the development of transactive memory, examining the sequence by which encoding unfolds over time.

More recent research has begun to address some of the conceptual and measurement problems identified by Kozlowski and Bell (2003) that have plagued this literature. Austin (2003), for example, integrated prior research to develop assessments of four dimensions of transactive memory, including (a) knowledge stock as the pool or combination of individual knowledge, (b) consensus about knowledge sources, (c) specialization of knowledge, and (d) the accuracy of knowledge identification. Examining 27 product teams $(N=263)$ in a sporting-goods company, results indicated that both specialization and accuracy were substantially related to external and internal evaluations of effectiveness and that accuracy was also related to external ratings of goal accomplishment. Lewis (2003), drawing on Moreland (1999), developed a three-dimensional perceptual measure of transactive memory. The dimensions included specialization, credibility, and coordination-which, although labeled differently, are consistent with Moreland (1999) and Austin (2003). Notably, within-group agreement on the transactive memory perceptions was used as a justification for aggregation of the perceptions to the team level. The study was rigorous in its development and validation of the assessment method. A related paper that appears to be based on a portion of the same data (Lewis, 2004) concluded that frequent face-toface communication (but not other forms of communication) facilitated the formation of transactive-memory systems and that transactive memory was related to team performance and viability.

This recent research is promising, although there is also a need for clear conceptual and empirical demarcations across the team cognitive constructs of climate, mental models, and transactive memory. For example, the assessment approach developed by Lewis (2003), which necessitates within-group perceptual consensus, blurs the distinction between climate, team mental models, and transactive-memory systems. The content of its perceptual dimensions is based on transactivememory conceptions, but because it incorporates the assumption of shared within-team perceptions to support data aggregation it mirrors assessments of shared team climate and some assessments of shared team mental models. It is the distribution of unique information that makes transactive memory distinctive. This observation is not meant to suggest that the technique is flawed. Rather, we simply note the need for clear conceptual and empirical demarcations across these team cognitive constructs.

There is merit to both the team-mental-models and transactive-memory approaches, but there are also important conceptual distinctions that may be differentially important for teams under different contingencies. In particular, it is likely that the difference between task interdependence, which necessitates differentiated role specialization (i.e., distributed expertise), and pooled tasks, which necessitate more common knowledge, 
will bear on the importance of knowledge distribution that would make transactive memory more important relative to knowledge sharing that would make shared mental models more relevant (Hollingshead, 2001).

As research on transactive memory goes forward, there is a need to expand on the formative work (e.g., Austin, 2003; Lewis, 2003, 2004) that examined its formation, emergence, and effects in work teams (Mohammed \& Dumville, 2001). With respect to shaping the formation of transactive memory, some research suggests that face-to-face interaction is important for its emergence and that computer-mediated communication presents barriers (Hollingshead, 1998a; Lewis, 2003). Given the rise of virtual teams, this finding should prompt concerted efforts to understand the reasons for such barriers and to try to develop augmentations for computer-based and other forms of remote communication. Research also shows that common experience or training (i.e., learning the task together as an intact team) may be useful for developing transactive-memory systems (Liang et al., 1995; Moreland, 1999). Thus, this may be an area in which the use of interpositional cross-training, which has proven useful in the development of shared mental models, may also help to foster the development of better transactive-memory systems.

In summary, we believe that the concept of transactive memory shows considerable promise for explaining distributed and compatible memory and knowledge systems in teams, making it a unique and useful supplement to the concept of team mental models. On that basis, we conclude that teams with better transactive-memory systems (i.e., knowledge of member specialization and strategies to access the knowledge) will be more effective. However, beyond familiarity, shared experience, and faceto-face interaction, the research base to help identify techniques for enhancing transactive memory is as yet not sufficiently developed to warrant specific recommendations for how to enhance it in teams. This is an obvious target for vigorous and rigorous research.

\section{Team Learning}

The concept of group or team learning refers to the acquisition of knowledge, skills, and performance capabilities of an interdependent set of individuals through interaction and experience. Team learning is fundamentally based on individual learning, but when viewed as more than a mere pooling of individual knowledge it can be distinguished as a team-level property that captures the collective knowledge pool, potential synergies among team members, and unique individual contributions. Certainly, the concept of learning is broad enough to be applied to levels of social organization beyond the individual-i.e., to teams, organizations, and collections of organizations-and it has been so applied. Indeed, the literature on organizational learning has developed over the last four decades into a rich, multifaceted, and multidisciplinary area of inquiry focused on creating, retaining, and transferring knowledge among higherlevel entities (Argote, McEvily, \& Reagans, 2003).
One of the key challenges is to distinguish team learning from related concepts such as team mental models and transactive memory, which also develop through collective interaction and common experience. One way to make such a distinction is to regard team climate, mental models, and transactive memory as emergent states that develop from learning as a dynamic behavioral process of interaction and exchange among team members (Kozlowski \& Bell, in press). When viewed as a process, it becomes more apparent that learning is contextually based and socially bound. For example, the concept of vicarious learning represents a potent form of knowledge transfer within groups, and it is certainly an important means by which knowledge is transmitted and acquired in group contexts (Argote et al., 2003).

One emerging perspective on collective learning that is consistent with this process view is represented by Edmondson's (1999) model of team learning. She noted that much of the relatively limited literature on team learning has been conducted in the laboratory, which limits the nature of the phenomena that can be observed. Edmondson provided a rigorous evaluation of her model in 51 work teams, using a combination of qualitative and quantitative techniques. The key construct in this model is the team perception of psychological safety, a climate-like shared perception that the team is a safe context for interpersonal risk taking. Team psychological safety, in turn, influenced team learning behaviors indicative of a team learning process_-such as seeking feedback, sharing information, experimenting, asking for help, and discussing errors-which then influenced team performance. Finally, a supportive organizational context and effective coaching by the team leader contributed to the development of perceptions of team psychological safety (see also Edmondson, Bohmer, \& Pisano, 2001).

Although Edmondson's work focuses on the learning aspects of these team behaviors, in a subsequent section we will address similar team behaviors as underpinnings for team performance as a dynamic process. Because learning, motivation, and performance are entwined, Edmondson's approach to team learning provides a useful linkage with this other emerging work, suggesting the potential for an effective integration in a broader model that will become apparent in the concluding section of this monograph.

Apart from Edmondson's research, there has been relatively little research on team learning outside of the laboratory. Here we provide a couple of illustrations of lab research on team learning. For example, Argote, Insko, Yovetich, and Romero (1995) studied the impact of individual turnover and task complexity on learning in a laboratory group task. Group performance-making origami birds-exhibited a performance learning curve, with output increasing significantly at a decreasing rate over six trials. High turnover and high complexity of the task were detrimental to group performance, with the detrimental effect increasing as groups gained experience, 
suggesting in the case of turnover that aspects of group knowledge were being lost.

Using a complex command-and-control radar simulation and four-person teams, Ellis et al. (2003) found that team composition and structure influenced learning. Team learning was assessed as an aggregate of the effectiveness and efficiency with which individual team members took action against unknown radar contacts, where effectiveness and efficiency represented the degree of match between resources expended to take action and the capabilities possessed by a contact (e.g., if a contact was moderately powerful and the action taken used excessive power, the action would be considered inefficient). Because each member had some unique information to help identify the type of contact, teams that were more effective and efficient on average could be inferred to have shared information or learned from one another. Teams composed of members with higher average cognitive ability and teams whose workloads were more evenly distributed among members learned more. With respect to personality composition, those teams whose members were higher on agreeableness did worse. Finally, teams configured as two subgroups learned more than did those without subgroups.

Although there is interesting work being conducted on collective knowledge management, it is largely at levels beyond teams and focuses on processes that are more macro in origin and effect (e.g., Argote et al., 2003; Epple, Argote, \& Devadas, 1991). At best, the research on team learning is still in the formative stage and needs improved focus and rigor. First, team learning as an outcome is typically inferred from changes in team performance. It is rarely assessed directly as a construct in its own right. Relatedly, many of the factors having an impact on team learning (e.g., turnover) are also likely to affect team performance via pathways other than learning. That is, while the removal or replacement of team members can influence collective knowledge, changing team members will also disrupt communication, coordination, and other emergent states that directly affect team performance. It is impossible to disentangle the process pathways and to map the pattern of effects as long as researchers continue to rely on the assumption that teams have learned rather than on direct assessments of team learning. Thus, there is a need for research in this area to directly measure changes in individual and team knowledge or some other direct evidence that learning has occurred-distinct from behaviors that directly contribute to performance. In a related vein, there is some question as to whether team learning as a knowledge-based outcome can be meaningfully distinguished from team mental models and transactive memory. In essence, one could consider team mental models and transactive memory as different manifestations of team learning, but then team learning would have no unique standing as a construct. It would merely be a more general conceptual handle for referencing more specific constructs.

Second, as we suggested earlier, it may be more valuable to conceptualize team learning as a process that yields shared knowledge, team mental models, and transactive-memory structures as emergent states (Kozlowski \& Bell, in press). However, with the exception of the work conducted by Edmondson (1999), there has been relatively little research to specify the process by which team learning occurs. Recent theoretical work by Ellis and Bell (2005) that conceptualizes team learning as a form of information processing (Hinsz et al., 1997) involving key conditions of capacity, collaboration, and commonality may also be useful in elaborating a process view. A process perspective necessitates simultaneous attention to both the individual and team levels of analysis. Researchers would not be able to simply combine disparate individual actions into an aggregate. Rather, they would have to more carefully delineate how disparate individual learning and action emerge as a collective phenomenon. We think that such an effort has longterm potential to illuminate the process of collective learning.

In summary, we see team learning as another team-level cognitive resource that has promise to help in understanding how team members are able to combine their knowledge to improve team effectiveness. On that basis, we conclude that teams that learn more collectively will demonstrate enhanced effectiveness. However, we also conclude that the research base to specify the meaning of team learning as a construct distinct from other team cognitive constructs and emergent states, and the research base to identify antecedents that enhance team learning, are not yet sufficiently developed to warrant specific recommendations for how to enhance team learning beyond individual knowledge acquisition. This is an obvious target for vigorous and rigorous theory development and research.

Team Interpersonal, Motivational, and Affective Processes and Emergent States

Research on processes has a long history in small-group research, with much of that effort traditionally centered on processes that capture motivational tendencies, relations among team members, and affective reactions. These processes imply a dynamic unfolding, but measures of team processes are most often static assessments that fail to capture temporal dynamics. That is why Marks et al. (2001) suggest that it is more accurate to describe the construct measures of team processes as emergent states. We will use both terms interchangeably and explicitly acknowledge that these constructs emerge from dynamic interactions among team members that tend to stabilize over time. We focus on a set of constructs-team cohesion; team efficacy and group potency; affect, mood, and emotion; and team conflictthat capture bonding to the team and its task; confidence in members' task competencies; affective processes and reactions; and their fractures, frictions, and disagreements.

\section{Team Cohesion}

Group cohesion is one of the earliest and most widely studied team-process characteristics. Team researchers have offered multiple definitions of cohesion. Festinger (1950) defined 
cohesiveness as "the resultant of all the forces acting on the members to remain in the group" (p. 274). Festinger is also responsible for suggesting the three facets that comprise cohesion-member attraction, group activities (i.e., task commitment), and prestige or group pride-although early researchers tended to view cohesion as a unitary construct. Nonetheless, other researchers have often emphasized only one of the facets. For example, Evans and Jarvis (1980) identified mutual attraction of members to the collective as the most common definition of cohesiveness. Carron (1982) defined cohesiveness as a process that reflects a group's tendency to stick together and remain united to reach a common goal. Goodman, Ravlin, and Schminke (1987) defined cohesiveness as the commitment of members to the group's task.

These somewhat mixed definitions or emphases are reflected in different conceptualizations of the dimensionality of group cohesion. Gross and Martin (1952) described cohesiveness in terms of two underlying dimensions: task cohesiveness and interpersonal cohesiveness. Task cohesiveness is defined as a group's shared commitment or attraction to the group task or goal (Hackman, 1976). Task cohesiveness is thought to increase commitment to the task and to increase individual effort on the task by group members. Interpersonal cohesiveness is defined as the group members' attraction to or liking of the group (Evans \& Jarvis, 1980). Interpersonal cohesiveness allows groups to have less inhibited communication and to effectively coordinate their efforts. Note that the third facet suggested by Festinger (1950), group prestige or pride, is missing from this conceptualization. Indeed, a recent meta-analysis by Beal, Cohen, Burke, \& McLendon (2003) found that it has been largely neglected in over 50 years of research, although it contributes to team effectiveness at levels comparable to the other cohesion facetsbut we are getting ahead of the story.

Research has generally supported a positive relationship between team cohesion and performance. For example, Smith et al. (1994) found that the level of cohesiveness in top-management teams was positively related to return on investment and sales growth. Similar results in top-management teams have been found by Hambrick (1995) and Katzenbach and Smith (1993). Moreover, several meta-analytic reviews conducted over the last 15 years have consistently supported a positive relationship between cohesion and group performance. An early meta-analytic review by Evans and Dion (1991) that focused solely on group-level cohesion and group performance concluded that the relationship is positive, although their study was based on only 18 effect sizes; they reported a wide confidence interval ( $r=.085$ to .643$)$; and they did not examine moderators, even though sampling error accounted for only $64 \%$ of effectsize variance. These factors suggest that there was much more to the relationship than was revealed in the review.

A more comprehensive meta-analysis by Mullen and Cooper (1994) also concluded that cohesion is significantly related to performance in a variety of teams, with an overall effect size of $r=.248$. To their credit, the Mullen and Cooper (1994) review examined the effects of several moderators of the relationship, including requirements for member interaction, cohesion dimensions, study setting (lab vs. field), and the effects of time. Of interest, they did not find significant effects for interaction requirements, suggesting that the relationship between cohesion and performance was not influenced by the extent to which members had to coordinate their knowledge and skills or could essentially work alone. Based on a temporal analysis, they concluded that the more likely causal direction is that performance influenced cohesion, although their methodology (which collapsed across highly variable time intervals) necessitates strong caution in the interpretation of this conclusion.

Unfortunately, as detailed in an incisive conceptual analysis by Gully, Devine, and Whitney (1995), both the Evans and Dion (1991) and Mullen and Cooper (1994) reviews suffer from serious limitations that make interpretation of their meta-analytic estimates problematic. In particular, the reviews confound team task interdependence (Evans \& Dion, 1991) and levels of analysis (Mullen \& Cooper, 1994). With respect to task interdependence, even though Mullen and Cooper examined this moderator and found no effect, this result is counter to theoretical expectations and, if correct, raises serious questions about the meaning of cohesion. With respect to levels of analysis, the problem is one of misspecification by mixing data at the individual level with team-level data but drawing conclusions at the team level. There are strong conceptual distinctions between cohesion as an individual perception and cohesion as a shared perception among members. Moreover, this confound is not merely a conceptual problem. Both factors are significant moderators of the cohesion-performance relationship.

Unlike the prior reviews, Gully et al. (1995) distinguished between research that examined cohesion appropriately at the team level of analysis, where theory predicts that the relationship should be stronger, and studies that measured cohesion at the individual level, which is a conceptual misspecification that should yield weaker relationships. They also examined task interdependence as a moderator. Theoretically, team cohesion should be more strongly related to team performance when team members have to coordinate their knowledge, skill, and effort in complex and highly interdependent workflows, relative to when interdependence is a simple pooling or additive aggregate of individual efforts by team members.

Their meta-analysis yielded an overall effect size of $r=.265$ with a confidence interval ranging from .211 to .318. Sampling error accounted for $64 \%$ of the effect-size variance. These findings for the overall effects, which mix team- and individuallevel studies, are comparable to those reported by Mullen and Cooper (1994). However, the picture changes when the individual and team levels are distinguished. At the individual level, the cohesion-performance relationship was .228 with a confidence interval ranging from .176 to .281. Sampling error accounted for $98 \%$ of the effect-size variance. For the team-level 
relationship, the effect size was .317 with a confidence interval ranging from .231 to .401. Sampling error accounted for $60 \%$ of the effect-size variance. As expected, the relationship at the team level was stronger, with relatively little overlap in the two confidence intervals. In addition, task interdependence was also a moderator. When team task interdependence was low, the effect size was $r=.201$ with a confidence interval ranging from .109 to .305 . Sampling error accounted for $82 \%$ of the effect-size variance. In contrast, when team task interdependence was high, the effect size was $r=.464$ with a confidence interval ranging from .366 to .562. Sampling error accounted for $96 \%$ of the effect-size variance. This work by Gully and colleagues represents an incisive conceptual analysis and rigorous metaanalysis of the cohesion-performance relationship. Moreover, their differential findings for levels of analysis and team task interdependence are consistent with our emphasis on the importance of these characteristics with respect to understanding team effectiveness.

More recently, Beal et al. (2003) also meta-analytically reviewed the relationship between group cohesion and performance. In many ways, their analysis was a refinement of the Gully et al. (1995) review. First, based on the Gully et al. (1995) findings, they only examined research that appropriately treated the relationship at the team level and they also examined task interdependence (defined as workflow complexity) as a moderator. Second, they carefully distinguished the three types of cohesion-interpersonal cohesiveness, task cohesiveness, and group pride-and performance criteria. In this regard, they distinguished performance as behavior, which is more under the team's control, from performance as outcomes, which may be influenced by a variety of other contingencies. They also distinguished whether outcomes were adjusted for inputs (efficiency measures) or not (effectiveness measures), arguing that efficiency measures are more indicative of team performance.

As expected, their analysis revealed that group cohesion was more strongly related to performance behaviors than to outcomes and was more strongly related to efficiency than to effectiveness measures. The mean corrected correlation between cohesion and performance behaviors was .301, whereas the mean corrected correlation between cohesion and performance outcomes was .168, a difference that was statistically significant. The mean corrected correlation between cohesion and efficiency measures was .310, whereas the mean corrected correlation between cohesion and effectiveness measures was .175 , a difference that was statistically significant.

In contrast to the findings reported by Mullen and Cooper (1994), Beal et al. (2003) found that all three components of cohesion were significant and, although varying in magnitude, did not differ significantly from each other. The effect sizes were .199 for interpersonal cohesion, .261 for group pride, and .278 for task commitment. However, because of the way the facets were distributed across primary studies, the Beal et al. metaanalysis did not clearly resolve whether each of the three facets makes a unique contribution to team performance. Resolution of that issue necessitates a larger base of primary research that incorporates all three facets. Finally, as would be expected, the magnitude of the relations between the cohesion components and the different performance criteria paralleled the overall findings described above, with stronger relations exhibited for behavior and efficiency measures. And, consistent with Gully et al. (1995), they found that as workflow interdependence increased, the cohesion-performance relationship increased.

The meta-analyses conducted by Gully et al. (1995) and Beal et al. (2003) have done much to clarify the relationship between the components of team cohesion and team performance. All of the cohesion components are significantly related to team performance at the team level of analysis, with task commitment and group pride exhibiting the strongest relations. Whether all three facets are uniquely related to performance, however, is still not clear. Cohesion is more strongly related to what team members do (i.e., behavior) than to team outcomes, but both relations are significant. And, as one would expect, team cohesion is more strongly related to team performance when the team task has a more complex workflow, thereby making team members more interdependent and placing more emphasis on team-member coordination.

On the other hand, research has relatively little to reveal regarding the antecedents of team cohesion. One could speculate that the composition of the team in terms of member personalities may be important. Barrick, Stewart, Neubert, and Mount (1998), for example, found that teams high in extraversion and emotional stability had higher levels of social cohesion. Clear norms and goals may help a team to develop both task and interpersonal cohesion. However, it is difficult to know the direction of this relationship. We do not know much about group pride; Beal et al. (2003) only had six effect-size estimates, but their findings suggest that this component should receive more research attention.

In summary, the research foundation for team cohesion is sufficiently well developed to conclude that it is an emergent affective state that is related to team performance and that the relationship strengthens as team workflow demands increase interdependence and require greater coordination of information and effort. On the other hand, there has been relatively little attention to the antecedents of team cohesion and there is causal ambiguity regarding the direction of the relationship; it is likely reciprocal. On that basis, we conclude that teams with greater collective task and interpersonal cohesion and pride will be more effective. However, the research base to help identify techniques for enhancing group cohesion is as yet not sufficiently developed to warrant specific recommendations for how to develop these desirable emergent states. This is an obvious target for research.

\section{Team Efficacy and Group Potency}

Self-efficacy is an individual's appraisal of his or her taskspecific capability to achieve a particular level of performance 
in goal accomplishment (Bandura, 1977). Self-efficacy is central in social-cognitive theory. As individuals direct action in the pursuit of goals, they monitor progress through feedback and reflect on discrepancies between current performance and their goals. To the extent that perceptions of progress are adequate, their appraisals of self-efficacy build. Self-efficacy is important because it leads to setting higher level goals when initial goal levels are accomplished (Phillips, Hollenbeck, \& Ilgen, 1996), it boosts persistence when goals are difficult and challenging, and it fosters adaptation to increasing task complexity (Kozlowski, Gully et al., 2001). Meta-analytic findings (Stajkovic \& Luthans, 1998) at the individual level of analysis have shown that self-efficacy is significantly related to performance (corrected $r=.38$ ). Given these findings for the important role of self-efficacy in individual effort and performance, parallel concepts of team efficacy and collective efficacy (we use the terms interchangeably, although collective efficacy can reference higher levels such as departments, organizations, and beyond) have been proposed, as has the related but distinct concept of group potency.

Self- and team efficacy are distinct in that the collective construct represents a group or team-level property that is shared, consensual, and held in common across group members and may be distinct from individuals' own self-perceptions of competence (Feltz \& Lirgg, 1998). Team or collective efficacy can be defined as a shared belief in a group's collective capability to organize and execute courses of action required to produce given levels of goal attainment (Bandura, 1997; Lindsley, Brass, \& Thomas, 1995; Zaccaro, Blair, Peterson, \& Zazanis, 1995). As noted above, it is not a simple aggregate of self-efficacy across group members; rather, it references the team as the collective entity with respect to shared perceptions (Gully, Incalcaterra, Joshi, \& Beaubien, 2002). Similar to selfefficacy, collective efficacy is hypothesized to influence what a group chooses to do (i.e., goal setting), how much effort it will exert, and its persistence in the face of failure (Bandura, 1997).

Shea and Guzzo (1987) defined group potency as a generalized collective belief that the group can be effective. Although many researchers view team efficacy and group potency as very similar constructs, they are distinct in that collective efficacy is task specific and group potency is a shared group-level belief about its general effectiveness across multiple tasks and contexts. Moreover, meta-analytic findings indicate distinctive moderator effects across the two constructs (Gully et al., 2002).

Empirical support for the positive effects of team efficacy and team potency on team performance is substantial (Gully et al., 2002). Much of the supporting experimental research involves ad hoc teams performing simulated tasks. Although the generalizability of this research is often questioned because of the use of student samples, simple tasks, and the relatively short duration of the studies (e.g., Prussia \& Kinicki, 1996), some of this work involves simulations of complex tasks that entail higher levels of interdependence, greater demands for coor- dination, and more psychological fidelity with their real-world counterparts. Examples include negotiation, business strategy, and military command-and-control simulations (e.g., Durham, Knight, Locke, 1997; DeShon, Kozlowski, Schmidt, Milner, \& Wiechmann, 2004). Another stream of supportive research examines intercollegiate sports teams such as ice hockey and football teams in naturalistic settings (e.g., Feltz \& Lirgg, 1998; Myers, Feltz, \& Short, 2004; Myers, Payment, \& Feltz, 2004). Other supportive field research has taken a qualitative approach (e.g., Edmondson, 1999) or has relied on survey questionnaires (e.g., Campion, Medsker, \& Higgs, 1993; Campion, Papper, \& Medsker, 1996).

A recent meta-analysis by Gully et al. (2002) reported a significant mean corrected correlation between team-level efficacy and team performance of .41 and a significant mean corrected correlation of .37 between team-level potency and team performance. In addition, their analysis showed that team efficacy is more likely to be a critical aspect of team processes when interdependence is higher. That is, when interdependence is low, team members essentially make contributions as individuals that are pooled to represent team performance (e.g., a sales team in which team performance is the sum of individual sales), whereas when interdependence is high, team members are more likely to share goals, effort, strategy, and efficacy (DeShon et al., 2004) and team-level efficacy is a more important contributor to team performance. In support of this reasoning, Gully et al. (2002) found that interdependence significantly moderated the team efficacy-performance relationship; the predicted effect size for the team efficacy-performance relationship at the lowest level of interdependence was .09, whereas at the highest level of interdependence it was .47 . As a more general construct, group potency did not evidence moderation by team interdependence in its relationship to team performance.

Given the well-supported relationship between team efficacy and team performance, there is a clear interest in understanding the antecedent factors that help to promote its development. However, most research has examined the team efficacy-performance relationship, with far less attention devoted to the antecedents of team efficacy, making it difficult to provide direct recommendations about the ways in which managers and organizations can build efficacy at the team level.

Some scholars suggest that antecedents that influence the development of self-efficacy may have a similar role to play, albeit at the team level. For self-efficacy, antecedents include enactive mastery, vicarious experience, and verbal persuasion (Bandura, 1977), as well as individual differences such as a learning or mastery goal orientation (Dweck, 1986). Extrapolating from self-efficacy, it has been suggested that teams that are exposed to difficult challenges they can master, that have opportunities to observe effective and ineffective teams, and that are persuaded that they can persist and succeed are more likely to develop team efficacy (Bandura, 1997; Kozlowski et al., 1999). 
At the team level, collective efficacy is more likely to develop when team members are more interdependent and interactive and have to coordinate task processes, as shared experiences provide a basis for the development of shared perceptions of collective efficacy (Paskevich, Brawley, Dorsch, \& Widmeyer, 1999). Similarly, one would expect that teams composed of learning-oriented members would be more likely to develop team efficacy than would teams composed of performance-oriented members. On the other hand, teams may be more likely to be composed of members with different prominent traits-a pattern or configuration of traits across members-rather than a composition of members with very similar prominent traits. Thus, we can also assume that team-level goal orientation may be an emergent state rather than a composition characteristic (DeShon et al., 2004) and that team goal orientation is distinct relative to the pattern of individual traits (DeShon et al., 1999).

Theory and research suggest that team efficacy can be developed by the action of leaders, who can shape team experiences and interactions, and by different forms of team training. For example, Kozlowski and colleagues (Kozlowski, Gully, McHugh et al., 1996; Kozlowski, Gully, Salas et al., 1996) have proposed prescriptive models of team leadership. A key role of leaders in these theoretical frameworks is to create mastery experiences in order to give team members an opportunity to build self-efficacy, and then to shift the focus of members toward the team and shape collective experiences so the team can build collective efficacy. In addition, Chen and Bliese (2002) conducted a field study of 2,585 soldiers in 85 units and found that leadership climate-task direction and socio-emotional support-was a strong predictor of collective efficacy. We will address how leaders can develop team efficacy in more detail at the conclusion of the paper. We will also address training in more detail later. Just to illustrate its potential, however, an interesting experiment by Brown (2003) provides a good example of how persuasion can be harnessed to build collective efficacy. Based on prior work on verbal self-guidance (VSG; e.g., Meichenbaum, 1971), Brown devised training that targeted teamlevel efficacy. His findings demonstrated that VSG training improved collective efficacy, which in turn mediated the effects of VSG on team performance.

With respect to research issues, we believe that further attention to levels-of-analysis concerns; the role of team efficacy in a broader conception of team learning, motivation, and performance processes; and greater attention to the antecedents of team or collective efficacy are warranted. First, team or collective efficacy is distinct from self-efficacy. They have different antecedents and consequences at different levels of analysis (Chen \& Bliese, 2002). Moreover, the strength of the relationship of team efficacy with team performance is stronger depending on whether it has been conceptualized (appropriately) at the team level or (inappropriately) at the individual level (Gully et al., 2002). Thus, team and collective efficacy should be appropriately assessed and composed (i.e., aggregated) to the team level. That is, items assessing team efficacy should reference the team, not an individual perspective (i.e., "we," not "I"). Moreover, team efficacy as a shared perception should be explicitly evaluated prior to aggregation to the team level (Kozlowski \& Klein, 2000). In other words, we assert that team or collective efficacy should be treated as a reference-shift aggregation model (i.e., individuals respond to items that reference the team) rather than as an additive or direct consensus model (i.e., individuals respond to items that reference the self; Chan, 1998) and recommend that a statistical evaluation be used to justify aggregation using well-established techniques (Bliese, 2000; see DeShon et al., 2004, for an example).

Second, the research base demonstrates that team efficacy is an important contributor to team performance. However, team efficacy is but one key emergent state in the broader phenomenon of team learning, motivation, and performance. The supportive findings for team efficacy likely stem from its role in the regulation of attention and effort in the team context. Recent research has validated a homologous multilevel model of individual and team regulation, indicating that team efficacy plays an analogous role to self-efficacy in action initiation and control at the team level (DeShon et al., 2004). Thus, team efficacy is but one part of a broader team-motivation process. And, third, most research has examined the collective-efficacy-performance relationship. There has been much less attention focused on the antecedents of collective efficacy. However, as we noted above, some initial theory and research are beginning to tackle the issue with promising results.

In summary, the research foundation for team efficacy is sufficiently well developed to conclude that it is an emergent motivational process or state that is related to team performance, and that the relationship strengthens as team workflow demands require greater coordination of information and effort (Gully et al, 2002). Based on the meta-analytic findings, group potency as a more global assessment of team capabilities also evidences a meaningful relationship with team performance. On that basis, we conclude that teams with greater team-level efficacy and potency will be more effective. We conclude that factors influencing the development of self-efficacy can be adapted to develop team efficacy and potency. In particular, we believe that team leadership and team-training interventions are leverage points for shaping the development of team efficacy and potency. We also acknowledge that additional research is needed in this promising area of intervention.

\section{Team Affect, Mood, and Emotion}

In their Annual Review of Psychology chapter on affect in the workplace, Brief and Weiss (2002) differentiate among affect, moods, and emotions. All three involve good or bad feelings, but they differ in specificity, duration, and the target of the feelings. Emotions (e.g., anger) have specific affective characteristics, exist for a finite period of time, and evoke particular behaviors and biological responses directed toward specific identifiable 
objects. Moods (e.g., happiness) also evoke feelings with specific identifiable characteristics, but they last longer and the targets and feelings are more diffuse. Finally, affect is usually evoked by specific targets and is short lived.

As we examine this area of literature, there are a couple of issues relating to precision of terminology and the proximity of effects that warrant attention. First, the literature on team-level feelings also refers to emotions, moods, and affect. However, this literature is far less precise in its distinction among these feelings-oriented constructs. "Emotion" often is the preferred term (see Hartel, Zerbe, \& Ashkanasy, 2005) for team-level affective states in spite of the fact that emotions rarely or ever refer to feelings that are narrowly focused. As we describe this area of work, we will be specific with respect to the authors' terminology, asking readers to keep in mind that they often may not be labeling their affective-state construct with the precision of Brief and Weiss (2002). For our part, we will use the term affect when referring to feelings. Second, it is also worth noting that the potential effects on team effectiveness of team affect, mood, and emotion are likely to be more distal than emergent states that are more specific and proximal. That is, although it has long been recognized that feelings play a major role in teams, only recently have researchers focused on feelings per se. It has been much more common to address feelings and affect as aspects of more specific components of behavioral episodes having affective components and implications-for example, cohesion and conflict. The latter concepts are, in a sense, behaviorally defined scripts more proximal to team outcomes like performance and more focused on a specific set of behaviors than are the more distal concepts of mood, emotions, and affect. Nonetheless, these differing affectively laden proximal and distal foci have tended to be examined as distinct, rather than overlapping, domains.

The effects of team affect have been investigated both in terms of the team- or mean level of affect and the dispersion of affect across team members. In almost all cases, the effects of teamlevel affect are addressed with respect to its impact on team members' cognitions, behavior, or other affective characteristics. Barsade and her colleagues (Barsade, 2002; Barsade \& Gibson, 1998; Barsade, Ward, Turner, \& Sonnenfeld, 2000; Kelly \& Barsade, 2001) refer to these as "top-down" effects. George (1990), for example, assessed the positive and negative affectivity (PA and NA) of team members and then examined the relationship between individual members' PA and NA and their teams' mean PA and NA with the members' individual affect score removed. There was a positive correlation between the individual and team scores for both PA and NA, implying that the overall affect level of the team influenced that of the individual team members. She also found team NA negatively related to the level of prosocial behavior in the teams. Finally, PA was negatively correlated with absences in the teams. George (1991) found that the impact of team-level affect was moderated by the similarity among team members on the affect variable as well as on the mean level. When there was within-group agreement (homogeneity) on group affective tone, either positive or negative affective tone influenced organizational spontaneity (George \& Brief, 1992) and absenteeism. This finding is indicative of the well-established principle in multilevel theory that within-group agreement, homogeneity, or sharing is essential for the aggregation of facets measured at the individual level to have meaning at the group level. Similarly, Jinnett and Alexander (1999) examined group-level job satisfaction and found that it was associated with groups members' intentions to quit, over and above their own individual level of job satisfaction. In multilevel theory, these types of findings are regarded as evidence for a contextual effect-the collective characteristic creates a context that influences individual responses (Kozlowski \& Klein, 2000) - suggesting that team affect creates a situation that influences individual affect in a top-down fashion.

Taking a somewhat different perspective on dispersion, Barsade et al. (2000) examined the fit between individual affect and collective affect for TMTs. In a sample of 62 chief executive officers (CEOs) and 239 of their top managers, they found that the more individuals' positive affectivity fit with that of the team, the more positive their attitudes were about group relations and their own influence in the team. Indexing within-team diversity on positive affectivity by the average Euclidian distance among members (i.e., the average of positive-affectivity distance between all member pairs), they found that greater diversity was associated with less use of participatory decision making by the CEO and with lower firm financial performance. When fit was also associated with higher mean levels of positive affectivity, reported levels of team task conflict were lower. Negative affectivity was unrelated to any of the criteria.

Another way to think about dispersion focuses on within-team conflict. High conflict indicates variance among members that may create negative affect. Higher levels of intrateam conflict were associated with greater turnover in a laboratory study (Bayazit \& Mannix, 2003). Intrateam conflict is typically seen as the opposite of cohesion. Studying hockey teams, Sullivan and Feltz (2001) argued that conflict may be constructive when there is free expression of conflicting ideas or strategies and may be destructive when it is personal and divisive. They found destructive conflict styles negatively correlated with task and social cohesion and positively correlated with the frequency of positive conflict.

Three general processes are believed to influence the way that affective states develop in teams: attraction-selection-attrition (ASA; Schneider \& Reichers, 1983), which is a combination of bottom-up and top-down processes; contagion, which is bottomup; and contextual influences, which are top-down. George (1990) suggested that team affect develops over time as a result of an ASA process theory that describes how organizations may become more homogeneous over time. Applied to teams, the ASA process theory assumes that individuals are attracted to teams with members who share similar affective orientations and 
that existing team members are more likely to select new members who are similar to themselves. Over time, those more similar to others in the team are more likely to remain with the team and those who are more dissimilar are more likely to leave. The result is that, over time, a team should move toward homogeneity on affective constructs. George argued and found that individual team members' PA and NA correlated more highly over time with team-level PA and NA when the individual in question was removed from the calculation of team-level PA and NA. She also found team NA to be negatively related to the level of prosocial behavior. PA was negatively correlated with level of absenteeism in the team.

A second process for the development of team-level affect is contagion. Emotional contagion occurs when the emotions and moods of one person are transferred to other proximal individuals (Kelly \& Barsade, 2001). In a nicely controlled laboratory study, Barsade (2002) investigated the effect of emotional contagion on team process and performance. The research involved using a confederate trained to express either positive or negative affect and to do so either with strong or weak commitment. Welldesigned method checks supported the confederate's successful manipulation of emotions through verbal and facial expression. No effect for level of commitment was found. Confederate behavior did lead to group-level changes in affect-that is, to "emotional" (really mood) contagion, both for positive and negative affect. In other words, contagion occurred regardless of whether expressed affect was positive or negative. On the other hand, positive-emotional-contagion group members improved cooperation, decreased conflict, and increased perceived performance; there were no effects of negative contagion on perceptions or behavior. Providing somewhat less direct support for contagion, Totterdell, Kellett, Teuchmann, and Briner (1998) had nurses record their moods each day at work over 3 weeks. They found significant covariation within teams and over time, thereby implying contagion. There was more convergence among older, more committed nurses, who, in turn, reported fewer problems with their teammates. Similar convergence was found in teams of accountants and on cricket teams (Totterdell, 2000).

Contextual features of the team or its environment provide a third source influencing the development of team affect, mood, or emotions. For example, intergroup conflict resulting from competition and external threat creates within-group homogeneity of feelings and affect toward the in-group and out-group (Sherif, 1966). The simple intervention of requiring teams to hold a discussion on a particular topic created greater polarization in teams given a positive mood induction prior to discussion, but not in those teams that experienced a negative mood induction (Forgas, 1990). Thus the top-down effect of mood was moderated by the team problem context-that of discussing the problem. Given the wide variety of contextual conditions that may impact team affect, our point is not to identify all such contextual factors but simply to illustrate that contextual conditions shape team affect, moods, and emotions and provide a third general process through which these affective states are influenced.

In summary, research in the area of collective affect, mood, and emotions in work teams is in its infancy, both conceptually and empirically. Conceptually, the rising tide of interest in feelingfocused constructs at the individual level is just beginning to flow to teams. Some of this work shows promise; for much of the rest of it, we must wait and see. For example, even the most basic constructs of team affect, mood, and emotions are less well developed conceptually or less consistently construed across investigators than is the case at the individual level. At this juncture, we recommend continued research to develop the constructs as meaningful team-level phenomena. However, the research base is not sufficiently well developed to provide guidance for application recommendations.

With respect to team outcomes, the most consistent findings relate more strongly to factors relevant to bonding members to the team than to factors influencing team performance. Prosocial behavior, citizenship behaviors, and the reduction of turnover were associated with affective characteristics. Moreover, when affect was further divided into positive and negative affectivity, the strength of the impact was greater for the positive affectivity. Given our focus on teams embedded in organizations with a past, present, and future, where affective bonds with team members and the team as a unit develop over time, these affective states are likely to play important roles. Three decades ago, Hackman (1976) stressed the importance of the "glue" that bonded team members to each other. Affect, moods, and emotions are likely to play a central role in creating that glue and need to be better understood as further research attention is focused on these constructs at the team level.

Finally, although affect, moods, and emotions are just beginning to be studied in their own right with respect to teams, they permeate a number of well-established team constructs, particularly cohesion (addressed previously) and conflict (considered next). Team cohesion and conflict are more targeted concepts that are proximal in a causal chain to critical team outcomes. Thus, the proximal factors of team cohesion and conflict may mediate the relationship between the distal factors of affect, moods, and emotions and team outcomes. For the most part, cohesion and conflict are studied independently of the growing literature on team affect, moods, and emotions, and vice versa. Thus, the relative contribution and mechanisms for shared effects are relatively uncharted. Greater integration between the two literatures should be a fruitful avenue for future research that endeavors to build a more solid empirical foundation to capture antecedents and effects.

\section{Team Conflict}

The team cognitive and affective processes we have reviewed thus far are largely shared phenomena and have positive relationships with team performance. However, anyone with any experience in work groups or teams knows that things are not 
always so neat, consensual, and convergent. Conflict and divisiveness are common phenomena in teams and organizations. Theoretical perspectives on team conflict, however, have been, well, conflicting. One perspective views rifts or "faultlines" that fracture teams as undermining team-member satisfaction and hindering performance (Lau \& Murnighan, 1998). Although a low level of conflict may be stimulating and may help to prevent group-think (the tendency for groups to pressure consensus and conformity; Janis, 1972), to the extent that conflict interferes with team information processing-diverting attention, increasing cognitive load, and limiting flexibility — it will degrade team performance (Carnevale \& Probst, 1998; Saavendra, Earley, \& Van Dyne, 1993).

On the other hand, other research and theory suggest that conflict is not monolithic (Guetzkow \& Gyr, 1954; Jehn, 1997) and that not all conflict is bad. Conflict can be functional and contribute positively to team performance to the extent that it is moderate; focuses on task-relevant issues; and reveals different points of view, important information, or methods and solutions to problems (Amason, 1996). This perspective underlies approaches for minimizing group-think (Janis, 1972) and the presumed advantages of diversity - that it enhances different perspectives — on team innovation and decision quality (Mannix \& Neale, 2005). Moreover, Jehn (1995) suggests that this positive effect is more pronounced for team tasks that entail greater degrees of interdependence. In contrast, when conflict is focused on interpersonal relations and factors not related to the task, it interferes with group information processing and undermines team satisfaction and performance.

This perspective- that conflict can be beneficial-is a thread running through several lines of work (e.g., diversity, constructive controversy, group-think). More recently, however, it has emerged from the work by Jehn and colleagues as a salient prescription for management training; the take-away message from such training is to enhance task conflict and minimize relationship conflict (De Dreu \& Weingart, 2003). A metaanalysis by De Dreu and Weingart (2003), however, raises caution in the interpretation of this research. Their findings indicate that both task and relationship conflict are negatively associated with member satisfaction and team performance. Although the associations with member satisfaction were distinctive (i.e., mean corrected correlations of -.32 and -.54 for task and relationship conflict, respectively), associations with team performance were nearly identical (i.e., mean corrected correlations of -.23 and -.22 for task and relationship conflict, respectively). Moreover, the negative effects were more pronounced when team tasks were more interdependent. De Dreu and Weingart concluded that their findings support an information-processing perspective on the effects of team conflict and do not support the idea that task conflict has beneficial effects on team performance.

De Dreu and Weingart were careful to point out, however, that their findings were based on cross-sectional correlation-based studies and that the causal ambiguity inherent in such designs (i.e., does conflict influence performance or does performance influence conflict?) suggests that their findings should not be overinterpreted. That is, there is some support in laboratory research for a curvilinear effect of task conflict on creativity and innovation. At the current time, however, prescriptive recommendations to promote conflict of any sort would seem to be premature. Further and more precise work is needed to better specify the effects of conflict on team performance.

In the meantime, understanding how to manage conflict in teams may be a more promising direction for action. One important factor to consider in understanding team conflict is that the scales to assess task and relationship conflict developed by Jehn (1995), while empirically distinct, are highly correlated. A study by Simons and Peterson (2000) showed that team trust moderated the degree to which task and relationship conflict were correlated. They interpreted their findings as indicating that team trust is useful for helping team members tolerate task conflict without it spilling over into destructive relationship conflict. Thus, team trust may play an important role in how teams manage different forms of conflict and may have the potential to be an important conflict-management tool. Moreover, De Dreu and Weingart (2003) found that the extent to which both types of conflict were correlated influenced the association between task conflict and performance. When task and relationship conflict were less correlated, the association between task conflict and team performance was weaker, albeit still negative. These joint findings suggest a potentially promising area for further research on team trust. At the current time, however, work on team trust is underdeveloped.

One potential avenue to pursue focuses on interpersonal competence. For example, Klein, DeRouin, and Salas (in press) developed a typology of interpersonal skills that are important to building relationships and fostering trust. They describe interpersonal skills as "an umbrella term that refers to a wide variety of concepts and associated terms, such as social skills, social competence, people skills, face-to-face skills, human skills, and soft skills" (pp. 3-4) and suggest that such skills likely play a key role in helping team members to minimize conflict and resolve it when it occurs.

In a related vein, Marks et al. (2001) identified two strategies for managing conflict within teams. One strategy-preemptive-establishes conditions to prevent, control, or guide team conflict prior to its occurrence. The other strategy-reactive-is intended to resolve conflicts once they manifest by working through task, process, and interpersonal disagreements among team members. For the most part, research has focused on reactive conflict-management strategies, such as specifying the nature of the conflict between team members, problem solving, willingness to accept differences of opinion, openness and flexibility, and compromising. There has been some research on preemptive conflict management, but it is more limited. For example, some work has focused on the use of team 
contracts or charters that specify a priori how team members agree to handle difficult situations (Smolek, Hoffman, \& Moran, 1999). Similarly, Marks et al. (2001) suggest creating team rules and norms regarding the nature and timing of conflict, and Tjosvold (1985) suggests developing norms for cooperative versus competitive approaches to conflict resolution (Tjosvold, 1985).

In summary, although there has been considerable research on team conflict and its effects on team effectiveness, one would have to conclude that the research foundation is not sufficiently well developed to formulate hard recommendations. In general, we would suggest that team members should possess interpersonal skills to build trust and to minimize and manage conflicts-both task and interpersonal-when they arise. Recommendations targeted at the promotion of particular types or amounts of conflict, however, await a better-developed and more rigorous research foundation.

\section{Team Action and Behavioral Processes}

Although one can regard coordination, cooperation, and communication processes as mediators of team performance, we advance a different point of view. What teams do-their actions to strive toward goals, resolve task demands, coordinate effort, and adapt to the unexpected - constitute team performance. We regard team performance as an active, dynamic, ongoing process rather than a retrospective evaluation. Here we make an important distinction between performance as a behavioral process and performance outcomes that represent judgments by others about the effectiveness of the team's performance process in achieving some desired standard (e.g., Hackman, 1992; Kozlowski et al., 1999). Team performance processes have cognitive and affective underpinnings (discussed earlier in this section) and distinct foci at the individual and team levels. Efforts to understand the underpinnings of team performance as behavior have focused on coordination, cooperation, and communication; team skill competencies and performance functions; and regulation, performance dynamics, and adaptation. Because these foci are distinctive but entwined, we treat them as a set with regard to our recommendations.

\section{Coordination, Cooperation, and Communication}

Kozlowski and Bell (2003) identified coordination, cooperation, and communication as key team behavioral processes, with much of the research centered on coordination of effort as the critical behavioral process in teamwork (Salas, Stagl, \& Burke, 2004). Coordination can be distinguished from related concepts of cooperation and collaboration in that coordination involves (a) the combination of disparate team-member actions and effort and (b) temporal entrainment (i.e., linked rhythms) and action synchronization in the combination process, whereas cooperation and collaboration do not involve these things (Kozlowski \& Bell, 2003). Much of the research on cooperation and collab- oration has focused on free riding and social loafing (Latané, Williams, \& Harkin, 1979), in which some group members coast instead of contributing to the group product. Research in social psychology has focused considerable energy on identifying factors that eliminate uncooperative behavior and induce more cooperation in groups (Kerr \& Bruun, 1983), such as making contributions visible and members accountable. Explicit communication is often used as a means to prompt or maintain coordination in action teams. Glickman et al. (1987) and Morgan, Salas, and Glickman (1993) suggest that communication supports taskwork (i.e., exchanging task-related information and developing team solutions to problems) and teamwork (i.e., establishing the patterns and quality of interactions) processes. Thus, communication is most typically regarded as a support for coordination behaviors. In this sense, we can regard all three factors as interrelated and important, with coordination of information and effort as primary. The key question is, what enables effective team coordination, or "teamwork"?

\section{Team-Member Competencies}

One approach to understanding team-member competencies has adopted a selection perspective, focusing on the identification of individual team-member knowledge, skills, and abilities (KSAs) thought to underlie effective teamwork. That is, the focus is on those KSAs that enable team members to work together effectively rather than on those that enable taskwork-the ability to perform individual tasks. The presumption is that teams composed of members by selecting members who are higher on teamwork KSAs will be more effective than those with lower teamwork KSAs. To develop this typology of teamwork KSAs, Stevens and Campion (1994) conducted a broad review of the teamwork literature and identified through inference individuallevel KSAs they believed were related to effective teamwork across a wide range of work teams (i.e., generic teamwork skills). The typology consists of two primary dimensions, each with subdimensions (i.e., interpersonal KSAs of conflict resolution, collaborative problem solving, and communication; and selfmanagement KSAs of goal setting and performance management, planning, and task coordination). More specific KSAs are nested under the subdimensions. Subsequent work by Stevens and Campion (1999) developed an instrument to self-assess the teamwork KSAs and provided some evidence supporting its validity, although the results were mixed. One study demonstrated some significant incremental validity beyond a traditional aptitude test for the teamwork-KSA assessment for supervisor ratings of teamwork performance (8\% incremental variance) and overall performance (6\% incremental variance), but not for taskwork performance ( $1 \%$ incremental variance) as expected. However, the teamwork-KSA assessment demonstrated substantial overlap with the aptitude test $(r=.81)$ and a second study failed to replicate the findings. More work is needed on this approach. 
Another line of work directed at understanding the underpinnings of team performance as a dynamic behavioral process takes a training perspective, focusing on the essential knowledge and skills that enable teamwork. Relevant team competencies have been derived for task knowledge, attitudes, and processes (Cannon-Bowers, Tannenbaum, Salas, \& Volpe, 1995; Salas \& Cannon-Bowers, 2001), and they have a well-developed observationally based research foundation (e.g., Cannon-Bowers \& Salas, 1998). Note that the conceptual organization for these team competencies roughly corresponds to our process categories of cognition, motivation/affect, and behavior. With respect to key behavioral and action competencies, Cannon-Bowers and colleagues specify (a) mutual performance monitoring, back-up behavior, and feedback; (b) coordination; (c) communication; (d) decision making; and (e) adaptability. They also specify other competencies (i.e., shared situational awareness, interpersonal relations, and team leadership) that better fit with our cognitive or motivational/affective processes. These teamwork competencies are centered on team members prompting and maintaining coordination by monitoring and assisting one another (competencies a-c) and solving problems and adapting to the unexpected (competencies d-e). Research by Tesluk and Mathieu (1999), for example, demonstrates how work teams can use problem-solving strategies to maintain cohesion and teamwork in the face of shifting performance constraints.

Another stream of work, summarized by Fleishman and Zaccaro (1992), has developed a taxonomy of team performance functions, the "synchronized activities" that enable team performance. Team performance has two primary components in their model-individual task behaviors and coordinated taskrelated processes/functions/behaviors - and is the result of four classes of antecedents-external conditions imposed on the team, member resources, task characteristics and demands, and team characteristics. The taxonomy builds on prior work (Nieva, Fleishman, \& Rieck, 1978; Schiflett, Eisner, Price, \& Schemmer, 1982) and consists of seven functional categories:

(1) Orientation functions, such as information exchange regarding member resources and constraints

(2) Resource-distribution tasks that involve balancing the task load across members

(3) Timing functions that influence how activity is paced

(4) Response-coordination functions, such as the timing and synchronization for coordination

(5) Motivational functions, such as balancing attention to individual and team goals

(6) Systems-monitoring functions that enable the adjustment of team and member activities in response to errors and omissions

(7) Procedure maintenance, such as monitoring of general procedures and activities.

Note that several aspects of these functions are also represented in the team competencies. Thus, although these are different lines of research, they have common underpinnings and foci. It is also noteworthy to highlight that Edmondson's (1999) teamlearning behaviors also have substantial conceptual overlaps with this research. Such convergence is encouraging.

\section{Team Regulation, Performance Dynamics, and Adaptation}

Other recent theory and research has, instead of focusing on discrete team KSAs, competencies, or performance functions, adopted a more explicit perspective of team performance behavior as a dynamic, cyclic, and episodic process-a process driven by shifting environmental contingencies and consequent task demands that necessitate commensurate performance adaptation by team members (see Fig. 1). Taking a systems perspective (cf. Arrow et al., 2000), Kozlowski and colleagues (Kozlowski, Gully, McHugh et al., 1996; Kozlowski et al., 1999; Kozlowski, Gully, Salas et al., 1996; Kozlowski, Watola, Nowakowski, Kim, \& Botero, in press) have developed theoretical frameworks that link team learning and performance to episodic task cycles and developmental progression. They view teams as embedded in broader organizational systems or performance environments creating team task demands that are resolved by team performance processes. System and environmental contingencies are shifting, thereby creating team task demands that also vary and cycle around a task episode that entails (a) preparation for task engagement, (b) engagement, and (c) disengagement/reflection. This cyclic process has implications for how and to what extent the cognitive, motivational, and behavioral resources of team members are task directed. Moreover, the researchers argue that this task performance cycle can be explicitly linked to processes of individual and team regulation and goal striving. Over time, the development of regulatory capabilities enables team members and the team as a collective to continuously improve and adapt to the unexpected (Kozlowski et al., 1999).

Models of self-regulation are the dominant psychological models of learning, motivation, and performance at the individual level (Karoly, 1993). Self-regulation is conceptualized as an iterative process that involves difficult goals to which individuals are committed; behavior directed at goal striving; feedback and self-reactions to current progress; and revision of effort investment, strategies, or goal levels to lessen the discrepancy between the goal and performance. Kozlowski and colleagues posited that a parallel regulatory process can be extended to the team level and that task cycles can be harnessed by leaders to build team regulatory skills (cf. Prussia \& Kinicki, 1996). At the onset of a task cycle, leaders can help prepare the team by setting goals and suggesting task strategies. As the team engages in the task, member resources (attention, affect, and behavioral effort) are allocated to team performance. Leaders monitor discrepancies between current action and desired goals. Discrepancies are documented for subsequent feedback and reflection. As the task is accomplished, the leader prompts team members to reflect on their performance processes (or functions) 
and how they can be improved, and the episode concludes. Reflection then provides input to subsequent goals and strategies as the task-engagement cycle iterates.

Marks et al. (2001) also adopt an episodic perspective on team tasks as temporal cycles of goal-directed activity, a perspective largely consistent with team performance as a regulatory process centered on goal striving and accomplishment. They describe task episodes as "distinguishable periods of time over which performance accrues and feedback is available.... [Episodes] constitute the rhythms of task performance for teams, and they are marked by identifiable periods of action and transition periods between actions .... [and] are most easily identified by goals and goal accomplishment periods" (p. 359). This framework also highlights that teams are often engaged in multiple tasks that vary in the duration and cycling of episodes-that is, in their action (task engagement) and transition (task preparation and post-task reflection) phases.

Marks and colleagues then use team action and transition phases to integrate and structure the team-performance functions (Fleishman \& Zaccaro, 1992) and team competencies (Cannon-Bowers et al., 1995) discussed previously. That is, they argue that certain team-performance processes are more relevant during a transition when the team is preparing or ending an engagement (i.e., mission analysis, goal specification, strategy formulation and planning), others are more important when the team is engaged in action (i.e., monitoring goal progress, systems monitoring, team monitoring and back-up behavior, coordination), while others are temporally independent and relevant across phases (i.e., conflict management, motivating and building confidence, affect management). Their framework is a parsimonious integration of the prior work and, with its temporal structure, provides a means to target processes or emergent states that are critical at different points during team performance episodes.

Formative research has been conducted to examine the utility of the team transition-action phases and process linkages postulated by Marks et al. (2001). In this initial work, the focus has centered on the utility of the transition-action-interpersonalprocess emergent states as mediators between team inputs and performance outcomes, rather than on episodic performance dynamics (e.g., Mathieu \& Schulze, in press). This early work suggests that the framework has promise but that relationships are more complex than the model implies. Additional work by the research team (DeChurch \& Marks, 2006; Marks, DeChurch, Mathieu, Panzer, \& Alonso, in press) has also extended the framework to the multi-team system (MTS) level of analysis (i.e., teams of teams; Mathieu et al., 2001). A particularly good illustration of this approach by DeChurch and Marks (2006) showed that MTS-level leader training targeted at specific MTS transition-action processes influenced the exhibition of those leadership functions and the targeted MTS emergent states, both of which mediated the effects of the training on MTS performance. Thus, in aggregate, the Marks et al. framework shows potential as a useful tool for understanding the emergence of team processes and their role in team- and higher-level performance.

One notable point we would make is that while there are distinctive contributions in these different lines of thinking, they are highly compatible in their focus on performance dynamics; the means by which performance processes can be regulated, managed, and enhanced; and the centrality of the performanceprocess behaviors for team adaptation. Previously in this monograph, we have established that a key regulatory process factor or emergent state, team efficacy, exhibits a meaningful positive relationship with team performance and that the relationship is stronger when the team task necessitates more complex workflow interdependence and coordination among team members. Often, the research underlying these meta-analytic findings treats team efficacy as a mediating process factor that links inputs to performance as a team output. However, factors responsible for, and processes underlying, the formation of team efficacy have received less research attention. In part, this neglect is due to a tendency to address "team processes" with research designs that are somewhat static. Thus, the dynamics inherent in team processes are still somewhat elusive, although this is beginning to change.

A key factor underlying team performance and adaptation as dynamic processes is the capability of team members to appropriately allocate limited cognitive and behavioral resources to accomplish multiple goals that contribute to effective individual and team performance and to adapt their resource allocations to meet dynamic task demands. Team members often have latitude in terms of how, and how much of, their personal resources are allocated to teamwork and team performance (Shiflett, 1979). In many action teams, members assume individual goals, but they also coordinate effort and provide assistance to other team members to meet distinct higher-level team objectives such as choosing to coordinate collective effort, back-up a teammate, or aid a teammate in resolving a problem. The degree to which members allocate attention and effort across both individual and team goals is discretionary but critical to team performance.

Because individuals allocate attention and effort around multiple goals, regulatory processes in teams are multilevel. Most research targeted at improving team performance, however, has either focused only on the individual level-ignoring the nesting of individuals within the team context-or on the team as a collective-ignoring the distinctive contributions individuals make to team processes and outcomes. Recent research by DeShon et al. (2004) has treated team regulation and performance as multilevel phenomena that occur at both levels simultaneously. The researchers first developed a conceptualization of the influence of multiple goals-individual and team-on goal-feedback loops underlying the regulation of individual attention and allocation of behavioral resources. They then extrapolated the dynamic self-regulatory implications of the 
multiple-goal resource-allocation model to develop a multilevel model that captured regulatory processes at both the individual and team levels.

The essential characteristics required to validate a multilevel model are (a) that team-level constructs, conceptually parallel to those at the individual level, satisfy theoretical and statistical criteria to support aggregation to the team level (i.e., composition); and (b) that the linkages among parallel constructs at both levels demonstrate functional equivalence (Kozlowski \& Klein, 2000). In an experimental design that examined 237 trainees organized into 79 teams of 3, DeShon et al. (2004) provided empirical support for their multilevel model of individual and team regulation. Of particular importance, the relative salience of either individual or team goal feedback loops was the primary factor driving individual resource allocations and, ultimately, team performance. In essence, their research demonstrated that the key regulatory processes responsible for individual resource allocation, skill acquisition, and performance also substantially hold at the team level. Thus, a key finding of this research is that rather than being a holistic concept, team performance is emergent (Kozlowski \& Klein, 2000). That is, it emerges bottomup from the combined pattern of team members' resource allocations to individual and team goals. Follow-up work has started to investigate factors that influence dynamic multiple-goal regulation (Schmidt \& DeShon, in press). In general, this line of systematic theory development and research on team regulation, performance dynamics, and adaptation shows good promise.

Other work, drawing on this theoretical and empirical foundation, has extended the basic concepts in novel and useful directions. Chen, Thomas, and Wallace (2005) evaluated a multilevel model of training transfer and performance adaptation. Integrating the work by Kozlowski, Gully, McHugh et al. (1996), Kozlowski et al. (1999), Marks et al. (2001), and DeShon et al. (2004), they posited that multilevel regulatory processesindividual and team-would account for the link between cognitive, motivational/affective, and behavioral outcomes at the end of team training and at the end of subsequent post-training performance adaptation. Examining 78 two-person teams trained to operate a PC-based flight simulation, they found general support for their approach. Although the finding did not support a true multilevel homology-some of the measures lacked structural identity across levels (i.e., strict isomorphism or composition)—relations were sufficiently similar to support the promise of the approach and the extension of multilevel regulation to explain team-training transfer. In that sense, the research provides additional support for regulatory processes to capture team performance and adaptation.

A related but distinct line of work by LePine (2003, 2005) also supports the promise of team performance-regulation processes as a means to explain team adaptation, in this case role adaptation. The primary focus of this research is the effects of team composition-different patterns of individual differences in cognitive ability and personality—on the team's capability to adapt its role structure in response to an unforeseen breakdown in a key communication link necessary for successful task performance. The basic paradigm used a PC-based three-person team decision-making simulation. Teams were trained on the appropriate task-role structure and then an essential information channel was either cut (LePine, 2003) or degraded (LePine, 2005). The task stabilized and teams had a period to adjust. Team composition factors were then examined as predictors of adaptation.

Although the composition effects across the two studies are interesting in their own right (i.e., cognitive ability, achievement, openness, low dependability, and learning goal orientation positively predicted role adaptation), it is the application of the regulatory model to account for adaptation that is pertinent to the current discussion. In a nicely conducted supplementary analysis, LePine (2005) examined transition-action processes prior to, during, and after disruption. He found that teams that focused more on transition processes (i.e., analysis and planning) during disruption and maintained a positive interpersonal tone, rather than focusing on action processes (i.e., performance monitoring), were more likely to adapt after the disruption. Moreover, as one would expect, whereas action processes were detrimental during disruption-most likely because they detract from a diagnosis of the nature of the change and its resolution (Kozlowski et al., 1999) - they were positively related to role adaptation after the change ended and the situation stabilized.

In summary, considerable systematic theory and research support the important role of coordination, monitoring, member back-up, and other dynamic performance-oriented behaviors in enhancing team effectiveness. Moreover, team regulatory processes - which are the underpinnings for the expression of such behaviors-are important determinants of team performance and adaptation and have the potential to be leveraged by a variety of interventions such as leadership, training, and provision of goals and feedback. On that basis, we conclude that teams with better individual teamwork KSAs, competencies, and functions will be more effective. Moreover, we conclude that teams with better regulatory-process dynamics that express these competencies as synchronized individual and team action will be more effective. We conclude that factors that influence the development of self-regulation can be adapted to develop team regulation. In particular, we believe that team leadership and team-training interventions are key leverage points for shaping the development of team regulatory-process competencies. We also acknowledge that additional research is needed in this promising area of intervention.

\section{ALIGNING AND LEVERAGING TEAM PROCESSES TO PROMOTE EFFECTIVENESS}

Our review has focused on team processes-what members think, feel, and $d o$-as a primary means to understand the 
dynamics of teams in action and to capture the states that emerge from those dynamics as team members interact with the task and each other over time. Several of these emergent states have amassed a solid, and in several cases quite substantial, research foundation supporting a relationship (both correlational and causal) with team performance or other indicators of team effectiveness. We view these factors-which include unit and team climate, team mental models and transactive memory, collective learning, team cohesion, team efficacy and potency, and team regulation skills (competencies, functions, and dynamic adaptation) — as promising targets for interventions designed to enhance team effectiveness. Other emergent states that focus on shared affect, mood, emotion, and conflict, while showing potential promise, are in need of more basic research that demonstrates their role in promoting team effectiveness. Thus, while those states are likely to be important in the long run, we concentrate our recommendations for leveraging and aligning team processes on those factors with solid research support or potential. Our review also provided some early highlights of types of interventions that enhance team processes and, hence, performance. There are three primary areas for intervention that are promising: team design, team training and development, and team leadership.

\section{Team Design}

At a fundamental level, one has to ensure that a team is aligned with its organizational context and has adequate resources to perform its task and fulfill its mission. Yet, anyone with any experience in organizations knows that such alignment is often missing. We consider the issue of team design to be fundamental and self-evident. Thus, even though there is relatively little specific research investigating such issues, the implications of poor team design are in most instances patently obvious.

\section{Normative Model}

Hackman (1992) presented a normative model of team design that is useful for highlighting necessary factors to be considered when teams, and the supporting organizational system, are configured. Key areas that should receive attention include ensuring that the organizational context supports the team, that the team design promotes competence, and that material resources are sufficient.

The normative model specifies that the organizational context needs to provide appropriate rewards, education, and information. Consider, for example, that organizational reward systems are typically focused on individual performance rather than team performance (Ilgen \& Sheppard, 2001). When that is the case, individuals are more likely to invest effort that will enhance their own performance relative to that of the team if both goals cannot be simultaneously accomplished (DeShon et al., 2004; Ilgen \& Sheppard, 2001). Rewards should accrue to both individual and team performance. In addition, there needs to be training support to ensure that members have necessary skills underlying taskwork and teamwork and that information is sufficient to allow the team to plan a performance strategy, consider alternatives, and monitor progress.

Team-design factors center on the structure of the team task, group composition (i.e., combination of member knowledge, skills, abilities, and other characteristics; KSAOs), and groupperformance norms. For example, as teams have become more prominent in organizations, it is not unusual to find situations in which jobs that are essentially performed by independent individuals are reorganized into "team" work structures. Such "designs" create teams that exist in name only and, if anything, are more likely to impede individual performance than to enhance it. A basic prescription of team design is not to form teams if the task can be accomplished by individuals operating independently (Steiner, 1972)—a prescription often violated in practice.

It may seem obvious that teams should be composed of members with an appropriate combination of KSAOs to perform the task, but this is not always the case. In many cases, the problem is due to a failure to apply well-established research findings. It is known, for example, that general cognitive ability $(\mathrm{g})$ is a valid predictor of job performance across a wide range of jobs (Schmidt \& Hunter, 2004), yet many organizations do not use $g$ for selection and assignment. We also acknowledge that research support for the validity of team (average) cognitive ability and team performance is beginning to emerge (e.g., Barrick et al., 1998; LePine, 2003, 2005; LePine, Hollenbeck, Ilgen, \& Hedlund, 1997; Tziner \& Eden, 1985), suggesting that the relationship may generalize to the team level.

In other cases, the problem is more due to the fact that the research foundation has yet to develop sufficiently. Although there may be many team-member characteristics for which more is better for the team-as in the case of $g$-there are other individual differences that may benefit the team when there is a balanced pattern across members (Kozlowski \& Klein, 2000). Consider personality, for example. One might well want a team in which all members are high on emotional stability (Stewart \& Barrick, 2004). On the other hand, one may not want a team composed solely of extroverts who might be so socially engaged that taskwork is compromised, or a team composed solely of conscientious members who might be so task engaged that they neglect the social glue that bonds members together. Rather, one may want a team that is composed of a more balanced pattern of extroversion, agreeableness, and conscientiousness across members (Stewart \& Barrick, 2004). This area of research is quite promising although still in its infancy. Well-developed theoretical models are needed to help specify complex patterns of composition (Kozlowski \& Klein, 2000), particularly when one considers the many different demographic, ability, personality, cultural, and other characteristics that may be important to team composition (Chao \& Moon 2005; Harrison \& Klein, in press). At a broader level, conceptual frameworks that seek to 
integrate the implications of staffing across multiple levels of analysis-individual, team, and organizational-provide an important foundation for this promising emerging area (e.g., Ployhart, 2004; Ployhart \& Schneider, 2005; Schneider, Smith, \& Sipe, 2000).

Stewart, Fulmer, and Barrick (2005) assessed both individual and team-level variables in 45 teams of executive MBAs; they argued that team-member roles provided a mechanism through which individual inputs affected team-level outcomes. Individual-level personality variables explained from 9 to $12 \%$ of the variance in the team-member role definitions, and role characteristics between teams defined either as means (composition of individual roles) or variance (compilation models of individual roles) correlated with team outcomes of social cohesion and team performance.

Validated methods exist for identifying and assessing generic (i.e., generalizable) team-member KSAs (Stevens \& Campion, 1994, 1999) and there is initial research support demonstrating that they can be effectively imparted through training, with demonstrable effects on team-member behavior (Chen, Donahue, \& Klimoski, 2004; Ellis, Bell, Ployhart, Hollenbeck, \& Ilgen, 2005). Of course, this approach assumes that individuals possess requisite task and teamwork competencies. Often, supplemental training may be necessary in either or both areas.

Finally, the normative model specifies sufficient material resources to enable team members to accomplish task goals consistent with desired standards and within acceptable time frames. Again, this seems rather obvious. Indeed, it is a moderating factor in the Hackman model, such that no matter how effective team processes may be, insufficient resources will prevent the team from performing to standard. Yet, in this era of downsizing, cutbacks, and the press to do more with less, one has to question the wisdom of managers who believe that more can always be accomplished with less.

As noted earlier, we know of no direct evaluations of the Hackman normative model of design, although there are lines of work that provide reasonable indirect support. For example, Campion and colleagues conducted two studies to examine factors that influence team effectiveness (Campion et al., 1993, 1996). Based on a broad review of the literature, they identified five sets of "thematic" team characteristics, which they assessed from individual team members and related directly to facets of team effectiveness. The characteristics included job design (self-management, participation, task variety, task significance, task identity), team composition (heterogeneity, flexibility, relative size, preference for team work by members), contextual factors (training, managerial support, interteam communication and cooperation), task interdependence (task interdependence, goal interdependence, and interdependent feedback and rewards), and process (potency, social support, workload sharing, and intrateam communication and cooperation). With respect to Hackman's model and the perspective taken in this review, contextual factors and team composition serve as input condi- tions, job design and task interdependence as design factors, and process as, well, processes. Although the results across both studies are difficult to summarize succinctly, the basic conclusion is that all the factors related to facets of team effectiveness. One interesting observation is that the process factors tended to have stronger bivariate relationships with team effectiveness than the other characteristics did, suggesting the possibility of a more complex model than was evaluated, with processes as mediating factors.

Another line of work that provides indirect support for the normative model focuses on team empowerment - that is, how structural features of the work setting can create a sense of shared responsibility, motivation, and sense of psychological empowerment that influences team processes and effectiveness (Mathieu, Gilson, \& Ruddy, in press). Although this work was originally conceptualized at the individual level, more recent work has generalized it to the team level of analysis (e.g., Hyatt \& Ruddy, 1997; Kirkman \& Rosen, 1997, 1999; Kirkman, Rosen, Tesluk \& Gibson, 2004; Mathieu et al., in press). The essential point for our purpose is that the structural antecedents that give rise to a sense of team empowerment (Mathieu et al., in press) largely parallel those in Hackman's model and in the research by Campion and colleagues-namely, organizational support (climate for open communication and cooperation), work design (autonomous control), team-design practices (training, feedback), and appropriate leadership (resource facilitator).

\section{Structural Adaptation}

The normative model centers on fit, with a key aspect focused on the fit of the team task structure to environmental demands that drive the task. This is the essence of the logic of organizational contingency theory, which has a long and rich history in efforts to understand organizational design, functioning, and effectiveness (Burns \& Stalker, 1961; Galbraith, 1972). In general, this line of thinking takes the position that environmental uncertainty (i.e., ambiguity, unpredictability) fits better with more flexible, less tightly structured task designs and that environmental certainty fits better with more tightly controlled and efficient task designs. Thus, for example, organizations in more predicable environments seek to exploit that predictability with structure to maximize efficiency, whereas organizations in unstable environments seek flexible structures to cope with uncertainty via innovation and adaptation.

Similar logic has been applied to the fit between team design/ structure and team tasks; although like contingency-theory applications at the organizational level, the logic is static, with little attention paid to change over time. Nonetheless, the presumption is that teams can be designed to adapt their structures to fit changes in environmentally driven task demands. Recent work by Hollenbeck, Ilgen, and their colleagues (Hollenbeck et al., 2002), however, has challenged this notion by finding asymmetries in team adaptation to structural change depending on the pattern of structures across time. 
Using functional (i.e., distinct specializations) and divisional (i.e., generalist capabilities) team structures (Burns \& Stalker, 1961), Hollenbeck et al. (2002) first replicated the static findings of the past. Functional structures are those in which team members are assigned different specializations for working on the overall team task; divisional structures are those in which each team member can do all of the team's subtasks. Consistent with a large body of theory and research at the organizational level, the researchers found that functional structures outperformed divisional ones (i.e., they fit better) when teams worked in predictable task environments and vice versa when teams worked in unpredictable task environments. However, they found asymmetries when the task environment changed and team structures also changed to maintain fit. In other words, team performance depended not only on the fit of structure to the new task environment but also on the structure the team had worked under previously.

In essence, teams were able to effectively adapt from a functional to a divisional structure, but shifting from a divisional to a functional structure created difficulties. Team members working in a functional structure apparently learned to share resources and to develop teamwork skills in order to accomplish shared team goals; they had to learn to coordinate their distinct specializations. In contrast, each team member in a divisional structure had all the necessary resources to accomplish their individual aspect of the team task and did not develop coordination skills. This failure to engage in teamwork carried over to the functional structure, thereby hindering team effectiveness (Moon et al., 2004). Thus, there were asymmetric effects depending on experience developed during the initial structure. Asymmetries were also found for reward structures and for fit between team-member personality and structure (Johnson et al., in press). These findings do not contradict the basic tenets of contingency theory, but they do suggest potential boundary conditions that are important to acknowledge in any effort to apply contingency logic to develop dynamically adaptive teams. The fit between task environment and team structure is not a static phenomenon but one that must be monitored, redefined, and updated over the life of the team.

\section{Team Regulation and Adaptation}

We made a case in our review for considering team performance as a dynamic process in which team members regulate attention and effort in response to shifting task demands as they strive to accomplish individual and team goals. We also reviewed empirical work that supports team regulation as a parallel process working in tandem with individual regulatory activity. There is, in addition, other more specifically focused research that examines particular facets of the team regulatory process, such as goals and feedback.

At the individual level, goal-setting theory, which is one type of self-regulatory model, has amassed substantial support as a potent means for influencing motivation and performance
(Locke \& Latham, 1990), with the mean effect size hovering between .58 (Mento, Steel, \& Karren, 1987) and .55 (Wright, 1990). The essential prescriptions of goal-setting theory are that difficult and specific performance goals that individuals have accepted or to which they have committed direct attention and effort toward goal striving and yield higher performance than do easy or "do your best" goals. Because self-regulation is an episodic process, feedback is also essential so individuals can monitor the discrepancy between current performance levels and the standards they aspire to attain. Moreover, when tasks are more complex and effective performance requires not just effort but effort deployed in particular ways, task knowledge and appropriate strategies are also essential to effective performance and goal accomplishment. (Earley, Connolly, \& Ekegren, 1989).

Although there has been far less research examining goal setting in teams, the research that has been conducted is consistent with team regulation as a parallel behavioral control process. For example, research has shown that more difficult team goals yield higher performance than do easy goals and that the effects of team goals operate through their influence on planning, tactics, and effort (e.g., Durham et al., 1997; Weingart, 1992; Weingart \& Weldon, 1991). Moreover, the strong effect of team goals on team performance is supported by meta-analytic findings (O'Leary-Kelly, Martocchio, \& Frink, 1994).

DeShon et al. (2004) demonstrated that feedback is an essential part of regulation as a multilevel process, with effects on the levels of goals that were set and on the effort directed toward goal accomplishment. In particular, the kind of feedback provided-whether around individual, team, or both foci of performance-differentially influenced the salience of the different regulatory loops. Individual feedback yielded higher individual performance at the expense of team performance; team feedback yielded better team performance at the expense of individual performance; and the provision of both types of feedback resulted in tradeoffs such that both types of performance could not be maximized. The findings indicate that team-system designers need to be mindful of precisely what they want to be salient to team members and should design supporting goal and feedback systems accordingly. Such systems may need to be dynamically adaptive, shifting the level of focus depending on current needs. These regulatory findings also have implications for team leadership that we discuss later.

An application tool called PROMeas that has shown promise in promoting team performance is consistent with our regulatory perspective. Pritchard and his colleagues (Pritchard, 1995; Pritchard, Jones, Roth, Stuebing, \& Ekeberg, 1988; Sawyer, Latham, Pritchard, and Bennett, 1999) developed a theorybased applied process to facilitate the self-regulatory processes of work teams. Based upon a motivationally focused theory of behavior in organizations by Naylor, Pritchard, and Ilgen (1980), the PROMeas system assists team members in identifying dimensions and indicators of team effectiveness in units described by the language of a team's particular task context (e.g., man- 
uscripts written, tires changed, number of flower orders delivered per day), scaling the indicators in effectiveness units, and drawing contingency tables relating team time and effort inputs to team products. Once teams understand how their time and effort are converted into valued team outcomes, they are better able to set team goals and select strategies for investing time and effort in ways that are most valuable to accomplishing the goals. The PROMeas process provides a system for training teams to understand their work, and it also establishes a system for providing performance feedback in information units that are distinctly task relevant. Thus, teams can use the feedback for regulating behavior in ways that are consistent with accomplishing their performance goals.

In general, the overall theoretical and research support for the distinct elements that make up a regulatory perspective on team performance is impressive. Applications such as PROMeas have demonstrated that these elements can be translated into useful performance-management tools. Moreover, the increasing use of computer technology as the means by which many (though not all) team tasks are accomplished-whether in virtual or face-toface settings - provides a potent opportunity to apply the findings from this research stream to the regulation and control of action to enhance individual and team performance. Computermediated work provides a multitude of opportunities to embed aids, artificial agents, and other tools to guide goal setting and provide appropriately tailored feedback and support for desired regulatory processes and responses (e.g., Kozlowski, Gully et al., 2001). We view this area as a prime target for the application of research knowledge.

Cognitive Engineering Approaches to Normative Team Design From a human-performance perspective, team-based work systems should be designed to minimize required coordination among members as much as possible while still satisfying system performance requirements (Steiner, 1972). Yet, technologybased work systems, which require work teams to operate them, are often designed to meet system-performance objectives without very much attention to human team cognitive, motivational, and behavioral capabilities as an integral aspect of the design process. In other words, system design is accomplished with little regard for an optimal distribution of tasks between the technology and human operators, little regard for the distribution or workflow of tasks across team members, or optimal clustering of tasks to team-member roles. As Zachary, Campbell, Laughery, Glenn, and Cannon-Bowers (2001) note, "This ... reflects a (often implicit) focus on the system sans humans, as if the human role was unimportant, imponderable, or both. Increasingly, though, this view is being called into question, often as the result of designs that have proven unusable, untrainable, or unstaffable" (p. 222).

One of the key challenges to resolving this problem is that it is difficult to specify and plug human (individual and team) performance parameters into an engineering design. There has been, however, nearly 50 years of effort devoted to modeling individual and team performance, particularly for military applications (e.g., Siegel \& Wolf, 1962). Those early efforts have served as precursors for a class of task-network models capable of simulating large complex systems (Zachary et al., 2001). Within the same time frame, Allen Newell and his colleagues stimulated effort directed toward the development of general computational architectures capable of representing human cognition; these efforts eventually yielded exemplars such as SOAR (Newell, 1990) and ACT-R (Anderson, 1993), among others.

With respect to modeling team performance, two basic approaches, which have culminated in a third, now dominant, approach, have been pursued (Zachary et al., 2001). The micro approach utilizes the mathematics of graph theory to model dyadic relations that constitute the deep structure of socialinteraction networks. Although very sophisticated models have been derived from the use of this approach, practical constraints in the acquisition of data have hampered its broader development. The macro dynamical system approach focuses on larger social entities-organizations, cities, etc.-modeling the dynamic interactions of complex sets of constraints, without reference to lower-level component units (i.e., individuals, dyads, teams). In the third agent-based approach, a combination of the micro and macro approaches, individuals are represented as simplified agents within a team (or larger social system) linked by command, control, and communications networks. The models are typically dynamic such that learning and organizational change can be simulated over time. Key issues in the use of this approach center on the sophistication of the cognitive agents and that of their embedding network.

Agent-based models have enormous potential to resolve the problem of system-team design noted at the beginning of this section. Simulations that allow designers to experiment with different allocations of task requirements across the technology system and cognitive agents can be created. Different task distributions, roles, and role linkages can be explored with respect to their effects on performance efficiency and effectiveness before a team-technology system is implemented. The utility of such applications hinges on the closing caveats noted in the previous paragraph. Notably, some ongoing work seeks to integrate personality and interpersonal computational models with the cognitive architecture of the agents (e.g., Zachary, 2004). Consistent with the history of work in this area, the military tends to be the dominant stimulator and user of this technology for team design and training (e.g., Schiflett, Elliott, Salas, \& Coovert, 2004). We believe that, as agent and network sophistication continue to improve, application of these simulation techniques can alleviate significant problems in the design of team work systems. The high potential of this approach means that it merits much broader attention and application in organizational team design. 
Computer-Based Team Support Systems

Since the first conference on computer-supported cooperative work in 1986, there has been an explosion in the development of computer-based systems to support work teams (Olson \& Olson, 2003). The nature of this support varies from computerized tools for facilitating face-to-face team interactions-such as a digital white board for sharing and reacting to team-generated information-to elaborate communications systems through which collocated and distributed virtual teams can carry out complex tasks using groupware, collaboratory systems, and other commercial group-support tools. The potential of these systems for enhancing team-interaction effectiveness is enormous, but empirical verifications of their effects on team behavior are limited. Furthermore, these systems have been slow to be integrated into everyday organizational life (Olson \& Olson, 2002). As seen in the earlier section on cognitive engineering, these tools tend to get designed without a clear understanding of their implications for team processes, behavior, and effectiveness. Thus, the technological development of complex communication systems and tools has far outstripped behavioral investigation of how these systems are adapted into human interaction in teams and organizations. With all the technological development, it is only a matter of time until we achieve a better understanding of the behavioral implications of these systems. Without a doubt, there is much to be learned to facilitate team behavior as well as temper some existing unrealistic expectations (Olson \& Olson, 2000).

\section{Conclusion}

There is a wealth of information to guide the design of work teams and their support systems. The normative model (Hackman, 1992) provides a basic heuristic that identifies critical factors that need to be considered when team work systems are created. Going forward, there are several key areas that can be applied and that will also benefit from more basic research. Research on group composition is still in its infancy, with a primary focus on the aggregation of single characteristics; also needed is more research that examines the effects of more complex configurations of different KSAOs on team processes and effectiveness (Kozlowski \& Klein, 2000). In the meantime, basic assessment tools can be used to select members with appropriate KSA profiles (Stevens \& Campion, 1994, 1999). Team task structures are often ad hoc or driven by technology systems. More theory and basic research are needed from cognitive engineering and structural design to inform the configuration of such systems and their computer-based supports. That is, the application advice is to take a human-centered approach to system design rather than retrofitting team members to technology and work-system constraints (Zachary et al., 2001). Finally, there is substantial research on goal-setting, feedback, and application tools that merits widespread application (e.g., PROMeas). The potential to embed learning and performance regulation supports into technology merits research attention (Bell \& Kozlowski, 2002a; Kozlowski, Gully et al., 2001).

\section{Team Training}

As organizations have shifted their structures to be more team based over the last 15 years, corresponding interest has also been directed at team training as a key means to enhance team effectiveness. This interest is evidenced by the diversity of team-training approaches that have been developed (e.g., Swezey \& Salas, 1992), reviews of team-training effectiveness (e.g., Dyer, 1984), and large-scale research efforts designed to improve team effectiveness via training (Cannon-Bowers \& Salas, 1998). Indeed, although the rising dominance of work teams in organizations is a relatively recent phenomenon over the last decade and a half, one unique class of organizationsthe military — has long based its organization on small teams and has had enduring interest in the use of training to improve team effectiveness. This interest and research investment is evidenced in an early comprehensive review of the influence of team training on team effectiveness by Dyer (1984), in which most of the research was relevant to military teams.

\section{TADMUS}

Another excellent example of this interest and research investment is evidenced by the Team Decision Making Under Stress (TADMUS) program. Cannon-Bowers, Salas, and their colleagues conducted this 7-year, multidisciplinary, multimillion-dollar research effort designed to improve team training and the human factors of interface design for complex, missioncritical, military command-and-control teams (Cannon-Bowers $\&$ Salas, 1998). One of the important aspects of the TADMUS program was its active coordination of theory development, basic research, field testing, and application to the field. The program was driven by theory grounded in the performance context, which was evaluated by basic laboratory research. Promising approaches were subjected to field testing to ensure generalization to the operational environment. Finally, successful tools and techniques were deployed to the field. Many effective team-training approaches were spawned by this integrated effort. The TADMUS project is an excellent example of the way that theory and basic research can transition to effective organizational application. It is fair to acknowledge, however, that most applications of team training have tended to be limited to the military and to commercial aviation, along with some recent initiatives that are beginning to emerge in medicine. Broader application of team-training techniques to production, service, and R\&D teams in organizations at large has lagged behind the state of the art (Campbell \& Kuncel, 2001).

\section{Team-Training Design Issues}

The literature generally advises that training for task-relevant skills should be directed at the individual level to develop 
proficiency (Dyer, 1984), with team training focused on taskwork and teamwork skills that underlie the integration needed for coordinated action. We described these skills when we discussed team competencies and functions in the previous section; they constitute the primary instructional objectives for team training interventions (Cannon-Bowers et al., 1995; Fleishman \& Zaccaro, 1992; Salas \& Cannon-Bowers, 2001).

One important consideration in the design of team training concerns whether team members can be trained as individuals or whether they need to be trained together as an intact team. Cannon-Bowers et al. (1995) proposed a two-dimensional framework to guide such decisions. One dimension concerns whether the focus is on task-based competencies versus teamrelevant competencies. The other dimension focuses on whether the skills are specific-i.e., contextually grounded to the team or its task-or generic-i.e., more generally transportable across teams or tasks. In essence, to the extent that competencies are specific to a team or task context, training design should focus on intact teams training in real or synthetic representations of their performance environment. More generic competencies can be targeted for individually based training. In a related vein, Kozlowski, Brown, Weissbein, Cannon-Bowers, and Salas (2000) have argued that the decision whether training should be directed at individuals or intact teams is driven by the form of task or workflow interdependence inherent in the team task. When team-member contributions to team performance are similar actions that are pooled (i.e., composition models), members can be trained as individuals. However, when member contributions to performance are more complex patterns of workflow (i.e., compilation models), teams should be trained intact with real or simulated active practice.

As noted briefly above, there is emerging experimental evidence that generic (i.e., transportable) teamwork knowledge can be improved through training. Chen et al. (2004) developed a semester-long training program (Stevens \& Campion, 1994) that significantly improved students' knowledge of generic teamwork competencies. Research by Ellis et al. (2005) also demonstrated that knowledge of these generic team competencies improved significantly with a relatively brief training intervention (30 minutes) with significant effects on the expression of teamwork competencies.

\section{Team-Training Strategies}

As discussed above, depending on the particular KSAs to be learned, team training interventions are delivered to either individuals or intact teams. This means that the full range of training interventions applicable to individual learning is relevant to team training and, in addition, that there is a wide range of training strategies specifically suited to intact teams. And, as we noted previously, selection of targeted skills and specific applications has to be tailored to the team, its task, and the context. Thus, any effort on our part to fully characterize this wide range of applications-lecture to computer interactive to full-scale high-fidelity simulation-is far beyond the scope of this review. Interested readers are directed to Salas and CannonBowers (1997) for a more comprehensive overview of methods and techniques. Here we concentrate our attention on a smaller set of approaches highlighted earlier in the section on Team Processes-approaches that generally target intact teams and that have developed a sufficient research foundation to enable meta-analytic evaluation.

Dyer's classic review of team training suggested that teams learn best by doing - that is, by practicing in a way that approximated, simulated, or replicated their task and performance context. That is a common theme that cuts across many teamtraining techniques. In addition, the importance for team effectiveness of knowledge sharing, skill integration, and coordination behaviors has made the underlying competencies prime targets for team training.

Cross training, sometimes called interpositional skills training, is a technique that trains team members on other members' tasks, roles, and responsibilities. By directly exposing all team members to all positions, it is designed to improve shared mental models and the skills that enable coordination. Guided team self-correction training uses a variety of delivery methods to provide teams with skills needed to reflect on prior performance, discuss errors and provide constructive feedback, and plan for future learning and improvement. Crew Resource Management (CRM) training, also known as team-adaptation or team-coordination training, generally uses a variety of techniques including role playing to train team members on general competencies underlying team coordination and skill integration (e.g., mutual performance monitoring, backup behavior, feedback and communication, and interpersonal relations). CRM is used extensively in both the military and civilian aviation communities. Moreover, teams that operate in "high reliability" environments, such as the military, commercial aviation, and increasingly medicine, often use simulations with scripted scenarios to allow team members to practice a set of synthetic experiences important to their effectiveness. The particular simulations can range from relatively low-fidelity experiences delivered via personal computer to dedicated high-fidelity simulations that closely emulate the real-world task and context. One key advantage of simulation-based training is that scenarios enable practice of recurrent and routine critical tasks (e.g., takeoffs and landings), but they also allow teams to be exposed to potentially life-threatening but low-base-rate experiences so that they have a relevant skill set should the need arise (e.g., engine fire, landing-gear failure; Cannon-Bowers \& Bowers, in press).

\section{Team-Training Effectiveness}

There is an emerging research foundation for the team-training strategies that are briefly highlighted above. Recently, Klein et al. (2005) conducted a comprehensive meta-analytic review of their effectiveness in improving team processes, performance, and affective reactions. Their review encompassed both team- 
training and team-building interventions. Team-training and team-building interventions differ in important ways. Team training is a systematic strategy that targets for improvement specific objectives or competencies designed to enhance teamwork. In contrast, team building is a process intervention that prompts team members to reflect on their behavior and interpersonal relations (Beer, 1980). The outcomes from a teambuilding intervention flow from the process itself, which is variable across teams. In that sense, it is not systematic (Klein et al., 2005).

The meta-analysis focused on the effects of four team-training strategies_cross training, guided team self-correction training, team adaptation-coordination-CRM training, and forms of simulation-based training - and team-building interventions that focus on improving team processes, performance, and affect. Other analyses also considered effectiveness of each of the team-training techniques and the moderating effects of study type (lab vs. field) and team size (large, medium, or small). It is noteworthy that no corrections for unreliability in the predictor or criterion were made, making the reported findings conservative estimates of the true effects. There were 48 studies with 111 separate effect sizes that met the selection criteria. The overall effect across interventions yielded a correlation of .476, with a $95 \%$ confidence interval that ranged from .417 to .532 . Thus, in general, team training and team building accounted for $23 \%$ of the variance across outcomes.

Follow-up analyses for team-building interventions, based on only 10 studies and 29 effect sizes, showed an overall correlation across the outcomes of .573 , with the $95 \%$ confidence interval ranging from .422 to .694 . The separate estimates were .776 for process improvement, .428 for performance, and .384 for affect. These supportive findings for team building are in contrast to prior reviews and meta-analyses that have been largely inconclusive (i.e., conflicting; see Klein et al., 2005) or nonsupportive (e.g., Salas, Rozell, Driskell, \& Mullen, 1999). This positive support is encouraging, although confidence would be bolstered by a larger pool of primary studies. Given the inconsistent findings for team building in prior work, we advise caution in the interpretation of this finding pending a broader base of empirical support.

Follow-up analyses, based on 38 studies and 82 effect sizes, showed that team-training interventions evidenced an overall correlation of .444 across the outcomes with the $95 \%$ confidence interval ranging from .382 to .501 . The separate estimates were .481 for process improvement, .418 for performance, and .367 for affect. Separate analyses were also conducted for each of the training strategies. Based on six studies and 13 effect sizes, cross training yielded a correlation of .471 with the $95 \%$ confidence interval ranging from .376 to .556. Simulation-based training, based on 37 studies and 81 effect sizes, had a correlation of .446 with a $95 \%$ confidence interval that ranged from .384 to .504 . Team adaptation-coordination-CRM training, with 16 studies and 30 effects, yielded a correlation of .600 with the
$95 \%$ confidence interval ranging from .479 to .698 . These are all respectable effect estimates that are supportive of training effectiveness. In contrast, guided team self-correction training, based on only 2 studies and 3 effect sizes, had a correlation of .307 with a very wide-ranging $95 \%$ confidence interval $(-.289$ to .731) that included zero. Clearly, a large base of primary studies is needed for this technique before meaningful conclusions can be drawn.

\section{Conclusion}

Based on findings of this meta-analytic review, we would conclude that cross training, forms of simulation-based training, and team adaptation-coordination-CRM training all evidence sufficient research-based support to justify recommending them as credible and effective team-training techniques. As we noted at the onset of this section, these team-training approaches have been developed for, and largely applied in, the military and commercial aviation (Foushee, 1984; Helmreich \& Foushee, 1993). That is, they have been developed to improve team effectiveness for high-reliability, mission-critical teams where errors and mistakes are very costly in human and material terms. These approaches are beginning to be applied in medicine (Davies, 2001; Helmreich, 2000) and other high-reliability areas such as offshore oil drilling (Flin, 1995; Flin \& O'Connor, 2001). Will they have the same potential for improving team effectiveness in less critical, though no less important, team contexts such as design, production, and service? The techniques may need to evolve somewhat, but we think their potential is worth exploring-and exploring vigorously! More important, these training strategies have been developed using grounded theory and systematic methods, so the evaluation is as much about the underlying science of team-training design as it is about the techniques. We conclude that the science of teamtraining design can be applied and adapted to enhance team training across organizations.

\section{Team Development}

Whereas team training is a formal effort to impart targeted teammember competencies and team building is a formal effort to change team processes after they have developed, team development is generally regarded as an informal process by which group members attempt to create effective social structures and work processes on their own. To the extent that we can understand the process sufficiently well, there may be the potential to enhance team development. It is important to recognize that team development is typically regarded as a holistic process; that is, all team members go through it together. Yet, it is often the case that an ongoing team experiences outflows and influxes of new members that have to become integrated into the team. This form of development is the purview of socialization research. However, we would note that socialization research focuses principally on the socialization of newcomers to the 
organization, not the work group (see Kozlowski \& Bell, 2003). There is some limited and promising research on work-group socialization (Chao, Kozlowski, Major, \& Gardner, 1994; Chen, 2005; Chen \& Klimoski, 2003); more such work is sorely needed. Meanwhile, we focus our attention on team development.

\section{Developmental Stages}

Representative examples of group development include Tuckman's stage model (1965) and Gersick's (1988) punctuated equilibrium model (PEM). The Tuckman classic model of forming, storming, norming, and performing was derived from a review of the literature on clinical therapy and T-groups (training groups in which members seek self-insight through group interaction and reflection). It well represents the basic elements underlying virtually all stage models of group development (Kozlowski et al., 1999). During initial formation, members are brought together as a team and seek to create social and task structure to guide their interactions. As they realize that creating consensus on an approach is difficult, they shift to a storming stage in which different members vie for influence and conflict ensues. As members reconcile their differences and settle on a course of action, they set norms to guide subsequent interactions. As the norms take hold, members are able to focus on performing to achieve common goals. Work by Wheelan and her colleagues has focused on an instrument-the Group Development Questionnaire-that assesses perceptions of group development paralleling Tuckman's stage model, albeit with different stage labels (Wheelan, 1994; Wheelan \& Hochberger, 1996).

\section{Developmental Shift}

Rather than the smooth linear progression inherent in the stage approach, the PEM approach views group development as a more stable process punctuated by a discontinuous shift that occurs at the midpoint of a group's lifecycle. Gersick based her model on observations of eight project teams and eight studentproject groups (e.g., make a recommendation, produce a report) with a fixed project timeline. She reported that the groups rapidly formed a structure, established roles, and followed a pattern of interaction that persisted to the midpoint of their lifecycle. At that point there was a dramatic shift as groups reorganized the task, reallocated role responsibilities, and redoubled efforts to meet the project deadline. Although these two dominant perspectives on group development are often regarded as being in opposition, recent work suggests that aspects of both are operative as groups naturally develop (Chang, Bordia, \& Duck, 2003).

\section{Normative Development}

Such perspectives on group development are descriptive in nature; that is, they describe what groups do when left to their own devices as they form and organize. More recent theory de- velopment by Kozlowski et al. (1999) adopts a normative perspective on group development; their theory posits how teams should compile skills and develop adaptive processes in order to be effective. Key aspects of the theory are its attention to specific developmental content, processes, and outcomes relevant at different phases of skill compilation; and shifts across focal levels_-individual, dyad, and team network-as capabilities develop. As teams form, individuals should be focused on fitting into the team and understanding their role in its mission. A socialization process results in outcomes of interpersonal knowledge regarding one's teammates and team orientation as a basis for norms, goal commitment, and team climate. With social space resolved, individuals then should shift to a focus on acquiring task knowledge. A process of skill acquisition yields outcomes of task mastery and self-regulation skills. Having established task proficiency, the focal level of developmental activity shifts to dyads and a process of role negotiation that generates outcomes of role identification and role routinization. As dyadic interactions become routinized, the focal level of development shifts to the team. A process of network development yields a flexible network of role interdependencies that enables continuous improvement and adaptability. Although there are no direct evaluations of the theory, research has shown that the speed of team performance improves with developmental experience (Harrison, Mohammed, McGrath, Florey, \& Vanderstoep, 2003) as cognitive and task processes take over from the effects of early social structure (Balkundi \& Harrison, 2006). DeShon, Kozlowski, Schmidt, Wiechmann, and Milner (2001) supported the basic proposition that shifts in the focal level of development from individual to team contribute to team performance adaptation. In addition, Chen et al. (2005) used the model as a guide for their team-training module, which demonstrated adaptive transfer. One key feature of the normative perspective to team development inherent in the approach taken by Kozlowski et al. (1999) is the assumption that team developmental processes can be deliberately influenced and shaped, an assumption we will return to later when we consider team leadership.

\section{Conclusion}

Team-building efforts are interventions to change and improve team processes once they have developed and stabilized. Certainly, the inconsistent findings for the effectiveness of teambuilding interventions attest to the challenge of change. It seems self-evident that this approach would have more challenges to overcome than a more direct effort to shape team processes as they develop in context. As Kozlowski and Bell (2003) observe, "the process of team development, and its resulting quality, is largely taken as a matter of faith-leaders and teams are expected to muddle through and figure it out. From an applied perspective, one can't help but marvel at the magnitude of the lost opportunity to influence long-term team effectiveness" ( $p$. 345). Although we believe that shaping team developmental 
processes has the potential to be a potent lever of team effectiveness, we would be remiss if we did not strongly acknowledge that the empirical research foundation for this supposition is weak. The descriptive models are based on relatively limited observations of a few types of groups or are derived from the literature. Plus, there is no reason to believe that what group members do naturally is necessarily the best way to develop work teams. While the normative model of Kozlowski et al. (1999) is based on a synthesis of a broad base of empirical research, and although initial evaluations have been supportive, the model has been subjected to only very limited testing thus far. Clearly, team development as a process that can be shaped is a ripe target for systematic and rigorous research.

\section{Leadership}

The section on team processes identified leadership as a promising leverage point for enhancing team effectiveness. Here we consider some of the voluminous findings supportive of the general influence of leadership on team effectiveness. Leadership theory and leadership research in general imply that leadership is an important factor affecting team processes and outcomes, although it is important to acknowledge that most leadership theories and research do not explicitly focus on team settings; the theories tend to be presented as more generally applicable across people, settings, and levels. Notably, the most common criterion for leadership effectiveness is individual perceptions of the effectiveness of their leader, rather than team performance or team effectiveness. Thus, the implications for team effectiveness of the findings from leadership research are indirect rather than direct. Although we suspect that ratings of leadership effectiveness are likely to have a bearing on team effectiveness, we also believe that leadership research needs to focus on more compelling criteria that target team-level outcomes. Nonetheless, emerging meta-analytic findings from this heavily researched domain provide a useful indication of the potential value of leadership in the promotion of team effectiveness.

\section{The Behavioral-Style Approach}

The Ohio State University leadership dimensions of initiation of structure (i.e., leader attention to structuring subordinate task activity) and consideration (i.e., leader concern with subordinate needs and feelings) represent perhaps the earliest effort to comprehensively map the behavioral aspects of leadership (Stogdill, 1950), although this classic approach to leadershipnow over half a century old-has long fallen from favor. Judge, Piccolo, and Ilies (2004), however, recently conducted a metaanalysis of approximately 160 independent correlations with each dimension. Overall, the corrected correlation between consideration and initiation of structure with outcomes was .48 and .29 , respectively. Consideration strongly related to follower satisfaction, motivation, and leader-effectiveness ratings; initi- ation of structure was slightly more strongly correlated with subordinate performance ratings of their leader and group-organization performance ratings than was consideration. These findings suggest that this classic approach to leadership, though lacking current popularity, demonstrates reasonable potential as a viable approach to leadership.

\section{Transformational Leadership}

Interest in transformational leadership (i.e., leader behaviors to motivate their subordinates to improve the collective good) has grown over the 25 years since it was first proposed by Burns (1978) in reference to political leadership. Bass (1985) further elaborated the nature of transformational leadership and also argued that transactional leadership (i.e., leader behaviors to negotiate mutually beneficial exchanges with subordinates) was not antithetical, but also a relevant aspect of effective leadership. Transformational leadership includes the behavioral dimensions of charisma (i.e., admirable qualities that produce subordinate identification), inspirational motivation (i.e., an appealing vision of the future and meaningful goals), intellectual stimulation (i.e., challenge, provocation, and engagement), and individualized consideration (i.e., sensitivity to member needs). In the full-range model, transactional-leadership dimensions include contingent reward (i.e., clear expectations and outcome linkages that yield constructive exchanges), management by exception-active (i.e., proactive and corrective behavior management), and management by exception-passive (i.e., reactive behavior management after the fact). Finally, laissez-faire leadership is defined as the avoidance or absence of leadership.

Judge and Piccolo (2004) conducted a meta-analysis examining the prediction of overall leadership effectiveness, defined as a combination of subordinate satisfaction, motivation, and performance. They examined 626 correlations from 87 sources, reporting an overall corrected population correlation of .44 with transformational leadership. The primary transactional leadership dimension predicting effectiveness was reward contingency (.39). Of note, transformational leadership was highly correlated with contingent rewards (.80) from the leader and was negatively correlated (-.65) with laissez-faire leadership. Contingent-reward behavior is typically regarded as a transactional-leadership characteristic, not a transformational one, but the high correlation suggests a closer connection. Indeed, transactional leadership is typically touted as being less effective than transformational leadership. However, the Judge and Piccolo (2004) meta-analysis showed that the primary dimension of transactional leadership-contingent-reward leadership_-predicted effectiveness nearly as well as did transformational leadership (corrected correlation of .39 vs. .44, respectively). Closer inspection of the data showed that contingent-reward leadership tended to be more effective in business and military settings, where norms for rational rewarding were perhaps higher, and the gap between transformational and contingent reward was greater in favor of transformational 
leadership when the criteria for effectiveness were more independent of the ratings of leadership.

Other meta-analyses of transformational leadership have highlighted the importance of the source of leadership-effectiveness ratings. For example, when transformational leadership and leader effectiveness or performance measures are assessed independently, corrected correlations are in the mid-thirties (.34; Fuller, Patterson, Hester \& Stringer, 1996). In contrast, Lowe, Kroeck, and Sivasubramaniam (1996) reported a corrected correlation with effectiveness of .73. As Judge and Piccolo (2004) point out, the Lowe et al. meta-analysis was conducted when there was more reliance on self-report measures of leader effectiveness by subordinates who also provided measures of leadership behavior, thereby inflating the relationship.

In one of the few studies looking specifically at teams, Lim and Ployhart (2004) investigated the effects of transformational leadership for a sample of Asian military teams (39 teams, 276 team members) under conditions of typical performance and maximum performance. They found transformational leadership more strongly related to performance in maximal-performance contexts than in typical-performance ones $(r=.60$ vs. $r=.32$, $p<.10$, respectively), supporting the underlying theoretical position that transformational leadership facilitates subordinate motivation and effort.

Another recent study linked transformational leadership to facets of team collective personality and to performance (profitability) in pizza-delivery stores (Hofmann \& Jones, 2005). The basic premise is that transformational leader behaviors would facilitate the formation of desirable personality factors at the collective level and that those factors would account for store profit and profit variability over time. The results are complex, but the basic premise was supported. In addition, the collective personality factors interacted to predict store performance.

There is also some work suggesting that women tend to be more transformational in their leadership approach than men are. Eagly, Johannesen-Schmidt, \& van Engen (2003) in a metaanalysis of 45 studies looking at transactional, transformational, and laissez-faire leadership found that female leaders were more transformational and engaged in more contingent rewarding (a transactional leadership behavior) than males. Males tended to enact more active and passive management by exception and laissez-faire leadership, which are defined as ineffective leadership styles (Judge \& Piccolo, 2004). Although the differences were small, the fact that women displayed more transformational behaviors spoke positively to women leaders in today's work settings.

Overall, the solid meta-analytic findings for transformational leadership and the contingent-reward aspect of transactional leadership support these combined approaches as useful leverage points for leadership. A qualitative review of leadership research by Avolio, Sosik, Jung, and Berson (2003) reached similar conclusions about the impact of transformational-lead- ership training on team members and team performance. They also reported research findings showing that exposure to developmental experiences similar to those incorporated in transformational leadership training during a person's childhood or adulthood are associated with transformational leadership. The data are consistent with the conclusion that leaders' experiences can develop and shape leader behaviors and characteristics consistent with transformational leadership.

\section{Leader-Member Exchange (LMX)}

In contrast to most other theories of leadership, which assume that leaders behave in a consistent fashion to all team members, LMX focuses conceptually on the unique dyadic exchange relationship that develops between a leader and each of his or her subordinates (Dansereau, Cashman, \& Graen, 1973; Dansereau, Graen, \& Haga, 1975; Graen, 1976). Graen and Scandura (1987) indicate some boundary conditions for LMX theory, including leader discretion in task assignments; positional and personal resources and power and the imagination to use them; and the presence of some members with growth potential. LMX theory has developmental underpinnings. The initial "role taking" phase is a sampling or testing opportunity created by the leader to gauge a subordinate's willingness to engage in role development. If the subordinate's response is positive, this is followed by a transition to a "role making" phase-a negotiated process of role development based on a mutual contribution of valued resources including information, influence, tasks, support, and attention. Role making provides an opportunity for the subordinate to negotiate an enlarged role and to define areas of responsibility and expectations. Finally, the relationship stabilizes in the "role routinization" phase. Over time and across dyadic relationships, this process is presumed to yield different dyadic role relationships that cluster into in-groups-those trusted subordinates with enlarged roles and leadership latitude-and out-groups - those subordinates with more prescribed roles subject to supervision. It is useful to note that although LMX theory is process oriented and dyadic, efforts to evaluate the theory typically rely on an individual-level perceptual measure of LMX quality from the perspective of the subordinate.

Gerstner and Day (1997) identified 85 studies with sufficient information to calculate effect sizes and conducted meta-analyses on relationships observed in a minimum of six independent samples. The correlations were corrected for reliability and weighted by sample size, yielding the following findings for different criteria: leader performance ratings by members $(r=.55)$, performance ratings of members rated by leaders (.30), objective performance (.11), satisfaction with leaders (.71), overall satisfaction (.50), and organizational commitment (.42). One key issue with LMX theory (although this issue is relevant for all leadership models) concerns the agreement between leader and team-member LMX ratings; convergence is moderate, with correlations of .50 and below across studies. Finally, 
whether LMX should be treated as a team-level or individuallevel construct depends on whether the criteria are at the teammember level or aggregated to the team level. When considered at the team level, the pattern of results tends to parallel that of transformational leadership, suggesting that the approachesconceptual differences aside-may be tapping a common leadership construct domain.

As with the other general approaches to leadership highlighted previously, the combination of meta-analytic support and the general usefulness of LMX as an approach to understanding leadership make it a valuable tool for improving leadership in work settings.

\section{Team Leadership}

As we noted at the outset of this section, general leadership theories have useful but indirect implications for team effectiveness. In part, this is because they take a structural approach, focusing on the identification of a general set of behaviors that are broadly applicable across a wide variety of situations, tasks, and teams. Although such an approach is useful, it is also deficient contextually and static in nature. That is, it neglects unique aspects of the team task context and the dynamic processes by which team members-over time-develop, meld, and synchronize their knowledge, skill, and effort to be effective as a team (Kozlowski et al., in press).

More recently, several scholars have developed theoretical frameworks specifically focused on leadership in teams and the unique aspects of the team leadership process that are neglected by the structural approaches discussed previously. A particularly novel aspect of this emerging work is its treatment of team leadership as a dynamic process necessitating adaptive changes in leader behavior, as opposed to treating leadership as a fixed set of static and universal behavioral dimensions. Another important aspect of this work is that it treats leadership as a set of functions rather than as a set of specific behaviors (McGrath, 1964). That is, functions are viewed as "things that need to be accomplished" and that may often be accomplished in many different ways. In that sense, functions are more molar than specific behaviors. For leaders to be adaptive, they must be aware of the key contingencies that necessitate shifts in leadership functions, and they must possess the underlying skills needed to help the team maintain fit with its task environment and resolve challenges. Although there are many possible dynamic contingencies, two primary foci center on task cycles or episodes and the process of team skill acquisition and development.

The theoretical frameworks developed by Kozlowski, Gully, McHugh et al. (1996), Kozlowski, Gully, Salas et al. (1996), and Kozlowski et al. (in press) typify many of the key issues in this emerging perspective on team leadership. Consistent with the perspective underlying this review, their models conceptualize team tasks as embedded in a broader organizational system or environment that creates variable demands on team task pro- cesses and is responsive, to varying degrees, to team performance outputs. Their approach is normative, specifying what leaders should do to develop adaptive teams. One primary leadership function is instructional and regulatory in nature. By harnessing cyclic variations in team task cycles to the regulatory processes of goal setting, monitoring/intervention, diagnosis, and feedback, the leader is able to guide team members in the development of targeted knowledge and skills-the cognitive, motivational/affective, and behavioral capabilities that contribute to team effectiveness. Another primary leadership function is developmental. As teams acquire foundational knowledge and skills, the leader role shifts to help the team develop progressively more complex skills and capabilities (Kozlowski et al., 1999). Over time, this dual-pronged leadership process is hypothesized to yield team-level regulation and adaptive teams (Kozlowski et al., in press).

The theoretical framework developed by Zaccaro, Rittman, and Marks (2001) also focuses on "how leadership fosters integration of subordinate actions" (p. 452)—in other words, how leaders promote positive team processes. Zaccaro and his colleagues also adopt a functional perspective, viewing the leader as a social problem solver for the team, influencing team effectiveness through effects on cognitive, motivational, affective, and coordinative team processes. Key leadership functions center on problem solving with respect to goal attainment, generating and planning solutions, and implementing solutions. In its more specific aspects, the framework is consistent with the regulatory leadership functions and processes advanced by Kozlowski and colleagues.

More recently, Hackman and Wageman (2005) have proposed a model of team coaching consistent with this line of thinking. They define team coaching as "direct interaction with a team intended to help members make coordinated and task-appropriate use of their collective resources in accomplishing the team's work" (p. 269). They also adopt a functional perspective that is concerned with timing and conditions that direct appropriate coaching. In particular, consistent with their developmental underpinnings, motivational functions (i.e., getting team members acquainted to each other and the task) are applied early in the team lifecycle, consultative functions (i.e., fostering team task strategies) are applied in the mid-point of the team lifecycle, and educational functions (i.e., promoting reflection) are applied at the end of meaningful task cycles. Note that this last function represents a temporal discontinuity in that the first two functions address developmental time, which is slower and progressive, whereas the last one addresses task episodes, which are faster and cyclical.

Although there are no direct tests of these emerging models of team leadership, corroborating evidence is generally supportive. For example, recent research by Morgeson (2005) shows that efforts by external team leaders to actively coach shared understanding and better team self-management (i.e., team regulation) were more strongly related to perceptions of effec- 
tiveness under disruptive conditions. This addresses the basic thesis of team regulation: The role of the leader is to develop, utilize, and maintain the coherence of team regulatory processes (Kozlowski, Gully, McHugh et al., 1996).

More directly to the point, a recent comprehensive metaanalysis on team leadership goes to the primary question regarding team leadership. Burke et al. (in press) pose the question, "Does leadership in teams matter?" Their answer to the question is a resounding, "Yes!" Consistent with the emerging theoretical frameworks sketched previously (e.g., Kozlowski, Gully, McHugh et al., 1996), they adopt a functional view arguing that team leaders focus on leadership in two primary domains, that of the task and that of developing team members. Clustered in the former were transactional, structure-initiating, monitoring, authoritative, and directive leadership; in the latter were transformational, consideration, coaching, empowerment, facilitative, and participative leadership. In a meta-analysis of 63 empirical studies with 131 effect sizes relating leadership in teams to team performance, they found approximately $12 \%$ of the variance in team performance outcomes associated with task-focused leadership (uncorrected effect size of .343 with a 95\% CI of .288 to .396). Developmentally focused leadership behaviors accounted for approximately $10 \%$ of the variance (95\% CI for effect sizes was .270 to .369 centered on .320). Finally, when task interdependence was explored as a moderator of leader effects, the pattern of results was as expected. Leadership had less of an effect when team tasks were low in task interdependence than when tasks were highly interdependent. The $95 \%$ CI for effects under low task interdependence ranged from .179 to .291 controlling $6 \%$ of the variance, whereas it ranged from .272 to .347 controlling $10 \%$ of the variance under high interdependence. Although most of the research included in the meta-analysis was correlational, the consistency of the findings and the fact that the authors made conservative choices regarding options for their meta-analyses so as not to inflate the strength of relationships (e.g., corrections for unreliability were made only in the criterion variables), the results strongly point to the conclusion that leadership in teams affects team performance by influencing the way team members work with their tasks and by influencing social-emotional variables. Isolating the impact of leadership on specific variables that we discussed under cognitive processes and structures or affects and moods was not possible from their meta-analysis; nevertheless, it is clear that the constructs reviewed here were nested within their broader behavioral variables of task-focused and developmentally focused leadership.

In the taxonomy of team cognition, motivation/affect, and behavior that we discussed in the prior section, the several metaanalytic reviews of the leadership literature provide compelling evidence that leaders impact all three critical processes for effective team functioning. Although research that directly maps leader behaviors onto the cognitive, affective, and behavioral constructs of team theory is rare (though emerging), there is considerable general evidence that leaders impact these constructs. Kozlowski and Doherty (1989) have shown that leadership in the form of LMX relationships shapes the development of shared climate perceptions. It is also worth noting that relations among shared climate, factors that shape it (e.g., leadership), and behaviors can be complex. Hofmann et al. (2003) have shown that leadership in the form of LMX relations prompts team members to be more responsive to the imperatives signaled by unit climate. Although safety behavior was not a formal part of team-member roles, teams with strong climates for safety enacted roles that included safety behaviors when leader relations were good, whereas those with good leader relations in climates that did not emphasize safety did not engage in safety behaviors. Marks et al. (2000) have shown that leadership influences the development of shared mental models in teams and, subsequently, team performance. Chen and Bliese (2002) have shown that leadership climate influences collective efficacy. Lord and his colleagues (Lord, Brown, \& Freiberg, 1999) have shown that leaders influence team members' efficacy views of the team and themselves in ways that influence performance in the team setting. Transactional leadership targets cognitions about team goals, rewards, and the connection between rewards and team effort. Transformational leadership shapes team climate perceptions that include both team efficacy beliefs and individuals' beliefs about their efficacy in the team. In a similar way, LMX impacts the extent to which members view themselves and are viewed by others as sharing the leadership responsibilities for the team with the leader or simply performing their duties in a perfunctory way as would a hired hand.

\section{Conclusion}

Collectively, emerging theory and empirical findings support leaders as a key leverage point for enhancing team effectiveness. Leadership skills are amenable to training interventions, and training programs for leader skill building are available for each of the approaches discussed in this review. Moreover, organizations have demonstrated considerable interest in improving leadership through training, with surveys suggesting that leadership training is regarded as the most important training need (Human Technology, 1993) and is among the top three areas in which firms sponsor training (Lee, 1991). In addition to direct training of leader skills within the theoretical approaches, the types of experiences and assignments leaders accrue across a career are also a key point of leadership development. Indeed, research efforts in the military are attempting to identify key learning outcomes derived from experience and to create simulations to provide similar experiences in more compressed time frames to accelerate leader development (e.g., Day, Zaccaro, \& Halpin, 2004). Advances in training technology and delivery, and our accumulating knowledge of important leadership skills and capabilities, will make it increasingly possible to design synthetic experiences-simulations, games, and exercises - that leverage leader development. Given the existing 
evidence and growing knowledge base for application, we assert that implementing applications and making continued investments in this high potential area are highly recommended.

\section{IMPLICATIONS AND RECOMMENDATIONS}

Clearly, team effectiveness matters to individuals, to organizations, and to societies. Major changes in the structure of work and the interdependency and immediacy of life in a global society have only increased the importance of effective teams. We have shown that there is an emerging science of team effectiveness by highlighting what we know, what we think we know, and what we need to know in order to build team member competencies, design and staff teams, and provide experiences for teams and their members to facilitate team effectiveness. Current findings have a direct impact on policies related to promising research targets, educational experiences, and organizational practices in the public and private sectors.

\section{Research Recommendations}

More than 50 years of psychological research on small groups and teams has generated a substantial research foundation. Our review has covered much of that foundation, but we remind readers that our review was targeted and selective. We focused our attention on team processes and emergent states that have amassed meaningful research support or have otherwise evidenced promise for enhancing team effectiveness. We then turned our attention to interventions that can shape the nature of those team processes. Again, we concentrated on those points of leverage with solid research support or promise. We could have cast the net more broadly, but we chose to be conservative so that our conclusions and recommendations are solidly actionable. We summarize briefly the main points of our review in the discussion that follows.

\section{Team Processes}

Table 1 summarizes the results of our review of cognitive, motivational/affective, and behavioral team processes and emergent states that enhance team effectiveness. Although the volume of the research support varies across topics, ranging from multiple meta-analyses to a smaller base of theory and primary studies, we believe that these topics merit continued research investment and, in some instances, are ready for widespread application. Among team cognitive processes, climate is most mature and applicable; it can be shaped and has the potential to be quite potent, as has been revealed by 70 years of systematic theory development and research in this area. Research over the last two decades has extended climate from individual-level perceptions to collective constructs at the team and higher levels, linked it to antecedents and important outcomes, and developed techniques that facilitate its application. The contribution of team mental models to team effectiveness shows good support among primary studies and there is emerging evidence to support the utility of potential levers. Support for transactive memory is more limited, although we believe this concept has promise, particularly in combination with team mental models. We view team learning as quite promising from a theoretical perspective, but acknowledge that much work is needed to clarify its nature and to distinguish it from other concepts in this cluster.

Among the interpersonal, motivational, and affective processes, team cohesion, collective efficacy, and group potency all evidence well-supported relationships with team effectiveness. The biggest research need is to better establish and refine the antecedents of these emergent states, although there is a theoretical base that should aid this elaboration. Team affect, mood, and emotion have promise, but there is a pressing need for conceptual clarity and integration with the more established constructs of cohesion and conflict. Finally, the research base demonstrates that conflict has a negative influence on team effectiveness, hence the primary research concerns should focus on better understanding how conflict impedes positive processes in teams and on interventions that can mitigate conflict's development and effects.

Finally, among team action and behavioral processes, all three of these entwined clusters-coordination, cooperation, and communication; member competencies; and regulation, performance dynamics, and adaptation-evidence well-developed conceptual foundations, research support, and application potential. Primary research needs center on better refinement and specification of interventions for application in specific settings and situations.

\section{Interventions}

Table 2 summarizes the results of our review of interventions or levers that can shape, influence, and align team processes. All three of the levers we addressed-team design, training and development, and leadership_evidence solid conceptual foundations and research support. We recommend that research on these levers be applied as widely as possible. Although we also recommend continuing research to refine the interventions, each topic area warrants some specific research needs.

In the area of team design, targeted research to refine task and system-design interventions is sorely needed. We recommend that research should focus on enhancing knowledge of forms of team composition in terms of specifying desirable patterns of team-member KSAOs (i.e., fitting patterns of member capabilities and characteristics together to create the team); role design (i.e., creating optimal allocations of resources, responsibilities, and interdependencies across team members); and collaborative tools (i.e., developing technologies that aid member resource collaboration and combination).

With regard to designing supports for performance regulation and adaptation, there is a very extensive research base on goal setting. However, the research base for its critical companion- 
TABLE 1

Team Processes and Emergent States Related to Team Effectiveness: Levers, Support, and Recommendations

\begin{tabular}{|c|c|c|c|}
\hline Process & Levers & Support & Comments and recommendations \\
\hline \multicolumn{4}{|c|}{ Team cognitive processes and structures } \\
\hline $\begin{array}{l}\text { Unit and team } \\
\text { climate }\end{array}$ & $\begin{array}{l}\text { Strategic imperatives, goals; } \\
\text { leadership; interpersonal } \\
\text { interaction; contextual influences }\end{array}$ & $\begin{array}{l}\text { Body of systematic theory, method } \\
\text { development, and research }\end{array}$ & $\begin{array}{l}\text { Continuing research to refine; } \\
\text { ready for application }\end{array}$ \\
\hline $\begin{array}{l}\text { Team mental } \\
\text { models }\end{array}$ & $\begin{array}{l}\text { Training; leadership; shared } \\
\text { experience }\end{array}$ & $\begin{array}{l}\text { Body of systematic theory, method } \\
\text { development, and research }\end{array}$ & $\begin{array}{l}\text { Continuing research to refine; ready } \\
\text { for application }\end{array}$ \\
\hline $\begin{array}{l}\text { Transactive } \\
\text { memory }\end{array}$ & $\begin{array}{l}\text { Levers are not well specified, but } \\
\text { initial research suggests: } \\
\text { familiarity; face-to-face } \\
\text { interaction; shared experience }\end{array}$ & Theory and emerging research & $\begin{array}{l}\text { Initial research is promising; needs } \\
\text { research on construct refinement, } \\
\text { assessment techniques, and } \\
\text { antecedents }\end{array}$ \\
\hline Team learning & $\begin{array}{l}\text { Levers are not well specified, but } \\
\text { initial research suggests: } \\
\text { shared experience }\end{array}$ & Limited support & $\begin{array}{l}\text { Initial research is promising; needs } \\
\text { conceptual clarity, basic construct } \\
\text { development, measurement, and } \\
\text { antecedents }\end{array}$ \\
\hline
\end{tabular}

Team interpersonal, motivational, and affective processes and emergent states

\begin{tabular}{|c|c|c|c|}
\hline Team cohesion & $\begin{array}{l}\text { Levers are not well specified, but } \\
\text { initial research suggests: shared } \\
\text { experience; leadership }\end{array}$ & $\begin{array}{l}\text { Body of systematic theory and } \\
\text { research; meta-analytic findings }\end{array}$ & $\begin{array}{l}\text { Related to team effectiveness; needs } \\
\text { theory and targeted research on } \\
\text { antecedents; ready for application }\end{array}$ \\
\hline $\begin{array}{l}\text { Team efficacy } \\
\text { and group } \\
\text { potency }\end{array}$ & $\begin{array}{l}\text { Training; leadership; mastery } \\
\text { experiences; persuasion }\end{array}$ & $\begin{array}{l}\text { Body of systematic theory and } \\
\text { research; meta-analytic findings }\end{array}$ & $\begin{array}{l}\text { Related to team effectiveness; needs } \\
\text { targeted research to refine } \\
\text { antecedents; ready for application }\end{array}$ \\
\hline $\begin{array}{l}\text { Team affect, } \\
\text { mood, and } \\
\text { emotion }\end{array}$ & $\begin{array}{l}\text { Member similarity; social contagion; } \\
\text { contextual influences }\end{array}$ & Theory and emerging research & $\begin{array}{l}\text { Initial research is promising; } \\
\text { conceptual clarity and construct } \\
\text { distinctions need refinement; needs } \\
\text { integration with research on } \\
\text { cohesion and conflict }\end{array}$ \\
\hline Team conflict & $\begin{array}{l}\text { Interpersonal skills; conflict } \\
\text { management skills; trust }\end{array}$ & Meta-analytic findings & $\begin{array}{l}\text { Needs research to refine how conflict } \\
\text { impedes team performance; needs } \\
\text { more research on factors that } \\
\text { mitigate team conflict }\end{array}$ \\
\hline
\end{tabular}

Team action and behavioral processes

\begin{tabular}{llcl}
$\begin{array}{l}\text { Team } \\
\text { coordination, } \\
\text { cooperation, and } \\
\text { communication }\end{array}$ & Design; training; leadership & $\begin{array}{c}\text { Body of systematic theory and } \\
\text { research; meta-analytic } \\
\text { support for levers }\end{array}$ & $\begin{array}{c}\text { Need to refine levers; ready for } \\
\text { application }\end{array}$ \\
$\begin{array}{l}\text { Team member } \\
\text { competencies }\end{array}$ & Design; training; leadership & $\begin{array}{c}\text { Body of systematic theory and } \\
\text { research; meta-analytic support } \\
\text { for levers }\end{array}$ & $\begin{array}{c}\text { Need to refine levers; application } \\
\text { ready }\end{array}$ \\
$\begin{array}{l}\text { Team regulation, } \\
\text { performance } \\
\text { dynamics, and } \\
\text { adaptation }\end{array}$ & Design; training; leadership & $\begin{array}{l}\text { Bof systematic theory and } \\
\text { research; meta-analytic support }\end{array}$ & $\begin{array}{c}\text { Need to refine levers; application } \\
\text { ready }\end{array}$ \\
\hline \hline
\end{tabular}

feedback - at the team level is not nearly so well developed (DeShon et al., 2004). Because feedback has so many possible facets and can be augmented in so many different ways, it represents both a key leverage point and a pressing research need. Finally, performance regulation and adaptation processes (i.e., goals, feedback, situation assessment) have the potential to be supported and augmented by features embedded in work sys- tems and technology that can help team members calibrate goals, provide feedback commensurate with skill levels, and aid situational awareness and adaptation (Kozlowski, Toney et al., 2001). Work in this area is just emerging but is very promising; it warrants continued research investments.

For team training - from Dyer's (1984) review, through the explosion of research in the 1990s (Salas \& Cannon-Bowers, 
TABLE 2

Team Effectiveness Levers and Recommendations

\begin{tabular}{ll}
\hline \hline Levers & Comments and recommendations \\
\hline & \\
Task and system design & Team design \\
Group composition & Apply individual-level assessment tools for selection; need research on composition patterns \\
Role design & Promising work on structural adaptation, team performance modeling, and team-member modeling; \\
& preliminary application examples exist; more work needed \\
Collaborative tools & Need theory to guide tool design; need research on tool use, team processes, and team effectiveness \\
Performance regulation and adaptation & Meta-analytic support, potent effects, extended to team level; ready for application \\
Goal Setting & Promising research support, likely to be potent; preliminary application examples exist; more work needed \\
Feedback & Integrates goals and feedback; applications have been demonstrated; ready for application \\
PROMeas & Very promising technology; preliminary application examples exist; more work needed \\
Technology augmentation &
\end{tabular}

Team training and development

Training strategies

Team-member training

Cross training

Simulation-based training

Adaptability-coordinationCRM

Team development

Descriptive models

Normative models
Promising support for effectiveness; applications have been demonstrated; application potential; needs research to refine

Meta-analytic support for effectiveness; applications have been demonstrated; ready for application; needs research to refine

Meta-analytic support for effectiveness; applications have been demonstrated; ready for application; needs research to refine

Meta-analytic support for effectiveness; applications have been demonstrated; ready for application; needs research to refine

Promising theory; need rigorous large-sample longitudinal research to map domain and guide normative models Promising broad-based theory; limited support; need research to evaluate key model propositions
Leadership in general*

Task and support behaviors

Transformational and transactional leadership

Leader-member exchange

Team leadership

Task functions

Developmental functions

\section{Team leadership}

Meta-analytic support; applications have been demonstrated; ready for application Meta-analytic support; applications have been demonstrated; ready for application

Meta-analytic support; applications have been demonstrated; ready for application

Meta-analytic support; theory-based applications need development and evaluation Meta-analytic support; theory-based applications need development and evaluation

*Research to extend findings to the team level using team-performance criteria is needed.

2001), to recent meta-analytic findings (Klein et al., 2005) — the evidence has consistently supported the effectiveness of several training techniques as a means to enhance team processes; they should be applied. In general, research needs in the area of team training are primarily issues of refinement, although simulationand technology-based training research needs are more complex. Here the issue is one of continuing to explore new technology capabilities to advance the nature and richness of the "synthetic" experiences that can be created to guide individual and team learning, and tailoring the learning experiences to fit current team-member capabilities. Promising developments in this regard include our improved understanding of how to better engage learners' cognitive and motivational systems via learnercentered instructional design (e.g., Bell \& Kozlowski, in press) and our improving ability to create synthetic learning environ- ments by merging instructional design principles with the entertainment, engagement, and excitement afforded by the synthetic worlds that gaming and digital-media designers can create (Cannon-Bowers \& Bowers, in press).

With respect to team development, research is needed! Metaanalytic findings for team building, as a technique to redevelop teams after the natural process of team development has unfolded, are mixed at best. So, how do or how should teams develop? Descriptive research on team development is quite limited; observational samples are few, small in size, and limited to a few team types. Since descriptive research can often inform theory development, we believe that rigorous longitudinal descriptive research has high value. Normative models assert that team development should be proactively promoted at the point of team formation. Although they have been constructed from a 
broad literature synthesis, such models have seen very limited empirical evaluation. We believe that it is valuable to evaluate key propositions from the normative models in grounded settings. Moreover, we believe that both types of research on team development-descriptive and prescriptive-have synergistic value.

Leadership in general has a substantial research foundation and each of the approaches highlighted in our review-leader behavioral styles, transformational and transactional behaviors, and leader-member exchange-have one or more meta-analyses supporting their effectiveness. From that support base, we conclude that each of the approaches has useful generic value and ought to be part of core curricula and training. However, we would also note these theories have two primary research needs with respect to teams. First, the conceptual focus of the theories is generally on leader effects on individuals rather than on teams, the theories are generally insensitive to the interconnections that link team members, and empirical evaluations generally focus on ratings of leadership effectiveness by individuals. We recommend theory development and research that grounds leadership in the team context and that generalizes leadership effects to the team level. Second, the choice of criteria needs to be more rigorous. We recommend research that examines leadership effectiveness with respect to team-performance outcomes as well as the other facets of team effectiveness.

With regard to team leadership, recent meta-analytic findings are supportive of task and developmental functions. Although there is a base of normative theory formulated around these two leader functions, more specific research support for key theoretical propositions is limited thus far. Much like the area of team development, targeted research on the role of leaders in team development has the potential to pay big dividends. In that regard, we recommend evaluation of key aspects of the normative team-leader models and, assuming basic support, extensions to develop applications. There are two primary application research targets. First, there is the need to translate theoretical propositions into practical guidelines. Second, there is the need to train and develop leaders so they have the necessary capabilities specified by the theories. Given that team leadership also links back to the process of team development, we see this set of related research needs as promising and important.

\section{Emerging Research Needs}

Given the focus and scope of our review, we did not address emerging areas that only have very limited theory and research. However, we would be remiss if we did not highlight two emerging trends that are likely to affect many of the critical team processes and our recommended interventions. These two trends are the increasing proliferation of virtual teams and the growing use of teams composed of diverse, multiethnic, and multicultural members. Moreover, the convergence of these two trends- in the form of virtual, networked, multicultural teams-is creating research gaps and challenges.

The extensive research we reviewed addressing team processes is centered on teams that interact face to face (or nearly so) and in settings where members are in close proximity. Yet, the increasing penetration of computer technology into all facets of the workplace, coupled with increasing connectivity and bandwidth, are enabling greater use-by emergence or deliberate design — of virtual teams consisting of members linked by networks and distributed across space and time. We know that communication, interaction, and leadership processes differ in virtual teams (Bell \& Kozlowski, 2002b; Kirkman et al., 2004). We know that virtual teams are here to stay and are growing worldwide. Moreover, increasing globalization has yielded a degree of multicultural diversity in real-world teams that is not well reflected in the research foundation; we know that diversity creates challenges for team processes (Chao \& Moon, 2005; Mannix \& Neale, 2005). Teams are often virtual because their members span the globe. Thus, the confluence of these two trends - virtual, multicultural teams - is seen as inevitable and the source of new research challenges. And, while the research need is often framed as how to mitigate the negative effects of virtuality and multicultural diversity on team processes, we think the greater theory and research challenge is how to harness the emerging technological capabilities to enhance and evolve team processes in virtual environments that cut across different cultures.

\section{Educational Recommendations}

The evidence is clear that individuals' leadership and teamwork competencies influence team effectiveness and that these competencies can be learned. Yet, current educational practices are only beginning to provide students with the leadership and teamwork experiences needed to function in today's society. Two primary shortcomings stand out.

First, formal experiences to impart generic team-process and leadership experiences are generally not provided by the educational system. If they are provided at all, it tends to be very late in the process-such as in college courses or in professional programs like business school. Some college courses are beginning to appear to address these topics in business education, and simulations are being used to provide leadership and team experience. Yet, even here, few formal courses devoted specifically to leadership and teamwork exist. Sections of courses may address leadership or teamwork as topics, but these courses are usually more about imparting factual knowledge rather than about building skills. For example, we sampled a number of well-known MBA programs and found that fewer than half listed a course devoted primarily to leadership and/or teams.

Second, in addition to the limited opportunity to learn teamwork competencies in the educational system, there is a serious issue of quality regarding the experiences that do exist. The 
qualities of good learning experiences are well known. Clear learning objectives, assessment of skill levels, practice, and feedback are central to the learning process. These instructional conditions are incorporated in the teaching of reading, writing, mathematics, and technical skills. Unfortunately, far less attention is paid to these well-accepted educational principles when developing leadership and team skills. It is not uncommon for educators from elementary school through college to include assignments organized around group projects in which students may display teamwork and leadership behaviors. However, attention is usually on the group's output (e.g., a report) with little or no attention placed on guiding the nature and effectiveness of the team process (i.e., instructional conditions). Even when relatively elaborate simulations or business games designed to elicit team competencies are used, the focus is more often on performance (e.g., quality of the business plan) than on teamwork or leadership behaviors. Given the importance of the latter and the fact that we know these skills can be effectively developed and taught, it is imperative that formal educational experiences be incorporated into the curricula across the broad scope of the educational system as students develop in secondary schools and college.

\section{Organizational Recommendations}

Current knowledge of team effectiveness should affect policies and practices in public and private organizations. Here the primary focus centers on systems and team design, training and development, and leadership. It is true that more complex forms of team composition are still on the research horizon, although there is an emerging knowledge base for applying the technology of employee selection to teams (e.g., Morgeson, Reider, \& Campion, 2005). Organizations are advised to make use of this knowledge when composing teams. With two notable exceptions, training and development issues in organizations are similar to those in education; formal experiences need to be provided and guided. The first exception is that specific team competencies can be much better fit to the contextual characteristics of a specific team and organization, whereas the educational system has to focus on more generic, transportable competencies (Cannon-Bowers et al., 1995). Teamwork skills centered on sales, working as an auditing team, or functioning as an aircraft cockpit crew can be highly tuned to the problem at hand. Second, the fact that team members may function together over extended periods of time allows for issues of values, culture, coordination, and other conditions to be developed to a higher level than is typically possible in educational systems, which, by nature, are centered around individual students who develop their skill to generalize to a wide range of situations and team members. Because teamwork is so salient in the military, excellent models exist for training teamwork skills and for fostering the development of those skills over individuals' careers, through experiences gained from duty assignments and from formal education. The private sector could learn much from the application of training and leader-development systems used by the U.S. military.

Organizational policies and practices also can be targeted on teams per se. Here both leadership and team-design factors can be brought to bear. Our review demonstrated that team processes impact team effectiveness and can be influenced by team leaders and contextual conditions. One implication of this work is that organizations need to develop team-centric policies and practices to support team processes. Instead, policies and practices are much more likely to focus on individual employees (Cohen \& Bailey, 1997). Two examples illustrate team-centric practices. First, it is well known that cockpit crews who have worked together for some time, as is the case in space flight, perform better than do teams whose members have been brought together for the first time. However, commercial aviation uses the latter approach in spite of the performance data to the contrary because management wants the freedom to assemble crews quickly to meet scheduling needs and pilots prefer a seniority system that gives them individual freedom to choose flights and not be constrained by the seniority level of least senior member of the crew. We are not suggesting that the latter system is inferior when all things are considered, but if teams rather than individuals were the primary focus, other solutions to crew composition would likely surface. Another example is from system design. A common concern of human-factors experts is that technology systems are designed by first considering physical, financial, and other system characteristics. Because human factors is often an afterthought, humans have to be retrofitted to technology-system requirements. If the human factors of teamwork were considered throughout the development process, it is likely that the distribution of task responsibilities_-system and human — and the clustering of human task responsibilities into roles and workflow-interdependence requirements that implicate ways to enhance coordination, cooperation, and communication would be more optimally integrated into the design of teams than is currently the case. Clearly the state of our knowledge regarding team effectiveness can inform policies and practices related to team design in ways that will benefit the functioning of organizational teams.

\section{CONCLUDING REMARKS}

We began this article by highlighting the centrality and importance of teamwork across a wide landscape of modern life. Yet, given the centrality of work teams, it is more than a bit remarkable that we have a strong individual-centric perspective in the western world. We school our children as individuals. We hire, train, and reward employees as individuals. And, yet, we have great faith that individuals thrown together into a team with little thought devoted to team composition, training and development, and leadership will be effective and successful. 
Our purpose in this review has been to firmly establish that there is an emerging science of team effectiveness. Researchers have identified key team processes and emergent states that enable individuals to successfully combine their knowledge, effort, and skills to yield team performance and effectiveness. We readily acknowledge that there is still much to learn. Nonetheless, there is solid research-based evidence for the importance of cognitive (unit-team climate, team mental models, and transactive memory), motivational (team cohesion, team efficacy, and potency), and behavioral (team competencies, functions, and regulatory mechanisms) processes and emergent states. Moreover, theorists and researchers have developed effective interventions centering on team design, team training, and team leadership that shape team processes and enhance team performance. We conclude that there is a substantial research foundation yielding a wealth of actionable kno wledge on how team functioning and effectiveness can be improved. Team effectiveness can be enhanced. It is just a matter of applying the science.

Acknowledgments-We would like to thank Bradford S. Bell for his insights and contributions to our conceptualization of team processes and Eduardo Salas for his many influences on the perspective we take toward team effectiveness. We also acknowledge suggestions provided by members of our jointly taught seminar-Groups, Teams, and Leadership in Organizations (2004). Finally, we thank Richard J. Klimoski and four anonymous reviewers for the helpful and constructive comments they provided on a prior version of this monograph.

Our work on this monograph was sponsored by the Air Force Office of Scientific Research (Grant F49620-01-1-0283; Kozlowski \& DeShon, Principal Investigators), the Army Research Institute for the Behavioral and Social Sciences (Grant 1435-0403-CT-71272; Klein, Kozlowski, \& Xiao, Principal Investigators), and the Office of Naval Research (Grant N00014-00-10398; Ilgen \& Hollenbeck, Principal Investigators). The U.S. Government is authorized to reproduce and distribute reprints for Governmental purposes notwithstanding any copyright notation thereon.

The views and conclusions contained herein are those of the authors and should not be interpreted as necessarily representing the official policies or endorsements, either expressed or implied, of the Air Force Research Laboratory, the Army Research Institute for the Behavioral and Social Sciences, the Office of Naval Research, or the U.S. Government.

\section{REFERENCES}

Alderfer, C.P. (1977). Group and intergroup relations. In J.R. Hackman \& J.L. Suttle (Eds.), Improving the quality of work life (pp. 227296). Palisades, CA: Goodyear.

Allport, F.H. (1954). The structuring of events: Outline of a general theory with applications to psychology. Psychological Review, 61, 281-303.
Amason, A.C. (1996). Distinguishing the effects of functional and dysfunctional conflict on strategic decision making: Resolving a paradox for top management teams. Academy of Management Journal, 39, 123-148.

Ancona, D.G., \& Chong, C. (1996). Entrainment: Pace, cycle, and rhythm in organizational behavior. Research in Organizational Behavior, 8, 251-284.

Anderson, J.R. (1993). Rules of the mind. Hillsdale, NJ: Erlbaum.

Anderson, N., \& West, M.A. (1998). Measuring climate for work group innovation: Development and validation of the team climate inventory. Journal of Organizational Behavior, 19, 235-258.

Argote, L., Insko, C.A., Yovetich, N., \& Romero, A.A. (1995). Group learning curves: The effects of turnover and task complexity on group performance. Journal of Applied Social Psychology, 25, 512-529.

Argote, L., McEvily, B., \& Reagans, R. (2003). Managing knowledge in organizations: An integrative framework and review of emerging themes. Management Science, 49, 571-582.

Argote, L., \& McGrath, J.E. (1993). Group processes in organizations. In C.L. Cooper \& I.T. Robertson (Eds.), International review of industrial and organizational psychology (Vol. 8, pp. 333-389). New York: John Wiley \& Sons.

Arrow, H., McGrath, J.E., \& Berdahl, J.L. (2000). Small groups as complex systems: Formation, coordination, development, and adaptation. Thousand Oaks, CA: Sage.

Austin, J.R. (2003). Transactive memory in organizational groups: The effects of content, consensus, specialization, and accuracy on group performance. Journal of Applied Psychology, 88, 866-878.

Avolio, B.J., Sosik, J.J., Jung, D.I., \& Berson, Y. (2003). Leadership models, methods, and applications. In W.C. Borman, D.R. Ilgen, \& R.J. Klimoski (Eds.), Handbook of psychology: Vol. 12. Industrial and organizational psychology (pp. 277-307). New York: Wiley.

Balkundi, P., \& Harrison, D.A. (2006). Ties, leaders, and time in teams: Strong inference about network structure's effects on team viability and performance. Academy of Management Journal, 49, 49-68.

Bandura, A. (1977). Self-efficacy: Toward a unifying theory of behavioral change. Psychological Review, 84, 191-215.

Bandura, A. (1997). Self-efficacy: The exercise of control. New York: Freeman.

Banks, A.P., \& Millward, L.J. (2000). Running shared mental models as a distributed cognitive process. British Journal of Psychology, 91, 513-531.

Barrick, M.R., Stewart, G.L., Neubert, M.J., \& Mount, M.K. (1998). Relating member ability and personality to work-team processes and team effectiveness. Journal of Applied Psychology, 83, 377391.

Barsade, S.G. (2002). The ripple effect: Emotional contagion and its influence on group behavior. Administrative Science Quarterly, 47, 644-675.

Barsade, S.G., \& Gibson, D.E. (1998). Group emotion: A view from top and bottom. In D.H. Gruenfeld \& Colleagues (Eds.), Composition: Research on managing groups and teams (Vol. 1, pp. 81-102). Stamford, CT: JAI Press.

Barsade, S.G., Ward, A.J., Turner, J.D.F., \& Sonnenfeld, J.A. (2000). To your heart's content: A model of affective diversity in top management teams. Administrative Science Quarterly, 45, 802-836.

Bass, B.M. (1985). Leadership and performance beyond expectations. New York: Free Press.

Bayazit, M., \& Mannix, E.A. (2003). Should I stay or should I go? Predicting team members' intent to remain in the team. Small Group Research, 34, 290-321. 
Beal, D.J., Cohen, R.R., Burke, M.J., \& McLendon, C.L. (2003). Cohesion and performance in groups: A meta-analytic clarification of construct relations. Journal of Applied Psychology, 88, 989-1004.

Beer, M. (1980). Organization change and development: A systems view. Glenview, IL: Scott, Foresman \& Co.

Bell, B.S., \& Kozlowski, S.W.J. (2002a). Adaptive guidance: Enhancing self-regulation, knowledge, and performance in technology-based training. Personnel Psychology, 55, 267-306.

Bell, B.S., \& Kozlowski, S.W.J. (2002b). A typology of virtual teams: Implications for effective leadership. Group \& Organization Management, 27, 14-49.

Bell, B.S., \& Kozlowski, S.W.J. (in press). Active learning systems. In S.W.J. Kozlowski \& E. Salas (Eds.), Learning, training, and development in organizations. Mahwah, NJ: Erlbaum.

Bettenhausen, K.L. (1991). Five years of group research: What we have learned and what needs to be addressed. Journal of Management, 17, 345-381.

Blickensderfer, E., Cannon-Bowers, J.A., \& Salas, E. (1997). Theoretical bases for team self-corrections: Fostering shared mental models. In M.M. Beyerlein \& D.A. Johnson (Eds.), Advances in interdisciplinary studies of work teams (Vol. 4, pp. 249-279). Greenwich, CT: JAI Press.

Bliese, P.D. (2000). Within-group agreement, non-independence, and reliability: Implications for data aggregation and analysis. In K.J. Klein \& S.W.J. Kozlowski (Eds.), Multilevel theory, research, and methods in organizations (pp. 349-381). San Francisco: JosseyBass.

Brief, A.P., \& Weiss, H.M. (2002). Organizational behavior: Affect in the workplace. Annual Review of Psychology, 53, 279-307.

Brown, K.G., \& Kozlowski, S.W.J. (1999, April). Toward an expanded conceptualization of emergent organizational phenomena: Dispersion theory. Paper presented at the 14th Annual Conference of the Society for Industrial and Organizational Psychology, Atlanta, GA.

Brown, K.G., Kozlowski, S.W.J., \& Hattrup, K. (1996, August). Theory, issues, and recommendations in conceptualizing agreement as a construct in organizational research: The search for consensus regarding consensus. Paper presented at the Annual Convention of the Academy of Management Association, Cincinnati, $\mathrm{OH}$.

Brown, T.C. (2003). The effect of verbal self-guidance training on collective efficacy and team performance. Personnel Psychology, 56, 935-964.

Burke, C.S., Stagl, K.C., Klein, C., Goodwin, G.F., Salas, E., \& Halpin, $\mathrm{S}$. (in press). Does leadership in teams matter? A meta-analytic integration. Leadership Quarterly.

Burns, J.M. (1978). Leadership. New York: Harper \& Row.

Burns, T., \& Stalker, G.M. (1961). The management in innovation. London: Tavistock.

Campbell, J.P., \& Kuncel, N.R. (2001). Individual and team training. In N. Anderson, D.S. Ones, H.K. Sinangil, \& C. Viswesvaran (Eds.), Handbook of work and organizational psychology (pp. 278-312). London: Blackwell.

Campion, M.A., Medsker, G.J., \& Higgs, A.C. (1993). Relations between work group characteristics and effectiveness: Implications for designing effective work groups. Personnel Psychology, 46, 823-850.

Campion, M.A., Papper, E.M., \& Medsker, G.J. (1996). Relations between work team characteristics and effectiveness: A replication and extension. Personnel Psychology, 49, 429-452.

Cannon-Bowers, J.A., \& Bowers, C.A. (in press). Synthetic learning environments: On developing a science of simulation, games, and virtual worlds for training. In S.W.J. Kozlowski \& E. Salas (Eds.),
Learning, training, and development in organizations. Mahwah, NJ: Erlbaum.

Cannon-Bowers, J.A., \& Salas, E. (1998). Making decisions under stress: Implications for individual and team training. Washington, DC: American Psychological Association.

Cannon-Bowers, J.A., Salas, E., \& Converse, S.A. (1993). Shared mental models in expert team decision making. In N.J. Castellan (Ed.), Individual and group decision making: Current issues (pp. 221-246). Hillsdale, NJ: Erlbaum.

Cannon-Bowers, J.A., Tannenbaum, S.I., Salas, E., \& Volpe, C.E. (1995). Defining team competencies and establishing team training requirements. In R. Guzzo \& E. Salas (Eds.), Team effectiveness and decision making in organizations (pp. 333-380). San Francisco: Jossey-Bass.

Carnevale, P.J., \& Probst, T.M. (1998). Social values and social conflict in creative problem solving and categorization. Journal of Personality and Social Psychology, 74, 1300-1309.

Carr, J.Z., Schmidt, A.M., Ford, J.K., \& DeShon, R.P. (2003). Climate perceptions matter: A meta-analytic path analysis relating molar climate, cognitive and affective states, and individual level work outcomes. Journal of Applied Psychology, 88, 605-619.

Carron, A.V. (1982). Cohesiveness in sport groups: Interpretations and considerations. Journal of Sport Psychology, 4, 123-138.

Chan, D. (1998). Functional relations among constructs in the same content domain at different levels of analysis: A typology of composition models. Journal of Applied Psychology, 83, 234-246.

Chang, A., Bordia, P., \& Duck, J. (2003). Punctuated equilibrium and linear progression: Toward a new understanding of group development. Academy of Management Journal, 46, 106-117.

Chao, G.T., Kozlowski, S.W.J., Major, D.A., \& Gardner, P. (1994, April). The effects of individual and contextual factors on organizational socialization and outcomes. In S.W.J. Kozlowski (Chair), Transitions during organizational socialization: Newcomer expectations, information-seeking, and learning outcomes. Symposium presented at the 9th Annual Conference of the Society for Industrial and Organizational Psychology, Nashville, TN.

Chao, G.T., \& Moon, H. (2005). The cultural mosaic: A metatheory for understanding the complexity of culture. Journal of Applied Psychology, 90, 1128-1140.

Chen, G. (2005). Newcomer adaptation in teams: Multilevel antecedents and outcomes. Academy of Management Journal, 48, 101-116.

Chen, G., \& Bliese, P.D. (2002). The role of different levels of leadership in predicting self- and collective efficacy: Evidence for discontinuity. Journal of Applied Psychology, 87, 549-556.

Chen, G., Donahue, L.M., \& Klimoski, R.J. (2004). Training undergraduates to work in organizational teams. Academy of Management Learning and Education, 3, 27-40.

Chen, G., \& Klimoski, R.J. (2003). The impact of expectations on newcomer performance in teams as mediated by work characteristics, social exchanges, and empowerment. Academy of Management Journal, 46, 591-607.

Chen, G., Thomas, B., \& Wallace, J.C. (2005). A multilevel examination of the relationships among training outcomes, mediating regulatory processes, and adaptive performance. Journal of Applied Psychology, 90, 827-841.

Cohen, S.G., \& Bailey, D.E. (1997). What makes teams work: Group effectiveness research from the shop floor to the executive suite. Journal of Management, 23, 239-290.

Dansereau, F., Cashman, J., \& Graen, G. (1973). Instrumentality theory and equity theory as complementary approaches in predicting the 
relationship of leadership and turnover among managers. Organizational Behavior and Human Performance, 10, 184-200.

Dansereau, F., Graen, G., \& Haga, W.J. (1975). A vertical dyad linkage approach to leadership within formal organizations: A longitudinal investigation of the role making process. Organizational Behavior and Human Performance, 13, 146-178.

Davies, J.M. (2001). Medical applications of crew resource management. In E. Salas, C.A. Bowers, \& E. Edens (Eds.), Improving teamwork in organizations (pp. 265-281). Mahwah, NJ: Erlbaum.

Day, D.V., Zaccaro, S.J., \& Halpin, S. (2004). Leader development for transforming organizations: Growing leaders for tomorrow. Mahwah, NJ: Erlbaum.

DeChurch, L.A., \& Marks, M.A. (2006). Leadership in Multiteam Systems. Journal of Applied Psychology, 91, 311-329.

De Dreu, C.K.W., \& Weingart, L.R. (2003). Task versus relationship conflict, team performance, and team member satisfaction: A meta-analysis. Journal of Applied Psychology, 88, 741-749.

DeShon, R.P., Kozlowski, S.W.J., Schmidt, A.M., Milner, K.A., \& Wiechmann, D. (2004). A multiple-goal, multilevel model of feedback effects on the regulation of individual and team performance. Journal of Applied Psychology, 89, 1035-1056.

DeShon, R.P., Kozlowski, S.W.J., Schmidt, A.M., Wiechmann, D., \& Milner, K.R. (2001, April). Developing team adaptability: Shifting regulatory focus across levels. In S.W.J. Kozlowski \& R. P. DeShon (Chairs), Enhancing team performance: Emerging theory, instructional strategies, and evidence. Symposium presented at the 16th Annual Conference of the Society for Industrial and Organizational Psychology, San Diego, CA.

DeShon, R.P., Milner, K.R., Kozlowski, S.W.J., Toney, R.J., Schmidt, A., Wiechmann, D., \& Davis, C. (1999, April). The effects of team goal orientation on individual and team performance. Paper presented at the 14th Annual Conference of the Society for Industrial and Organizational Psychology, Atlanta, GA.

Devine, D.J., Clayton, L.D., Phillips, J.L., Dunford, B.B., \& Melner, S.B. (1999). Teams in organizations: Prevalence, characteristics, and effectiveness. Small Group Research, 30, 678711.

Durham, C.C., Knight, D., \& Locke, E.A. (1997). Effects of leader role, team-set goal difficulty, efficacy, and tactics on team effectiveness. Organizational Behavior and Human Decision Processes, 72, 203231.

Dweck, C.S. (1986). Motivational processes affecting learning. American Psychologist, 41, 1040-1048.

Dyer, J.C. (1984). Team research and team training: State-of-the-art review. In F.A. Muckler (Ed.), Human factors review (pp. 285323). Santa Monica, CA: Human Factors Society.

Eagly, A.H., Johannesen-Schmidt, M.C., \& van Engen, M.L. (2003). Transformational, transactional, and laissez-faire leadership styles: A meta-analysis comparing women and men. Psychological Bulletin, 129, 569-591.

Earley, P.C., Connolly, T., \& Ekegren, G. (1989). Goals, strategy development, and task performance: Some limits on the efficacy of goal setting. Journal of Applied Psychology, 74, 24-33.

Edmondson, A.C. (1999). Psychological safety and learning behavior in work teams. Administrative Science Quarterly, 44, 350-383.

Edmondson, A.C., Bohmer, R.M., \& Pisano, G.P. (2001). Disrupted routines: Team learning and new technology implementation in hospitals. Administrative Science Quarterly, 46, 685-716.

Ellis, A.P.J., \& Bell, B.S. (2005). Capacity, collaboration, and commonality: A framework for understanding team learning. In L.L. Neider \& C.A. Shriesheim (Eds.), Understanding teams: A volume in research in management (pp. 1-25). Greenwich, CT: Information Age.

Ellis, A.P.J., Bell, B.S., Ployhart, R.E., Hollenbeck, J.R., \& Ilgen, D.R. (2005). An evaluation of generic teamwork skills training with action teams: Effects on cognitive and skill-based outcomes. Personnel Psychology, 58, 641-672.

Ellis, A.P.J., Hollenbeck, J.R., Ilgen, D.R., Porter, C.O.L.H., West, B.J., \& Moon, H. (2003). Team learning: Collectively connecting the dots. Journal of Applied Psychology, 88, 821-835.

Ensley, M.D., \& Pearce, C.L. (2001). Shared cognition in top management teams: Implications for new venture performance. Journal of Organizational Behavior, 22, 145-160.

Epple, D., Argote, L., \& Devadas, R. (1991). Organizational learning curves: A method for investigating intra-plant transfer of knowledge acquired through learning by doing. Organization Science, 2 , $58-70$.

Evans, C.R., \& Dion, K.L. (1991). Group cohesion and performance: A meta-analysis. Small Group Research, 22, 175-186.

Evans, C.R., \& Jarvis, P.A. (1980). Group cohesion: A review and reevaluation. Small Group Behavior, 11, 359-370.

Feltz, D.L., \& Lirgg, C.D. (1998). Perceived team and player efficacy in hockey. Journal of Applied Psychology, 83, 557-564.

Festinger, L. (1950). Informal social communication. Psychological Review, 57, 271-282.

Fleishman, E.A., \& Zaccaro, S.J. (1992). Toward a taxonomy of team performance functions. In R.W. Swezey \& E. Salas (Eds.), Teams: Their training and performance (pp. 31-56). Norwood, NJ: Ablex.

Flin, R., \& O'Connor, P. (2001). Applying crew resource management on offshore oil platforms. In E. Salas, C.A. Bowers, \& E. Edens (Eds.), Improving teamwork in organizations (pp. 217-233). Mahwah, NJ: Erlbaum.

Flin, R.H. (1995). Crew resource management for teams in the offshore oil industry. Journal of European Industrial Training, 19, 23-27.

Forehand, G.A., \& Gilmer, B.H. (1964). Environmental variation in studies of organizational behavior. Psychological Bulletin, 62, 361-382.

Forgas, J.P. (1990). Affective influences on individual and group judgments. European Journal of Social Psychology, 20, 441-453.

Foushee, H.C. (1984). Dyads and triads at 35,000 feet: Factors affecting group process and aircrew performance. American Psychologist, 39, 885-893.

Fuller, B.J., Patterson, C.E.P., Hester, K., \& Stringer, D.Y. (1996). A quantitative review of research on charismatic leadership. Psychological Report, 78, 271-287.

Galbraith, J. (1972). Organization design: An information processing view. In J. Lorsch \& P. Lawrence (Eds.), Organizational planning: Cases and concepts (pp. 530-548). Homewood, IL: Irwin-Dorsey.

George, J.M. (1990). Personality, affect, and behavior in groups. Journal of Applied Psychology, 75, 107-116.

George, J.M. (1991). State or trait: Effects of positive mood on prosocial behaviors at work. Journal of Applied Psychology, 76, 299-307.

George, J.M., \& Brief, A.P. (1992). Feeling good, doing good: A conceptual analysis of moods at work. Psychological Bulletin, 112, 310-329.

Gersick, C.J.G. (1988). Time and transition in work teams: Toward a new model of group development. Academy of Management Journal, 31, 9-41.

Gerstner, C.R., \& Day, D.V. (1997). Meta-analytic review of leadermember exchange theory: Correlates and construct issues. Journal of Applied Psychology, 82, 827-844. 
Gladstein, C.R., \& Day, D.V. (1984). Groups in context: A model of task group effectiveness. Administrative Science Quarterly, 29, 499517.

Glickman, A.S., Zimmer, S., Montero, R.C., Guerette, P.J., Campbell, W.J., Morgan, B.B., \& Salas, E. (1987). The evolution of teamwork skills: An empirical assessment with implications for training (Tech. Rep. No. Tr-87-016). Orlando, FL: Naval Training Systems Center.

González-Romá, V., Peiró, J.M., \& Tordera, N. (2002). An examination of the antecedents and moderator influences of climate strength. Journal of Applied Psychology, 87, 465-473.

Goodman, P.S., Ravlin, E., \& Schminke, M. (1987). Understanding groups in organizations. In L.L. Cummings \& B.M. Staw (Eds.), Research in organizational behavior (Vol. 9, pp. 121-173). Greenwich, CT: JAI Press.

Graen, G.B. (1976). Role-making processes within complex organizations. In M.D. Dunnette (Ed.), Handbook of industrial and organizational psychology (pp. 1201-1245). Chicago: Rand McNally.

Graen, G.B., Orris, J.B., \& Johnson, T.W. (1973). Role assimilation processes in a complex organization. Journal of Vocational Behavior, 3, 395-420.

Graen, G.B., \& Scandura, T.A. (1987). Toward a psychology of dyadic organizing. In B.M. Staw \& L.L. Cummings (Eds.), Research in organizational behavior (Vol. 9, pp. 175-208). Greenwich, CT: JAI Press.

Gross, N., \& Martin, W.E. (1952). On group cohesiveness. American Journal of Sociology, 57, 546-554.

Guetzkow, H., \& Gyr, J. (1954). An analysis of conflict in decision making groups. Human Relations, 7, 367-381.

Gully, S.M. (2000). Work team research: Recent findings and future trends. In M.M. Beyerlein (Ed.), Work teams: Past, present, and future (pp. 25-44). The Netherlands: Kluwer Academic Publishers.

Gully, S.M., Devine, D.J., \& Whitney, D.J. (1995). A meta-analysis of cohesion and performance: Effects of levels of analysis and task interdependence. Small Group Research, 26, 497-520.

Gully, S.M., Incalcaterra, K.A., Joshi, A., \& Beaubien, J.M. (2002). A meta-analysis of team-efficacy, potency, and performance: Interdependence and level of analysis as moderators of observed relationships. Journal of Applied Psychology, 87, 819-832.

Guzzo, R.A., \& Dickson, M.W. (1996). Teams in organizations: Recent research on performance and effectiveness. Annual Review of Psychology, 47, 307-338.

Guzzo, R.A., \& Shea, G.P. (1992). Group performance and intergroup relations in organizations. In M.D. Dunnette \& L.M. Hough (Eds.), Handbook of industrial and organizational psychology (Vol. 3, pp. 269-313). Palo Alto, CA: Consulting Psychologist Press.

Hackman, J.R. (1976). Group influences on individuals. In M.D. Dunnette (Ed.), Handbook of industrial and organizational psychology (pp. 1455-1525). Chicago: Rand McNally.

Hackman, J.R. (1987). The design of work teams. In J. Lorsch (Ed.), Handbook of organizational behavior (pp. 315-342). New York: Prentice Hall.

Hackman, J.R. (1992). Group influences on individuals in organizations. In M.D. Dunnette \& L.M. Hough (Eds.), Handbook of industrial and organizational psychology (Vol. 3, pp. 199-267). Palo Alto, CA: Consulting Psychologist Press.

Hackman, J.R., \& Wageman, R. (2005). A theory of team coaching. Academy of Management Review, 30, 269-287.

Hambrick, D.C. (1995). Fragmentation and other problems CEOs have with their top management teams. California Management Review, $37,110-127$.
Harrison, D.A., \& Klein, K.J. (in press). What's the difference? Diversity constructs and separation, variety, or disparity in organizations. Academy of Management Review.

Harrison, D.A., Mohammed, S., McGrath, J.E., Florey, A.T., \& Vanderstoep, S.W. (2003). Time matters in team performance: Effects of member familiarity, entrainment, and task discontinuity on speed and quality. Personnel Psychology, 56, 633-669.

Hartel, C.E.J., Zerbe, W.J., \& Ashkanasy, N.M. (2005). Emotions in organizational behavior. Mahwah, NJ: Erlbaum.

Helmreich, R.L. (2000). On error management: Lessons from aviation. British Medical Journal, 320, 781-785.

Helmreich, R.L., \& Foushee, H.C. (1993). Why crew resource management? Empirical and theoretical bases of human factors training in aviation. In E.L. Weiner, B.G. Kanki, \& R.L. Helmreich (Eds.), Cockpit resource management (pp. 3-45). San Diego, CA: Academic Press.

Hinsz, V.B., Tindale, R.S., \& Vollrath, D.A. (1997). The emerging conceptualization of groups as information processors. Psychological Bulletin, 121, 43-64.

Hofmann, D.A., \& Jones, L.M. (2005). Leadership, collective personality, and performance. Journal of Applied Psychology, 90, 509522.

Hofmann, D.A., \& Morgeson, F.P. (1999). Safety-related behavior as a social exchange: The role of perceived organizational support and leadermember exchange. Journal of Applied Psychology, 84, 286-296.

Hofmann, D.A., Morgeson, F.P., \& Gerras, S.J. (2003). Climate as a moderator of the relationship between leader-member exchange and content specific citizenship: Safety climate as an exemplar. Journal of Applied Psychology, 88, 170-178.

Hofmann, D.A., \& Stetzer, A. (1996). A cross-level investigation of factors influencing unsafe behaviors and accidents. Personnel Psychology, 49, 307-339.

Hollenbeck, J.R., Ilgen, D.R., Sego, D.J., Hedlund, J., Major, D.A., \& Phillips, J. (1995). Multilevel theory of team decision-making: Decision performance in teams incorporating distributed expertise. Journal of Applied Psychology, 80, 292-316.

Hollenbeck, J.R., Moon, H., Ellis, A.P.J., West, B.J., Ilgen, D.R., Sheppard, L., Porter, C.O.L.H., \& Wagner, J.A. III (2002). Structural contingency theory and individual differences: Examination of external and internal person-team fit. Journal of Applied Psychology, 87, 599-606.

Hollingshead, A.B. (1998a). Communication, learning, and retrieval in transactive memory systems. Journal of Experimental Social Psychology, 34, 423-442.

Hollingshead, A.B. (1998b). Retrieval processes in transactive memory systems. Journal of Personality and Social Psychology, 74, 659671.

Hollingshead, A.B. (2001). Cognitive interdependence and convergent expectations in transactive memory. Journal of Personality and Social Psychology, 81, 1080-1089.

Human Technology. (1993). Training and development framework and descriptions of best practices. McLean, VA: Author.

Hyatt, D.E., \& Ruddy, T.M. (1997). An examination of the relationship between work group characteristics and performance: Once more into the breech. Personnel Psychology, 50, 553-585.

Ilgen, D.R., Hollenbeck, J.R., Johnson, M., \& Jundt, D. (2005). Teams in organizations: From input-process-output models to IMOI models. Annual Review of Psychology, 56, 517-543.

Ilgen, D.R., \& Sheppard, L. (2001). Motivation in teams. In M. Erez, U. Kleinbeck, \& H. Thierry (Eds.), Work motivation in the context of a globalizing economy (pp. 169-179). New York: Erlbaum. 
James, L.R., \& Jones, A.P. (1974). Organizational climate: A review of theory and research. Psychological Bulletin, 81, 1096-1112.

Janis, I.L. (1972). Victims of groupthink: A psychological study of foreign-policy decisions and fiascoes. Boston: Houghton Mifflin.

Jehn, K.A. (1995). A multimethod examination of the benefits and detriments of intragroup conflict. Administrative Science Quarterly, 40, 256-282.

Jehn, K.A. (1997). A qualitative analysis of conflict types and dimensions in organizational groups. Administrative Science Quarterly, $42,530-557$.

Jinnett, K., \& Alexander, J.A. (1999). The influence of organizational context on quitting intention: An examination of treatment staff in long-term mental health care settings. Research on Aging, 21, 176-205.

Johnson, M.D., Hollenbeck, J.R., Humphrey, S.E., Ilgen, D.R., Jundt, D., \& Meyer, C.J. (in press). Cutthroat cooperation: Asymmetrical adaptation to changes in team rewards. Academy of Management Journal.

Judge, T.A., \& Piccolo, R.F. (2004). Transformational and transactional leadership: A meta-analytic test of their relative validity. Journal of Applied Psychology, 89, 755-768.

Judge, T.A., Piccolo, R.F., \& Ilies, R. (2004). The forgotten ones? The validity of consideration and initiating structure in leadership research. Journal of Applied Psychology, 89, 36-51.

Karoly, P. (1993). Mechanisms of self-regulation: A systems view. Annual Review of Psychology, 44, 23-52.

Katz, D., \& Kahn, R.L. (1966). The social psychology of organizations. New York: Wiley.

Katzenbach, J.R., \& Smith, D.K. (1993). The wisdom of teams: Creating the high performance organization. Boston: Harvard Business School Press.

Kelly, J.R., \& Barsade, S.G. (2001). Mood and emotions in small groups and work teams. Organizational Behavior \& Human Decision Processes, 86, 99-130.

Kerr, N.L., \& Bruun, S. (1983). The dispensability of member effort and group motivation losses: Free-rider effects. Journal of Personality and Social Psychology, 44, 78-94.

Kerr, N.L., \& Tindale, R.S. (2004). Group performance and decision making. Annual Review of Psychology, 55, 623-655.

Kirkman, B.L., \& Rosen, B. (1997). A model of work team empowerment. Research in Organizational Change and Development, 10, 131-167.

Kirkman, B.L., \& Rosen, B. (1999). Beyond self-management: Antecedents and consequences of team empowerment. Academy of Management Journal, 42, 58-74.

Kirkman, B.L., Rosen, B., Tesluk, P.E., \& Gibson, C.B. (2004). The impact of team empowerment on virtual team performance: The moderating role of face-to-face interaction. Academy of Management Journal, 47, 175-192.

Klein, C., DeRouin, R.E., \& Salas, E. (in press). Uncovering workplace interpersonal skills: A review, framework, and research agenda. In G. Hodgkinson \& J.K. Ford (Eds.), International review of industrial and organizational psychology (Vol. 21). Chichester, UK: Wiley.

Klein, C., Salas, E., Burke, C.S., Goodwin, G.F., Halpin, S., DiazGranados, D., \& Badum, A. (2005). Does team training enhance team processes, performance, and team member affective outcomes? A meta-analysis. Manuscript submitted for publication.

Klimoski, R.J., \& Mohammed, S. (1994). Team mental model: Construct or metaphor? Journal of Management, 20, 403-437.

Knight, D., Pearce, C.L., Smith, K.G., Olian, J.D., Sims, H.P., Smith, K.A., \& Flood, P. (1999). Top management team diversity, group process, and strategic consensus. Strategic Management Journal, $20,445-465$.

Kozlowski, S.W.J. (1999, April). A typology of emergence: Theoretical mechanisms undergirding bottom-up phenomena in organizations. Paper presented at the 14th Annual Conference of the Society for Industrial and Organizational Psychology, Atlanta, GA.

Kozlowski, S.W.J., \& Bell, B.S. (in press). Team learning, development, and adaptation. In V.I. Sessa \& M. London (Eds.), Group learning. Mahwah, NJ: Erlbaum.

Kozlowski, S.W.J., \& Bell, B.S. (2003). Work groups and teams in organizations. In W.C. Borman, D.R. Ilgen, \& R.J. Klimoski (Eds.), Handbook of psychology: Vol. 12. Industrial and organizational psychology (pp. 333-375). London: Wiley.

Kozlowski, S.W.J., Brown, K.G., Weissbein, D.A., Cannon-Bowers, J.A., \& Salas, E. (2000). A multi-level perspective on training effectiveness: Enhancing horizontal and vertical transfer. In K.J. Klein \& S.W.J. Kozlowski (Eds.), Multilevel theory, research, and methods in organizations (pp. 157-210). San Francisco: JosseyBass.

Kozlowski, S.W.J., \& Doherty, M.L. (1989). Integration of climate and leadership: Examination of a neglected issue. Journal of Applied Psychology, 74, 546-553.

Kozlowski, S.W.J., Gully, S.M., Brown, K.G., Salas, E., Smith, E.A., \& Nason, E.R. (2001). Effects of training goals and goal orientation traits on multi-dimensional training outcomes and performance adaptability. Organizational Behavior and Human Decision Processes, 85, 1-31.

Kozlowski, S.W.J., Gully, S.M., McHugh, P.P., Salas, E., \& CannonBowers, J.A. (1996). A dynamic theory of leadership and team effectiveness: Developmental and task contingent leader roles. In G.R. Ferris (Ed.), Research in personnel and human resource management (Vol. 14, pp. 253-305). Greenwich, CT: JAI Press.

Kozlowski, S.W.J., Gully, S.M., Nason, E.R., \& Smith, E.M. (1999). Developing adaptive teams: A theory of compilation and performance across levels and time. In D.R. Ilgen \& E.D. Pulakos (Eds.), The changing nature of work performance: Implications for staffing, personnel actions, and development (pp. 240-292). San Francisco: Jossey-Bass.

Kozlowski, S.W.J., Gully, S.M., Salas, E., \& Cannon-Bowers, J.A. (1996). Team leadership and development: Theory principles, and guidelines for training leaders and teams. In M. Beyerlein, D. Johnson, \& S. Beyerlein (Eds.), Advances in interdisciplinary studies of work teams: Team leadership (Vol. 3, pp. 251-289). Greenwich, CT: JAI Press.

Kozlowski, S.W.J., \& Hults, B.M. (1987). An exploration of climates for technical updating and performance. Personnel Psychology, 40, 539-563.

Kozlowski, S.W.J., \& Klein, K.J. (2000). A multilevel approach to theory and research in organizations: Contextual, temporal, and emergent processes. In K.J. Klein \& S.W.J. Kozlowski (Eds.), Multilevel theory, research, and methods in organizations: Foundations, extensions, and new directions (pp. 3-90). San Francisco: Jossey-Bass.

Kozlowski, S.W.J., Toney, R.J., Mullins, M.E., Weissbein, D.A., Brown, K.G., \& Bell, B.S. (2001). Developing adaptability: A theory for the design of integrated-embedded training systems. In E. Salas (Ed.), Advances in human performance and cognitive engineering research (Vol. 1, pp. 59-123). Amsterdam: JAI/Elsevier Science.

Kozlowski, S.W.J., Watola, D., Nowakowski, J.M., Kim, B., \& Botero, I. (in press). Developing adaptive teams: A theory 
of dynamic team leadership. In E. Salas, G.F. Goodwin, \& C.S. Burke (Eds.), Team effectiveness in complex organizations: Cross-disciplinary perspectives and approaches. Mahwah, NJ: Erlbaum.

Krakauer, J. (1997). Into thin air. New York: Villard.

Latané, B., Williams, K., \& Harkin, S. (1979). Many hands make light the work: The causes and consequences of social loafing. Journal of Personality and Social Psychology, 37, 822-832.

Lau, D.C., \& Murnighan, J.K. (1998). Demographic diversity and faultlines: The compositional dynamics of organizational groups. Academy of Management Review, 23, 325-340.

Lawler, E.E., Mohrman, S.A., \& Ledford, G.E. (1992). Employee involvement and total quality management: Practices and results in Fortune 1000 companies. San Francisco: Jossey-Bass.

Lawler, E.E., Mohrman, S.A., \& Ledford, G.E. (1995). Creating high performance organizations: Practices and results of employee involvement and total quality management in Fortune 1000 companies. San Francisco: Jossey-Bass.

Lee, C. (1991). Who gets trained in what? Training, 28, 447-456.

LePine, J.A. (2003). Team adaptation and postchange performance: Effects of team composition in terms of members' cognitive ability and personality. Journal of Applied Psychology, 88(1), $27-39$.

LePine, J.A. (2005). Adaptation of teams in response to unforeseen change: Effects of goal difficulty and team composition in terms of cognitive ability and goal orientation. Journal of Applied Psychology, 90, 1153-1167.

LePine, J.A., Hollenbeck, J.R., Ilgen, D.R., \& Hedlund, J. (1997). Effects of individual differences on the performance of hierarchical decision-making teams: Much more than $g$. Journal of Applied Psychology, 82, 803-811.

Levine, J.M., \& Moreland, R.L. (1990). Progress in small-group research. Annual Review of Psychology, 41, 585-634.

Lewin, K., Lippitt, R., \& White, R.K. (1939). Patterns of aggressive behavior in experimentally created social climates. Journal of Social Psychology, 10, 271-299.

Lewis, K. (2003). Measuring transactive memory systems in the field: Scale development and validation. Journal of Applied Psychology, $88,587-604$.

Lewis, K. (2004). Knowledge and performance in knowledge-worker teams: A longitudinal study of transactive memory systems. Management Science, 50, 1519-1533.

Liang, D.W., Moreland, R.L., \& Argote, L. (1995). Group versus individual training and group performance: The mediating role of transactive memory. Personality and Social Psychology Bulletin, 21, 384-393.

Lim, B.C., \& Ployhart, R.E. (2004). Transformational leadership: Relations to the five-factor model and team performance in typical and maximum contexts. Journal of Applied Psychology, 89, 610-621.

Lindsley, D.H., Brass, D.J., \& Thomas, J.B. (1995). Efficacy-performance spirals: A multilevel perspective. Academy of Management Review, 20, 645-678.

Locke, E.A., \& Latham, G.P. (1990). A theory of goal-setting and task performance. Englewood Cliffs, NJ: Prentice-Hall.

Lord, R.G., Brown, D.J., \& Freiberg, S.J. (1999). Understanding the dynamics of leadership: The role of follower self-concepts in the leader/follower relationship. Organizational Behavior and Human Decision Processes, 78, 167-203.

Lowe, K.B., Kroeck, K.G., \& Sivasubramaniam, N. (1996). Effectiveness correlates of transformational and transactional leadership: A meta-analytic review. Leadership Quarterly, 7, 385-425.
Mannix, E., \& Neale, M. (2005). What differences make a difference? The promise and reality of diverse teams in organizations. Psychological Science in the Public Interest, 6, 31-55.

Marks, M.A., DeChurch, L.A., Mathieu, J.E., Panzer, F.J., \& Alonso, A. (in press). Teamwork in multi-team systems. Journal of Applied Psychology.

Marks, M.A., Mathieu, J.E., \& Zaccaro, S.J. (2001). A temporally based framework and taxonomy of team processes. Academy of Management Review, 26, 356-376.

Marks, M.A., Sabella, M.J., Burke, C.S., \& Zaccaro, S.J. (2002). The impact of cross-training on team effectiveness. Journal of Applied Psychology, 87, 3-13.

Marks, M.A., Zaccaro, S.J., \& Mathieu, J.E. (2000). Performance implications of leader briefings and team-interaction training for team adaptation to novel environments. Journal of Applied Psychology, 85, 971-986.

Mathieu, J.E., Gilson, L.L., \& Ruddy, T.M. (in press). Empowerment and team effectiveness: An empirical test of an integrated model. Journal of Applied Psychology.

Mathieu, J.E., Heffner, T.S., Goodwin, G.F., Salas, E., \& CannonBowers, J.A. (2000). The influence of shared mental models on team process and performance. Journal of Applied Psychology, 85, 273-283.

Mathieu, J.E., Marks, M.A., \& Zaccaro, S.J. (2001). Multi-team systems. In N. Anderson, D.S. Ones, H.K. Sinangil \& C. Viswesvaran (Eds.), Organizational psychology: Vol. 2. Handbook of industrial, work and organizational psychology (pp. 289-313). London: Sage.

Mathieu, J.E., \& Schulze, W. (in press). The influence of team knowledge and formal plans on episodic team process-performance relationships. Academy of Management Journal.

McGrath, J.E. (1964). Social psychology: A brief introduction. New York: Holt, Rinehart, \& Winston.

McGrath, J.E. (1991). Time, interaction, and performance (TIP): A theory of groups. Small Group Research, 22, 147-174.

Meichenbaum, D.H. (1971). Examination of model characteristics in reducing avoidance behavior. Journal of Personality and Social Psychology, 17, 298-310.

Mento, A.J., Steel, R.P., \& Karren, R.J. (1987). A meta-analytic study of the effects of goal-setting on task performance-1966-1984. Organizational Behavior and Human Decision Processes, 39, $52-83$.

Minionis, D.P., Zaccaro, S.J., \& Perez, R. (1995). Shared mental models, team coordination, and team performance. Paper presented at the 10th annual meeting of the Society for Industrial and Organizational Psychology, Orlando, FL.

Mohammed, S., \& Dumville, B.C. (2001). Team mental models in a team knowledge framework: Expanding theory and measurement across disciplinary boundaries. Journal of Organizational Behavior, 22, 89-106.

Mohammed, S., Klimoski, R.J., \& Rentsch, J.R. (2000). The measurement of team mental models: We have no shared schema. Organizational Research Methods, 3, 123-165.

Moon, H., Hollenbeck, J.R., Humphrey, S.E., Ilgen, D.R., West, B.J., Ellis, A.P.J., \& Porter, C.O.L.H. (2004). Asymmetric adaptability: Dynamic team structures as one-way streets. Academy of Management Journal, 47, 681-695.

Moreland, R.L. (1999). Transactive memory: Learning who knows what in work groups and organizations. In L.L. Thompson, J.M. Levine, \& D.M. Messick (Eds.), Shared cognition in organizations: The management of knowledge (pp. 3-31). Mahwah, NJ: Erlbaum. 
Moreland, R.L., Hogg, M.A., \& Hains, S.C. (1994). Back to the future: Social psychological research on groups. Journal of Experimental Social Psychology, 30, 527-555.

Morgan, B.B., Salas, E., \& Glickman, A.S. (1993). An analysis of team evolution and maturation. Journal of General Psychology, 120, $277-291$.

Morgeson, F.P. (2005). The external leadership of self-managing teams: Intervening in the context of novel and disruptive events. Journal of Applied Psychology, 90, 497-508.

Morgeson, F.P., Reider, M.H., \& Campion, M.A. (2005). Selecting individuals in team settings: The importance of social skills, personality characteristics, and teamwork knowledge. Personnel Psychology, 58, 583-611.

Mullen, B., \& Cooper, C. (1994). The relation between group cohesiveness and performance: An integration. Psychological Bulletin, $115,210-227$.

Myers, N.D., Feltz, D.L., \& Short, S.E. (2004). Collective efficacy and team performance: A longitudinal study of collegiate football teams. Group Dynamics: Theory, Research, and Practice, 8, 126138.

Myers, N.D., Payment, C.A., \& Feltz, D.L. (2004). Reciprocal relationships between collective efficacy and team performance in women's ice hockey. Group Dynamics: Theory, Research, and Practice, 8, 182-195.

NASA Goddard Space Flight Center (n.d.). The Apollo 13 accident. Retrieved December 13, 2005, from http://nssdc.gsfc.nasa.gov/ planetary/lunar/apl3acc.html

Naylor, J.C., Pritchard, R.D., \& Ilgen, D.R. (1980). A theory of behavior in organizations. New York: Academic Press.

Newell, A. (1990). Unified theories of cognition. Boston: Harvard University Press.

Nieva, V.F., Fleishman, E.A., \& Reick, A. (1978). Team dimensions: Their identity, their measurement, and their relationships. Washington, DC: ARRO.

O’Leary-Kelly, A.M., Martocchio, J.J., \& Frink, D.D. (1994). A review of the influence of group goals on group-performance. Academy of Management Journal, 37(5), 1285-1301.

Olson, G.M., \& Olson, J.S. (2000). Distance matters. Human-Computer Interaction, 15, 139-197.

Olson, G.M., \& Olson, J.S. (2002). Groupware and computer supported cooperative work. In J.J. Cacko \& A. Sears (Eds.), Handbook of human-computer interaction (pp. 409-442). Mahwah, NJ: Erlbaum.

Olson, G.M., \& Olson, J.S. (2003). Human-computer interaction: Psychological aspects of the human use of computing. Annual Review of Psychology, 54, 491-516.

Ostroff, C., Kinicki, A.J., \& Tamkins, M.M. (2003). Organizational culture and climate. In W.C. Borman, D.R. Ilgen, \& R.J. Klimoski (Eds.), Handbook of psychology: Industrial and organizational psychology (Vol. 12, pp. 565-593). London: Wiley.

Paskevich, D.M., Brawley, L.R., Dorsch, K.D., \& Widmeyer, W.N. (1999). Relationship between collective efficacy and team cohesion: Conceptual and measurement issues. Group Dynamics, 3, $210-222$.

Phillips, J.M., Hollenbeck, J.R., \& Ilgen, D.R. (1996). The prevalence and prediction of positive discrepancy creation: An integration of episodic and non-episodic theories of motivation. Journal of Applied Psychology, 81, 498-511.

Ployhart, R.E. (2004). Organizational staffing: A multilevel review, synthesis, and model. Research in Personnel and Human Resources Management, 23, 121-176.
Ployhart, R.E., \& Schneider, B. (2005). Multilevel selection and prediction: Theories, methods, and models. In A. Evers, O. SmitVoskuyl, \& N. Anderson (Eds.), Handbook of personnel selection (pp. 495-516). Chichester/London: Wiley.

Pritchard, R.D. (Ed.). (1995). Productivity measurement and improvement: Organizational case studies. Westport, CT: Praeger Publishers/Greenwood Publishing Group, Inc.

Pritchard, R.D., Jones, S.D., Roth, P.L., Stuebing, K.K., \& Ekeberg, S.E. (1988). The effects of feedback, goal setting, and incentives on organizational productivity. Journal of Applied Psychology, 73, $337-358$.

Prussia, G.E., \& Kinicki, A.J. (1996). A motivational investigation of group effectiveness using social-cognitive theory. Journal of Applied Psychology, 81, 187-198.

Rentsch, J.R. (1990). Climate and culture: Interaction and qualitative differences in organizational meanings. Journal of Applied Psychology, 75, 668-681.

Rouse, W.B., \& Morris, N.M. (1986). On looking into the black box: Prospects and limits in the search for mental models. Psychological Bulletin, 100, 349-363.

Rulke, D.L., \& Rau, D. (2000). Investigating the encoding process of transactive memory development in group training. Group and Organizational Management, 25, 373-396.

Saavendra, R., Earley, P.C., \& Van Dyne, L. (1993). Complex interdependence in task-performing groups. Journal of Applied Psychology, 78, 61-72.

Salas, E., \& Cannon-Bowers, J.A. (1997). Methods, tools, and strategies for team training. In M.A. Quinones \& A. Ehrenstein (Eds.), Training for a rapidly changing workplace: Applications of psychological research (pp. 249-279). Washington, DC: American Psychological Association.

Salas, E., \& Cannon-Bowers, J.A. (2001). The science of team training: A decade of progress. Annual Review of Psychology, 52, 471-499.

Salas, E., Dickinson, T.L., Converse, S.A., \& Tannenbaum, S.I. (1992). Toward an understanding of team performance and training. In R.W. Swezey \& E. Salas (Eds.), Teams: Their training and performance (pp. 3-29). Norwood, NJ: Ablex.

Salas, E., Rozell, D., Driskell, J.D., \& Mullen, B. (1999). The effect of team building on performance: An integration. Small Group Research, 30, 309-329.

Salas, E., Stagl, K.C., \& Burke, C.S. (2004). 25 years of team effectiveness in organizations: Research themes and emerging needs. International Review of Industrial and Organizational Psychology, 19, 47-91.

Sawyer, J.E., Latham, W.R., Pritchard, R.D., \& Bennett, W.R. (1999). Analysis of work group productivity in an applied setting: Application of a time series panel design. Personnel Psychology, 52, 927-967.

Schiflett, S.C., Eisner, E.J., Price, S.J., \& Schemmer, F.M. (1982). The definition and measurement of team functions (Rep. No. ARRO3068-FR-R81-4). Washington, DC: Advanced Research Resources Organization.

Schiflett, S.G., Elliott, L.R., Salas, E., \& Coovert, M.D. (Eds.). (2004). Scaled worlds: Development, validation, and applications. Burlington, VT: Ashgate.

Schmidt, A.M., \& DeShon, R.P. (in press). What to do? The effects of discrepancies, incentives, and time on dynamic goal prioritization. Journal of Applied Psychology.

Schmidt, F.L., \& Hunter, J. (2004). General mental ability in the world of work: Occupational attainment and job performance. Journal of Personality and Social Psychology, 86, 162-173. 
Schneider, B., \& Bowen, D.E. (1985). Employee and customer perceptions of service in banks: Replication and extension. Journal of Applied Psychology, 70, 423-433.

Schneider, B., \& Reichers, A.E. (1983). On the etiology of climates. Personnel Psychology, 36, 19-39.

Schneider, B., Salvaggio, A.N., \& Subirats, M. (2002). Climate strength: A new direction for climate research. Journal of Applied Psychology, 87, 220-229.

Schneider, B., Smith, D.B., \& Sipe, W.P. (2000). Personnel selection psychology: Multi-level consideration. In K.J. Klein \& S.W.J. Kozlowski (Eds.), Multilevel theory, research, and methods in organizations (pp. 91-120). San Francisco: Jossey-Bass.

Schneider, B., Wheeler, J.K., \& Cox, J.F. (1992). A passion for service: Using content analysis to explicate service climate themes. Journal of Applied Psychology, 77, 705-716.

Schneider, B., White, S.S., \& Paul, M.C. (1998). Linking service climate and customer perceptions of service quality: Test of a causal model. Journal of Applied Psychology, 83, 150-163.

Shea, G.P., \& Guzzo, R.A. (1987). Groups as human resources. In K.M. Rowland \& G.R. Ferris (Eds.), Research in personnel and human resource management (Vol. 5, pp. 323-356). Greenwich, CT: JAI Press.

Sherif, C.W. (1966). Adolescence: Motivational, attitudinal and personality factors. Review of Educational Research, 36, 437-449.

Shiflett, S. (1979). Toward a general model of small group productivity. Psychological Bulletin, 86, 67-79.

Siegel, A.I., \& Wolf, J.J. (1962). A model for the digital simulation of two-operator man-machine systems. Ergonomics, 5, 557-572.

Simons, T.L., \& Peterson, R.S. (2000). Task conflict and relationship conflict in top management teams: The pivotal role of intragroup trust. Journal of Applied Psychology, 85, 102-111.

Smith, K.G., Smith, K.A., Olian, J.D., Sims, H.P. Jr., O'Bannon, D.P., \& Scully, J.A. (1994). Top management team demography and process: The role of social integration and communication. Administrative Science Quarterly, 39, 412-438.

Smith-Jentsch, K.A., Zeisig, R.L., Acton, B., \& McPherson, J.A. (1998). Team dimensional training: A strategy for guided team self-correction. In J.A. Cannon-Bowers \& E. Salas (Eds.), Making decisions under stress: Implications for individual and team training (pp. 271297). Washington, DC: American Psychological Association.

Smolek, J., Hoffman, D., \& Moran, L. (1999). Organizing teams for success. In E. Sundstrom (Ed.), Supporting work team effectiveness (pp. 24-62). San Francisco: Jossey-Bass.

Stajkovic, A.D., \& Luthans, F. (1998). Self-efficacy and work-related performance: A meta-analysis. Psychological Bulletin, 124, 240261.

Steiner, I.D. (1972). Group process and productivity. New York: Academic Press.

Stevens, M.J., \& Campion, M.A. (1994). The knowledge, skill, and ability requirements for teamwork: Implications for human resource management. Journal of Management, 20, 503-530.

Stevens, M.J., \& Campion, M.A. (1999). Staffing work teams: Development and validation of a selection test for teamwork settings. Journal of Management, 25, 207-228.

Stewart, G.L., \& Barrick, M.R. (2004). Four lessons learned from the person-situation debate: A review and research agenda. In D.B. Smith \& B. Schneider (Eds.), Personality and organizations (pp. 61-87). Mahwah, NJ: Erlbaum.

Stewart, G.L., Fulmer, I.S., \& Barrick, M.R. (2005). An exploration of member roles as a multilevel linking mechanism for individual traits and team outcomes. Personnel Psychology, 58, 343-366.
Stogdill, R.M. (1950). Leadership, membership, and organization. Psychological Bulletin, 47, 1-14.

Stout, R.J., Cannon-Bowers, J.A., Salas, E., \& Milanovich, D.M. (1999). Planning, shared mental models, and coordinated performance: An empirical link is established. Human Factors, 41, $61-71$.

Sullivan, P.J., \& Feltz, D.L. (2001). The relationship between intrateam conflict and cohesion within hockey teams. Small Group Research, $32,342-355$.

Sundstrom, E., McIntyre, M., Halfhill, T., \& Richards, H. (2000). Work groups from the Hawthorne studies to work teams of the 1990s and beyond. Group Dynamics: Theory, Research, and Practice, 4, 4467.

Swezey, R.W., \& Salas, E. (1992). Guidelines for use in team training development. In R.W. Swezey \& E. Salas (Eds.), Teams: Their training and performance (pp. 219-245). Norwood, NJ: Ablex.

Tesluk, P.E., \& Mathieu, J.E. (1999). Overcoming roadblocks to effectiveness: Incorporating management of performance barriers into models of work group effectiveness. Journal of Applied Psychology, 84, 200-217.

Tjosvold, D. (1985). Implications of controversy research for management. Journal of Management, 11, 21-37.

Totterdell, P. (2000). Catching moods and hitting runs: Mood linkage and subjective performance in professional sport teams. Journal of Applied Psychology, 85, 848-859.

Totterdell, P., Kellett, S., Teuchmann, K., \& Briner, R.B. (1998). Evidence of mood linkage in work groups. Journal of Personality \& Social Psychology, 74, 1504-1515.

Tuckman, B.W. (1965). Developmental sequence in small groups. Psychological Bulletin, 63, 384-389.

Tziner, A., \& Eden, D. (1985). Effects of crew composition on crew performance: Does the whole equal the sum of its parts? Journal of Applied Psychology, 70, 85-93.

Wegner, D.M. (1986). Transactive memory: A contemporary analysis of the group mind. In B. Mullen \& G.R. Goethals (Eds.), Theories of group behavior (pp. 185-205). New York: Springer-Verlag.

Wegner, D.M. (1995). A computer network model of human transactive memory. Social Cognition, 13, 319-339.

Wegner, D.M., Giuliano, T., \& Hertel, P. (1985). Cognitive interdependence in close relationships. In W.J. Ickes (Ed.), Compatible and incompatible relationships (pp. 253-276). New York: Springer-Verlag.

Weingart, L.R. (1992). Impact of group goals, task component complexity, effort, and planning on group-performance. Journal of Applied Psychology, 77, 682-693.

Weingart, L.R., \& Weldon, E. (1991). Processes that mediate the relationship between a group goal and group member performance. Human Performance, 4, 33-54.

Wheelan, S.A. (1994). Group processes: A developmental perspective. Sydney: Allyn and Bacon.

Wheelan, S.A., \& Hochberger, J. (1996). Validation studies of the group development questionnaire. Small Group Research, 27, 143-170.

Wright, P.M. (1990). Operationalization of goal difficulty as a moderator of the goal difficulty-performance relationship. Journal of Applied Psychology, 75, 227-234.

Zaccaro, S.J., Blair, V., Peterson, C., \& Zazanis, M. (1995). Collective efficacy. In J. Maddux (Ed.), Self-efficacy, adaptation, and adjustment (pp. 305-328). New York: Plenum.

Zaccaro, S.J., Rittman, A.L., \& Marks, M.A. (2001). Team leadership. Leadership Quarterly, 12, 451-483. 
Zachary, W. (2004, Dec). Computational modeling and teams, Towards the Next Frontier in Research on Team Effectiveness. Workshop sponsored by the US Army Research Institute and the University of Central Florida. Orlando, FL.

Zachary, W., Campbell, G.E., Laughery, K.R., Glenn, F., \& Cannon-Bowers, J.A. (2001). The application of human modeling technology to the design, evaluation, and operation of complex systems. In E. Salas (Ed.), Advances in human performance and cognitive engineering research (Vol. 1, pp. 201-250). New York: JAI Press.
Zohar, D. (2000). A group-level model of safety climate: Testing the effect of group climate on microaccidents in manufacturing jobs. Journal of Applied Psychology, 85, 587-596.

Zohar, D. (2002). Modifying supervisory practices to improve subunit safety: A leadership-based intervention model. Journal of Applied Psychology, 87, 156-163.

Zohar, D., \& Luria, G. (2004). Climate as a social-cognitive construction of supervisory safety practices: Scripts as proxy of behavior patterns. Journal of Applied Psychology, 89, 322-333. 